\title{
MORTALITY AMONG AUTOWORKERS MANUFACTURING ELECTRONICS IN HUNTSVILLE, ALABAMA
}

\author{
Nathan L. L. DeBono
}

A dissertation submitted to the faculty of the University of North Carolina at Chapel Hill in partial fulfillment of the requirements for the degree of Doctor of Philosophy in the Department of Epidemiology.

\section{Chapel Hill}

2018

Approved by:

David Richardson

Alex Keil

Whitney Robinson

Melissa Troester

Stephen Marhsall 


\begin{abstract}
(C) 2018
Nathan L. L. DeBono

ALL RIGHTS RESERVED
\end{abstract}




\begin{abstract}
Nathan L. L. DeBono: Mortality among autoworkers manufacturing electronics in Huntsville, Alabama

(Under the direction of David Richardson)
\end{abstract}

This research was initiated in response to concerns raised by former workers at automotive electronics manufacturing facilities in Huntsville, Alabama regarding a suspected excess of mortality among their colleagues. Interviews conducted with workers identified exposure to a variety of industrial agents, including lead-based solder and chlorinated organic solvents, in addition to hazardous working conditions at the original plant building, as sources of concern. This work describes an epidemiologic investigation of mortality among workers at the Huntsville facilities.

A prospective cohort study of 4,396 hourly and salaried members of the United Autoworkers (UAW) ever-employed at the Huntsville facilities between 1972 and 1993 was conducted. The cohort was enumerated from UAW employment and pension records with mortality follow-up through 2016. Standardized mortality ratios (SMR) were estimated to compare cause-specific mortality in the cohort with U.S. and Alabama general population reference rates. Poisson regression was used to estimate mortality rate ratios (RR) within the cohort according to proxies for exposure, including duration of employment, calendar period of hire, and skilled trade job status.

Relative to U.S. referent rates, there was a modest excess of all-cause mortality among White female workers (SMR 1.08, 95\% CI: 0.99-1.18) and among workers hired pre-1977 (SMR 
1.10, 95\% CI: 0.99-1.22). There was a moderate excess of nervous system disorder (SMR 1.24, 95\% CI: 0.91-1.65) and brain and nervous system cancer (SMR 1.31, 95\% CI: 0.67-2.28) mortality in the overall cohort. Internal comparison analyses showed that pre-1977 hires exhibited elevated adjusted all-cause $(\mathrm{RR}=1.29 ; 95 \% \mathrm{CI} 1.09,1.52)$, cardiovascular $(\mathrm{RR}=1.38$; 95\% CI 1.03, 1.86), and digestive system disease ( $\mathrm{RR}=2.31 ; 95 \% \mathrm{CI}: 1.04,5.10)$ mortality rates relative to 1984-1993 hires.

All-cause mortality estimates from SMR analyses were greater than anticipated based on findings from other UAW cohorts. The moderate excess of malignant and non-malignant nervous system disease mortality is consistent with exposure to neurotoxic agents used in manufacturing processes. Elevated mortality among pre-1977 hires is also consistent with concerns over hazardous working conditions at the original plant building. The results of this study suggest that worker health was adversely impacted by employment at the facilities. 
To Derek, Julia, and Emma 


\section{ACKNOWLEDGEMENTS}

I would like to thank David Richardson for agreeing to advise me on this undertaking and for serving as a role model for my future career. His mentorship and patience were invaluable. I would like to thank Kaitlin Kelly-Reif for making the vital status ascertainment possible and for providing continuous support through the Institute of Occupational Medicine. I would like to thank Alex Keil for making himself readily available for lengthy discussions which taught me a great deal about the practice of our discipline. I am extremely grateful to others on my doctoral committee, Whitney Robinson, Melissa Troester, and Steve Marshall, who believed in the importance of this work and dedicated significant time to improving it. Their support throughout this process has been a deep source of motivation. I owe many thanks to Bonnie Rogers and the North Carolina Occupational Safety and Health Research Center, not only for funding my education for several years, but for funding all of the data collection necessary for this project. I feel immense gratitude for Steve Wing, who first introduced me to the concept of an occupational mortality investigation, and for telling me shortly before he passed that taking on this project would be a whole lot of fun.

I am thankful to Naeema Muhammad of the North Carolina Environmental Justice Network, for inspiring me to pursue community-oriented research, and to Valerie Tyson of the Concerned Citizens of West Badin, for sharing her story of work at the aluminum smelter. I would like to thank three of my lifelong friends, Mitchell Tome and Alex Wiseman, for sharing their experiences working on the production floor at Chrysler, and Nathan Lesperance, for using his brilliant intellect and curiosity to help shape this project from beginning to end. I am eternally 
grateful to two close friends I made during this process, Ryan Brady and Brett Doherty, who helped me cope with the rigors of my training. I would never have made it to this point without the support of Sarah Rhodes, who is the fiercest scientist I have ever met, and whose leadership gave me the courage to take this on. I would like to thank Robert Park for having the foresight to recognize the value those boxes of reel-to-reel tapes would have twenty five years later. I would like to thank both Robert and Andy Comai for teaching me about the practice of health and safety in the automotive industry, and for entrusting me with the responsibility to do good work. Most of all, I owe my most sincere feelings of gratitude to the UAW members who had the courage to speak with me about their experiences, and who shared documents, stories, and information that was crucial to the success of this research. 


\section{TABLE OF CONTENTS}

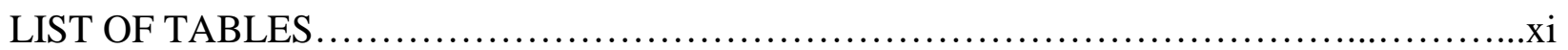

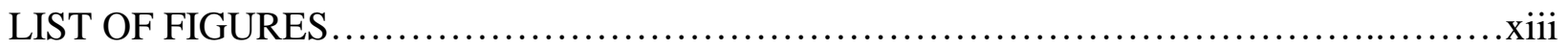

LIST OF ABBREVIATIONS ...........................................................

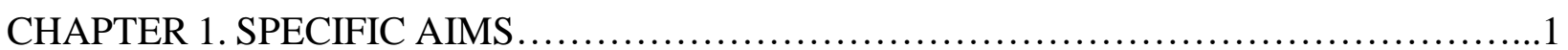

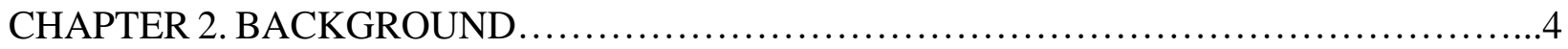

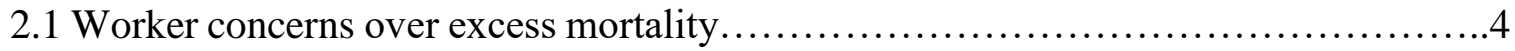

2.2 History of Chrysler electronics manufacturing in Huntsville, Alabama.................5

2.3 Worker descriptions of process history and exposures............................

2.4 Previous mortality studies in autoworkers................................. 14

2.5 Previous mortality studies in workers manufacturing electronic circuit boards........16

2.6 Diseases associated with suspected workplace exposures.......................21

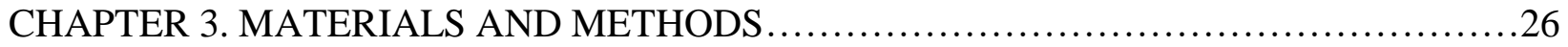

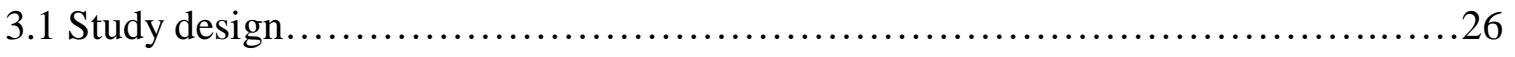

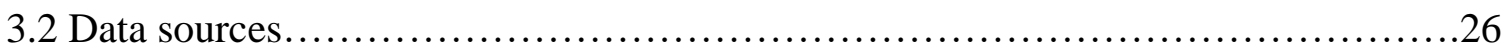

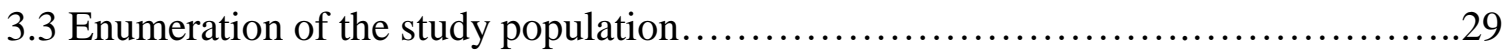

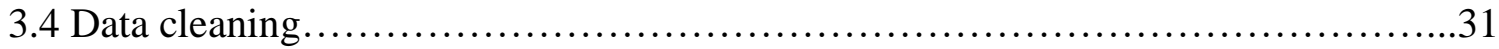


3.5 Study population.

3.6 Exposure ascertainment......................................................

3.7 Vital status ascertainment......................................................

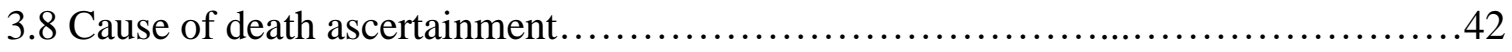

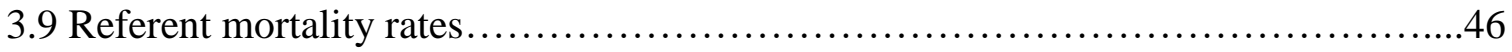

3.10 Effect measures...........................................................

CHAPTER 4. MORTALITY AMONG AUTOWORKERS MANUFACTURING ELECTRONICS IN HUNTSVILLE, ALABAMA: EXTERNAL COMPARISONS

OF CAUSE-SPECIFIC MORTALITY .............................................48

4.1 Introduction.............................................................. 48

4.2 Methods .................................................................. 49

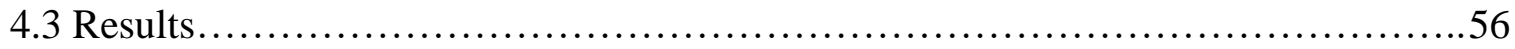

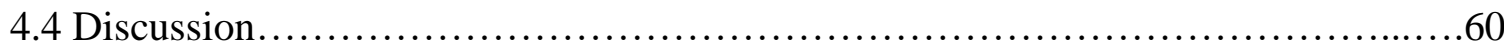

4.5 Figures and Tables...................................................... 72

CHAPTER 5. EMPLOYMENT CHARACTERISTICS AND CAUSE-SPECIFIC MORTALITY AT AUTOMOTIVE ELECTRONICS MANUFACTURING FACILITIES IN HUNTSVILLE, ALABAMA ...........................................79

5.1 Introduction............................................................. 79

5.2 Methods................................................................... 80

5.3 Results.................................................................... 87

5.4 Discussion................................................................ 
5.5 Figures and Tables.

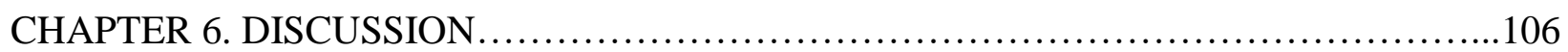

6.1 Fulfillment of the specific aims.............................................

6.2 Future investigations with the UAW .......................................113

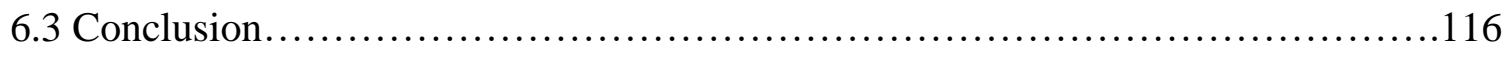

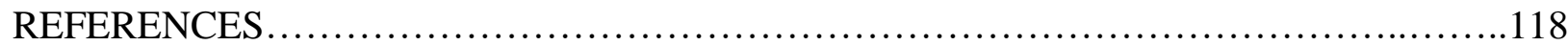




\section{LIST OF TABLES}

Table

2.1 Causes of death of a priori interest based on suspected workplace exposures at Huntsville facilities.................................................

3.1 Actual and observed operational history of plant codes at Chrysler electronics manufacturing facilities in Huntsville, Alabama

$(\mathrm{n}=4,396)$

3.2 Descriptive characteristics of the study population of 4,396 UAW hourly and salaried workers ever-employed at Chrysler electronics in Huntsville, Alabama from 1972-1993.

3.3 Criteria for selection and number of individuals submitted to the

National Death Index for vital status ascertainment $(n=1,714)$

3.4 Calendar years of death and number of individuals searched in each data source used for vital status ascertainment.

3.5 Observed number of deaths in the study population due to specific causes according to the NIOSH-119 major and minor cause of death categories.

4.1 Descriptive characteristics of 4,396 hourly and salaried UAW members ever-employed at automotive electronics manufacturing facilities from 1972-1993 in Huntsville, Alabama. 72

4.2 Standardized mortality ratios comparing cause-specific mortality among 4,396 UAW members ever-employed from 1972-1993 to U.S. and Alabama referent rates...

4.3 Standardized mortality ratios comparing mortality due to select

Causes of death among White female and White male UAW members ever-employed from 1972-1993 to U.S. referent rates (estimates for Black or other females and males shown in supplemental Table S4.2) 75

4.4 Standardized mortality ratios comparing mortality due to select causes of death among 4,396 UAW members to U.S. referent rates according to hire period and years since first hire...

4.5 Standardized mortality ratios comparing mortality due to select causes of death among 4,396 UAW members to U.S. referent rates according to employment status 
S4.1 Sensitivity analyses for race imputation methods on overall standardized mortality ratio estimates using U.S. referent rates

S4.2 Standardized mortality ratios comparing mortality due to select causes of death among Black (or other) female and male UAW members ever-employed from 1972-1993 to U.S. referent rates

5.1 Descriptive characteristics of 4,396 hourly and salaried UAW members ever-employed at automotive electronics manufacturing facilities between 1972-1993 in Huntsville, Alabama

5.2 Rate ratios for all-cause, all cancer, and cardiovascular disease mortality according to employment characteristics overall and according to sex among 4,396 hourly and salaried UAW members ever-employed at automotive electronics manufacturing facilities in Huntsville, Alabama, between 1972-1993.

5.3 Rate ratios for select malignant causes of death according to employment characteristics among 4,396 hourly and salaried UAW members ever-employed at automotive electronics manufacturing facilities in Huntsville, Alabama, between 1972-1993. 101

5.4 Rate ratios for mortality due to select chronic diseases according to employment characteristics among 4,396 hourly and salaried UAW members ever-employed at automotive electronics manufacturing facilities in Huntsville, Alabama, between 1972-1993. . .102

5.5 Rate ratios for mortality due to genitourinary and renal diseases according to employment characteristics among 4,396 hourly and salaried UAW members ever-employed at automotive electronics manufacturing facilities in Huntsville, Alabama, between 1972-1993.

5.6 Evaluation of 'healthy worker' effect with exclusion of short-term workers and stratification according to active versus inactive person-time in estimates of mortality rate ratios according to employment characteristics in the study cohort $(n=4,396)$ .104

S5.1 Sensitivity analysis for the imputation of employment duration for all cause and lymphatic and hematopoietic cancer mortality.... 


\section{LIST OF FIGURES}

Figure

2.1 Satellite image of the site of the original plant buildings at the former Chrysler automotive electronics operation in Huntsville, Alabama

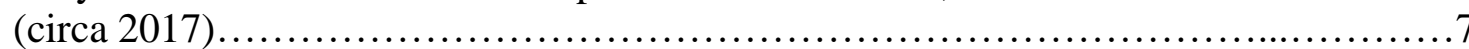

2.2 Satellite image of the site of the newest plant building (Plant 3) at the former Chrysler automotive electronics operation near Huntsville, Alabama (crica 2017)..........................................................

3.1 Illustration of the relationship between UAW data sources used to

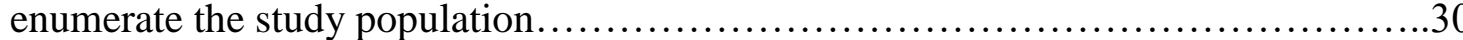

3.2 Number of study members active per year according to plant code at Chrysler electronics facilities in Huntsville, 1972-1993 ( $\mathrm{n}=4,396)$

3.3 Number of deaths identified in each data source and concordance between data sources used for vital status ascertainment.

5.1 Kaplan-Meier estimated overall survival proportion according to calendar period of first hire among UAW members employed at Huntsville electronics facilities, 1972-1993 ( $\mathrm{n}=4,396)$. 


\section{LIST OF ABBREVIATIONS}

$\begin{array}{ll}\text { AL } & \text { Alabama } \\ \text { CI } & \text { Confidence Interval } \\ \text { EPA } & \text { Environmental Protection Agency } \\ \text { GM } & \text { General Motors } \\ \text { IARC } & \text { International Agency for Research on Cancer } \\ \text { IBM } & \text { International Business Machines } \\ \text { IQR } & \text { Interquartile Range } \\ \text { NIOSH } & \text { National Institute of Occupational Safety and Health } \\ \text { TCE } & \text { Trichloroethylene } \\ \text { OSHA } & \text { Occupational Safety and Health Administration } \\ \text { RR } & \text { Rate Ratio } \\ & \text { Standardized Mortality Ratio } \\ & \end{array}$




\section{CHAPTER 1: SPECIFIC AIMS}

Former employees at automotive electronics manufacturing facilities in Huntsville, Alabama raised concerns over a suspected excess of mortality among their colleagues. In 2015, a list of over 400 deceased individuals formerly employed at the facilities was brought to the attention of the United Autoworkers (UAW) Health and Safety Department by a group of workers who have been maintaining a record of deaths among their colleagues for several years. Workers have reported exposure to lead-based solder, asbestos, and chlorinated solvents while employed at the facilities. The UAW requested the support of epidemiologists to investigate worker concerns.

Mortality rates in autoworkers are generally lower than expected for most causes of death with the exception of cancer, for which rates tend to be elevated for lung, reproductive, and digestive cancers compared to the general U.S. population ${ }^{1-3}$. Two studies in UAW-based cohorts have indicated employment in automotive and aerospace electronic equipment manufacturing is associated with prostate and brain cancer mortality ${ }^{4,5}$. However, mortality among workers employed at the Huntsville facilities has never been studied, nor have previous studies addressed mortality more broadly among workers employed in automotive electronic component manufacturing.

The overall objective of this study was to investigate cause-specific mortality among 4,396 workers employed at automotive electronics manufacturing facilities in Huntsville, Alabama between 1972 and 1993. The investigation involved the enumeration of a novel UAW- 
based cohort through a partnership with the UAW and the National Institute of Occupational Safety and Health (NIOSH). Primary data collection on individual demographic, employment, vital status, and cause of death information was conducted. The specific aims of the study were:

Aim 1: Address concerns about excess mortality among UAW members formerly employed at the Huntsville electronics manufacturing facilities. Compare the age-, sex-, race-, and calendar year-standardized cause-specific mortality rate for all major cause of death categories among workers ever-employed at the Huntsville facilities between 1972 and 1993 to reference rates for the general population of the U.S. and Alabama.

Sub-Aim 1 (a): Estimate age-, sex-, race-, and calendar year-standardized cause-specific mortality ratios stratified by new hires before and after the opening of a new plant building in 1977.

Sub-Aim 1 (b): Estimate age- and calendar period-standardized cause-specific mortality ratios among male, female, White, and Black (or other) workers.

Sub-Aim 1 (c): Investigate the potential for 'healthy worker' bias by estimating age-, sex-, race-, and calendar year-standardized cause-specific mortality ratios stratified by time since company first hire and by using employed versus post-termination persontime.

Aim 2: Estimate associations between employment characteristics and cause-specific mortality within the study population. Estimate incidence rate differences in all major categories of causespecific mortality according to employment characteristics including skilled trade job status and duration, plant code, and calendar period of employment. 
Sub-Aim 2 (a): Estimate the association between skilled trade job status, duration, plant code, and calendar period of employment and cause-specific mortality in male, female, White, and Black (or other) employees.

Sub-Aim 2 (b): Investigate the potential for 'healthy worker' bias by estimating the association between employment duration and cause-specific mortality with exclusion of short-term workers.

The results of this investigation address former worker concerns over a suspected excess of mortality at automotive electronics manufacturing facilities. The facilities are no longer operational, however, the results may support the advancement of the rights and safety of UAW members through the union's established advocacy process. 


\section{CHAPTER 2: BACKGROUND}

\subsection{Worker concerns over excess mortality}

Former employees at automotive electronics manufacturing facilities in Huntsville, Alabama have raised concerns over a suspected excess of mortality among their colleagues. Workers have been maintaining a record of deaths among their former colleagues and fellow retirees for several years. A list of names of deceased workers, including their job, death date, and cause of death, is being maintained by a concerned group of former workers on social media. The list is posted to a social media group of over 1,200 former workers at the Huntsville facilities and is continually updated through feedback on the site. The facilities closed in 2010, however, a recent asbestos lawsuit, in addition to public knowledge of widespread soil contamination at the plant site with chlorinated organic solvents, has increased former worker's awareness of potential health hazards associated with employment at the facilities. The list was widely shared on social media during contract negotiations with Chrysler and was brought to the attention of UAW representatives at the union's offices in Detroit, Michigan (Solidarity House).

In 2015, Huntsville electronics UAW Local 1413 representatives submitted a complaint over adverse working conditions and the perceived elevated rate of mortality among former workers at the facilities to the UAW Health \& Safety Department at Solidarity House. The list of names of deceased workers was used by Local 1413 representatives as evidence to support their claim, which at the time had over 400 individuals listed. The UAW Health \& Safety Department sought the support of epidemiologists to respond to worker concerns by conducting a mortality investigation among former workers at the Huntsville facilities. I met with the president of the 
UAW and the director of the Health \& Safety Department at Solidarity House in Detroit, Michigan in August of 2016 and obtained approval to conduct the investigation. The UAW authorized the investigation and released necessary study data two months later. Local 1413 members in Huntsville were notified of the investigation and were active collaborators in accomplishing study aims. As of September 2017, the list of deceased circulating on social media contained over 700 names and continues to be updated on a regular basis.

\subsection{History of Chrysler electronics manufacturing in Huntsville, Alabama}

An extensive description of the operational history of Chrysler electronics manufacturing facilities in Huntsville is available as an online resource ${ }^{6}$. The facilities served as the core of Chrysler's electronics division for over 40 years and pioneered numerous advancements in automotive technology. Chrysler's first electronics plant in Huntsville (Plant 1) was constructed in an industrial park adjacent to a military facility in 1952, when the company secured a defense contract to provide technical service and manufacturing support for the U.S. Army's Redstone guided-missile arsenal. The success of the Redstone program led Chrysler to become the primary contractor for rocketry and missile development for the Department of Defense. Chrysler began production of the Jupiter missile arsenal in Huntsville shortly after, manufacturing a variety of electronics and rocketry components for U.S. military over the next decade. In 1962, Chrysler began fulfilling electronics contracts for NASA. The Huntsville plant manufactured the telemetry systems for the Saturn rockets and the lunar excursion module used in NASA's Apollo missions. Three years later, Chrysler expanded the plant by 176,000 square feet to meet production requirements.

In 1968, Chrysler's involvement in the military and aerospace manufacturing began to decline. The company responded by adapting their existing plant infrastructure in Huntsville to 
focus on the development of electronics for automobiles. Many quality control and engineering processes used for the manufacture of aerospace equipment were transformed for automotive production, giving Chrysler an advantage in the automotive industry's shift toward producing cars installed with electronics. Given the anticipated growth of the market for automotive electronics, Chrysler's Huntsville electronics plant was considered a prime strength of the corporation and given significant investment.

In 1971, Chrysler's Huntsville plant began manufacturing several mass-production lines of electronic components for Chrysler vehicles. These products included electronic ignition modules, digital engine control computers, exhaust emission analyzers, and radio systems, including speakers, tape-decks, and head units. Engine control computers and emission analyzers consisted of printed circuit boards with soldered-on capacitors and resistors connected via copper traces. In the mid-1970's, Plant 1 was expanded twice and began manufacturing vacuum fluorescent display digital clocks, electronic trip computers (e.g. distance, fuel mileage, average speed calculator and display), and fully digital car radios. In 1977, Chrysler constructed a second 225,000 square foot plant (Plant 2) adjacent to the original Plant 1 building to support the growing market for automotive electronics. A satellite image of the original Plant 1 and 2 buildings is shown in Figure 2.1.

In the early 1980's, other notable product lines were added to the manufacturing processes at the Huntsville facilities. The facilities began producing electronic instrument clusters for vehicle dashboards, such as digital readout panels for displaying vehicle information, as well as digital fuel injection systems which included spark control computers and electronic feedback-carburetor controllers. They also produced the 'Navistar' electronic navigation system which featured digital display graphics using vacuum fluorescent tubes. 
In 1983, Chrysler revived some military manufacturing operations at a separate plant building located in the same industrial park as the two original automotive plants. The new operation was named Military-Public Electronics Systems and specific products manufactured there are largely unknown, although workers reported general processes similar to those at the automotive plants. The plant reportedly manufactured a computerized rail traffic and power control system for the Northeast corridor of the U.S. railway system. The operation was closed after six years of production and its small workforce returned to Chrysler automotive manufacturing. The physical plant for this operation was never again used by Chrysler.

As the demand for electronics in cars continued to grow, Chrysler completed construction on a third automotive electronics plant in Huntsville in 1988 (Plant 3). The new 750,000 square foot facility was larger than the previous two combined and was located on a separate 325 acre

Figure 2.1. Satellite image of the site of the original plant buildings at the former Chrysler automotive electronics operation in Huntsville, Alabama (circa 2017)

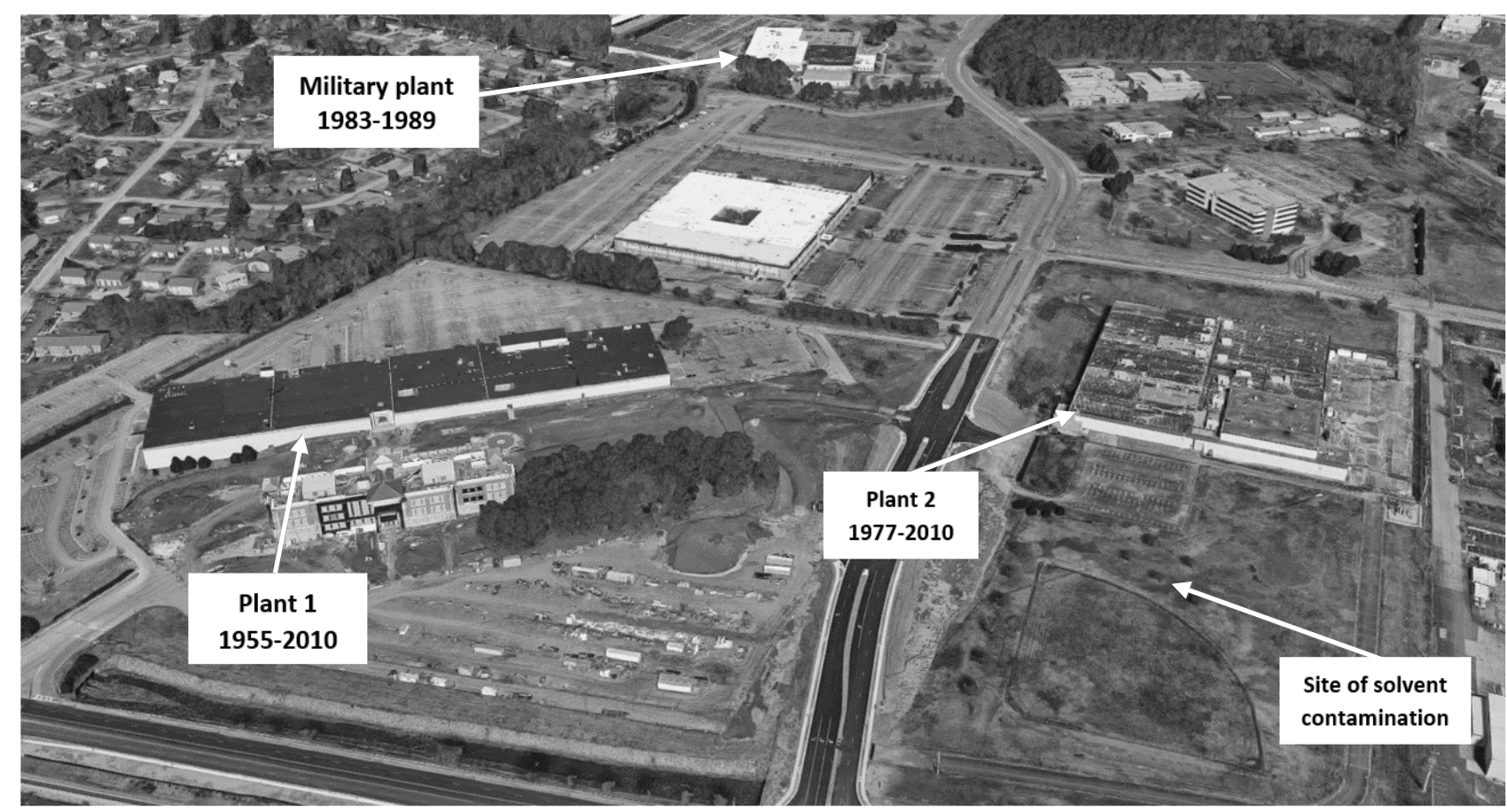


site outside of the city. The state-of-the-art complex largely replaced the manufacturing operations at the previous plants. Most of the workforce and equipment were transferred to the new location and production began there in early 1989. Some manufacturing operations continued intermittently at the original plants after the new facility was constructed, typically when new production lines were added or reorganized. A satellite image of the Plant 3 facility is shown in Figure 2.2.

In 1996, Chrysler's new Plant 3 facility reached peak production. The facility had 24 different assembly lines, which involved screen printers, various ovens, high-speed placement systems, wave solder machines, and printed computer board loaders. The plant manufactured radio/stereo systems, engine, transmission, four-wheel drive, body (e.g. power door, window, mirror, light) computers, and dashboard instrument clusters. The complex was operational for three eight-hour shifts and produced 49,000 units per day. Approximately 70\% of electronics found in Chrysler vehicles were manufactured at the complex in Huntsville. The complex also held Chrysler's first internal child care center and was reported to have a total of 2,804 employees (unionized and managerial).

In 1998, Chrysler merged with Daimler Benz, and the resulting restructuring process led to the Huntsville electronics facilities being sold to Siemens in 2004. After the sale, workers at the facilities remained unionized through the UAW and continued to manufacture automotive electronics under Siemens and then Continental. In 2010, Continental shut down all manufacturing operations in Huntsville, leaving all plant buildings abandoned for several years. Approximately 1,280 people were employed at the facilities at the time of their closing. 


\subsection{Worker descriptions of process history and exposures}

I conducted interviews with nine former employees at the Huntsville electronics facilities to understand plant process histories and identify exposures of concern. Interviewees were contacted through the retiree group of the local UAW chapters, Local 1413 (hourly) and Local 1929 (salaried). The interviewees included two former Local 1413 presidents, the UAWChrysler retiree benefits representative, two Local 1413 health and safety representatives, one plant clerical worker, and one Chrysler chemical engineer. The former health and safety representatives were able to describe common exposure concerns voiced by workers during their time in the positions. The employment history of the interviewees spans the entire operational history of the plants from 1971 to 2010 . Interviews were conducted by phone, email, and inperson during the spring of 2017. I visited all of the plants in-person during this time to verify

Figure 2.2. Satellite image of the site of the newest plant building (Plant 3) at the former Chrysler automotive electronics operation near Huntsville, Alabama (circa 2017)

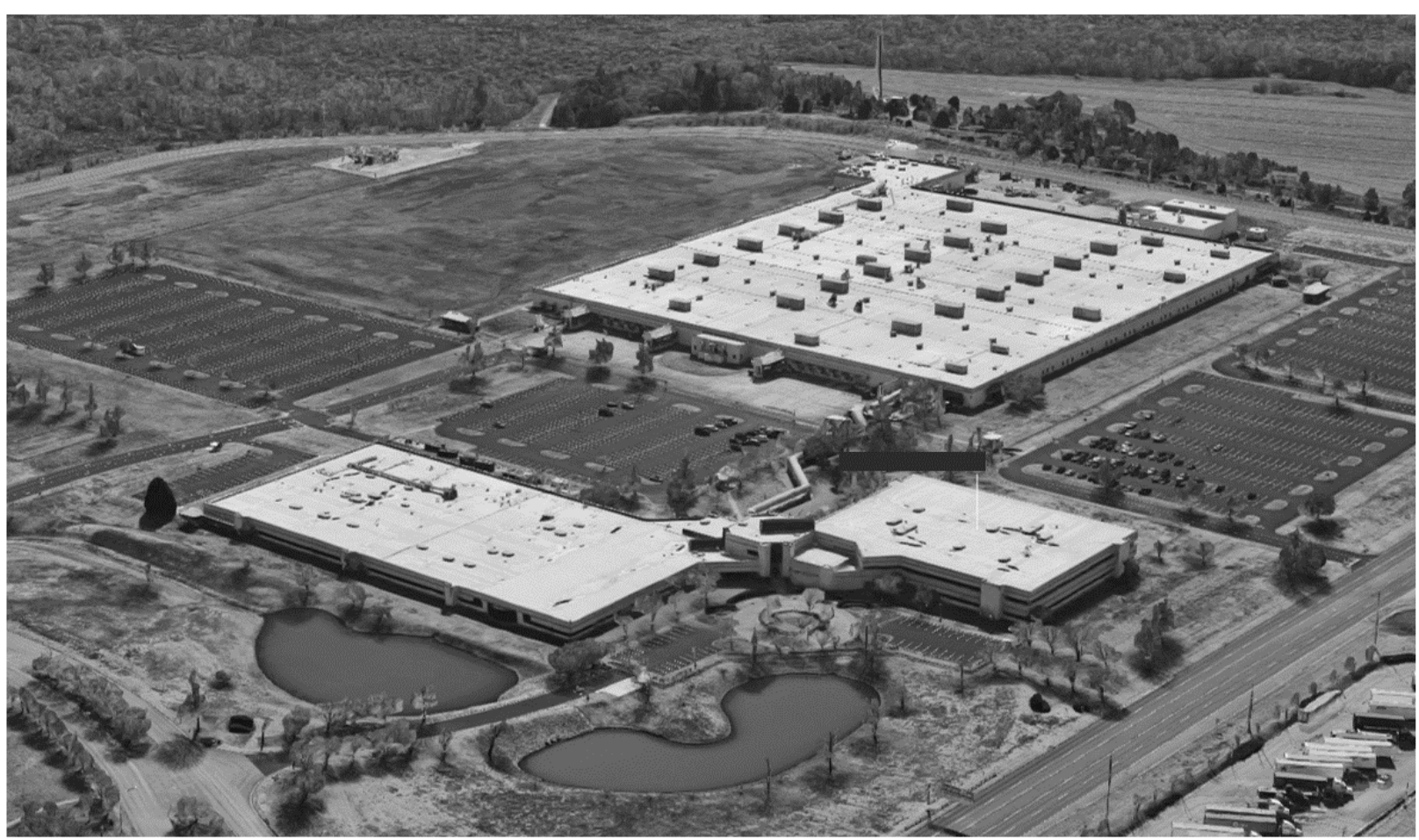


information obtained through interviews.

Interviewees described two exposures of primary concern related to plant processes: inhalation and dermal exposure to lead-based solder and chlorinated organic solvents, specifically trichloroethylene (TCE) and 1,1,1-trichloroethane. Other major exposures of concern included asbestos, which was discovered in the ceiling of Plant 1 in the 1980's, conformal coating fumes, and fiberglass dust inhalation.

The operational history of the plants was characterized predominantly by the assembly of electronic circuit boards. Boards were cut from fiberglass sheets and would enter production lines to have electronic components soldered to them. The transistors and capacitors soldered to boards were not manufactured at the facilities, but were shipped to Huntsville from elsewhere. Once boards were assembled and soldered, they were sprayed with a conformal coating (silicone- or polyurethane-based resin for moisture and heat protection) and baked in industrial ovens. The circuit boards would then be installed into various enclosures including radio or dashboard units before being wired and sealed for shipment to vehicle assembly plants.

Hand soldering, solder paste application, and wave soldering were the three main solder processes used throughout each plant's history. Wave soldering was an automated process where circuit boards were loaded into machines and transferred over a tub of molten solder. Hand soldering required workers to solder individual components to boards by hand, often for boards needing repair or when wave solder machines underwent maintenance. Solder paste application involved the spreading of solder onto boards with adhesive tape or handheld tools. All three of these soldering processes were used until all facilities were closed in 2010, although wave soldering became more common during later years of facility operation as electrical components 
shrunk in size. Wave solder machines had been used at the original plants as early as 1983 and were introduced to increase production speed. No workers on the solder lines wore personal protective equipment. The hand and paste solder workers were provided gloves, but they were rarely worn.

The UAW health and safety representatives stated that the solder contained lead up until at least 2001. It was common for workers in the solder lines to inhale solder fumes, and those working with solder manually would often finish their shifts with paste on their hands and clothing. Wave solder machines were attended by workers who would stand at the machines for an entire shift and could smell the molten solder fumes at their workstation. Their tasks involved the loading and removal of circuit boards from the machine and adding bricks of hardened solder to the molten mixture. At the original Plant 1 and 2 buildings, wave solder machines had no ventilation, however, most machines at the newer Plant 3 facility had ventilation units to reduce the intensity of the fumes. In the mid-1990's, one interviewee applied a home lead testing kit to dust samples collected from the intake vent over their wave solder machine. The sample tested positive for lead, indicating that lead was present in the fumes emanating from their machine.

Chlorinated organic solvents are chemicals that were used widely at the facilities for solder degreasing. Excess solder on circuit boards, tools, and machine components was removed using a variety of chlorinated solvents including trichloroethylene (TCE) and 1,1,1trichloroethane. Workers were required to manually scrub solder from circuit boards using solvents that they would apply to metal brushes. Some workers were also required to spray solvents on circuit boards or machinery in enclosed spaces with little or no ventilation. At the original plants, workers would clean solder from their hands by washing them in open containers of trichloroethylene before using soap and water. One interviewee stated that in the 1970's, 
management told them that trichloroethylene was safe enough to drink. Large drums of trichloroethylene were available for workers to use freely and those who worked with the chemical rarely wore any personal protective equipment. Trichloroethylene was used primarily during earlier years of facility operation, as this chemical was phased out of use broadly in the U.S. during the 1980's in response to emerging evidence of its toxicity. While 1,1,1trichloroethane largely replaced trichloroethylene for degreasing purposes, the extent to which specific solvents were used throughout facility history is unknown.

The Plant 2 building constructed in 1977 housed a 5,000 gallon tank of chlorinated solvents that was used as a reservoir for the plant's manufacturing operations. In the mid-1980's, it was discovered that the tank had been leaking into the soil around the plant for several years. Employees frequently played softball on a field adjacent to the plant during their breaks, but after the contamination was discovered, they were prohibited from using it. This caused alarm among workers as they had already been directly exposed to solvents in the workplace for years. Many workers were prepared to go on strike in protest of their solvent exposure, but it never occurred. High school baseball teams were also prohibited from using the field during this time and this policy has persisted to the present. After the plants closure in 2010, a firm was hired to clean the site so the property could be sold to a community college. A news article published in 2010 reported the site was contaminated with 1,1,1-trichloroethane, dichloroethane (a feedstock in chemical synthesis of 1,1,1-trichloroethane), and 4,4'-methylenebis(2-chloroaniline) (MOCA) ${ }^{7}$.

Skilled tradespeople were hourly workers who were trained or apprenticing in specific skills not directly related to manufacturing processes. Skilled tradespeople at the Huntsville facilities consisted predominantly of electricians, machine repairers, carpenters, tool makers, and air conditioning technicians. When new production lines were installed or reorganized, plant 
electricians would be required to rewire electrical lines in the plant to provide machinery with power. In the 1980 's, asbestos was discovered when new electrical lines were being installed in the ceiling at the original Plant 1 building. Electricians who often worked in the ceilings and walls of the original plant may have been routinely exposed to asbestos without their knowledge.

Working conditions at the original Plant 1 building were described as the most adverse and were of particular concern. Plant 1 was used exclusively until 1977 had no ventilation in production areas or enclosures on wet processing lines. Interviewees described the production area to be excessively hot with strong chemical odors. There were windows near the ceiling that would be opened occasionally, but this did little to keep the production space aerated. Fiberglass dust contaminated the air on production lines where circuit boards were cut from large sheets of fiberglass cloth before being implanted with epoxy resin. The dust was a large source of irritation and workers often complained it interfered with their breathing. The most common health and safety complaints at the original plant included musculoskeletal strains, burns, nose bleeds, headaches, and excessive heat. There was at least one instance of a solder spill that resulted in an OSHA complaint and UAW health and safety investigation.

The new Plant 3 facility constructed in 1989 was considered a 'state of the art' manufacturing complex at the time of its opening. The facility had significantly improved ventilation, enclosures, and air conditioning compared to the original plants. In addition to ventilation units over the wave solder machines, chlorinated solvent use was better restricted to enclosed booths and ventilated spaces. However, employees were occasionally transferred to the original plants for certain manufacturing operations after the new facility was constructed. This typically occurred when new products were added to production or when production lines were reorganized for plant maintenance. 
Despite Chrysler's sale of the Huntsville facilities in 2004, workers indicated that the general processes at the plants, as well as the workforce itself, largely remained the same. The workforce remained unionized even after ownership of the plants changed. The workforce gradually declined during the last decade of plant operation. When the facilities were shut down in 2010, workers were given the option to transfer to other automotive manufacturing facilities in the U.S.

\subsection{Previous mortality studies in autoworkers}

The mortality experience of autoworkers in the U.S. has been characterized by two large UAW-based cohorts in Ford and GM employees ${ }^{1-3,8}$. The UAW-Ford cohort consists of 198,245 hourly employees active from 1973 to 1990 in a range of automotive production sectors nationwide. Delzell et al. reported results of standardized mortality ratio analyses (SMR) from the UAW-Ford cohort using U.S. general population reference rates and a median of 27 years of follow-up for mortality. Their results indicate a lower than expected mortality rate for all-causes (SMR 0.92, 95\% CI: 0.91, 0.92) and for all major cause of death categories except for cancer, which was similar to the expected (SMR 1.00, 95\% CI: $0.98,1.02$ ). The deficit in the SMR for all-cause mortality was greater among Black (or other) compared to White workers, however, Black (or other) workers had a higher all-cause and cancer mortality rate compared to their White counterparts. Among shorter-term ( $<20$ years) workers hired $>20$ years prior to the end of follow-up, mortality rates were greater than expected for all causes (SMR 1.20, 95\% CI: 1.17, 1.23), including heart disease (SMR 1.22, 95\% CI: 1.17, 1.27) and all cancers (SMR 1.18, 95\% CI: 1.12, 1.23). SMRs were elevated for non-Hodgkin's lymphoma and stomach, lung, breast, and kidney cancer. 
Delzell et al. did not report results for workers employed in electronic component manufacturing. However, among vehicle assembly workers, those ever-employed in welding/soldering jobs had lower than expected mortality rates overall and for all cancers and heart disease. Those ever-employed in maintenance/skilled trade jobs also had lower than expected rates for the same cause-of-death categories, although this job group exhibited an excess of lung cancer mortality (SMR 1.16, 95\% CI: 1.06, 1.27).

The UAW-GM cohort consists of 46,399 hourly employees hired between 1917 and 1981 at three automotive plants in Michigan that manufactured transmissions and metal gear, axel, and drivetrain components. This cohort was enumerated to investigate health hazards associated with occupational exposure to metalworking fluids. Eisen et al. reported results of SMR analyses among males in the UAW-GM cohort using reference rates from the U.S. general population and mortality follow-up through 1994. Among White men, the mortality rate in the cohort was similar to the expected for all-causes (SMR 1.01, 95\% CI: 0.99, 1.03) and for all-cancers (SMR 1.05, 95\% CI: 1.01, 1.09). Among Black men, the mortality rate was lower than expected for allcauses (SMR 0.86, 95\% CI: 0.82, 0.90) and for all-cancers (SMR 0.95, 95\% CI: 0.86, 1.04). Friesen et al. reported SMR results among females with updated mortality follow-up through 2004 using Michigan reference rates. The mortality rate was lower than expected for all-causes (SMR 0.82, 95\% CI: 0.77, 0.87) but elevated for all-cancers (SMR 1.10, 95\% CI: 0.98, 1.22). Excess mortality was reported for lung, brain, leukemia, and pancreatic cancer. Other studies in smaller populations of autoworkers employed in engine foundry or metalworking facilities corroborate the findings of the UAW-GM cohort, in that external comparisons of mortality show similar or lower than expected mortality for non-malignant causes, but greater mortality for lung, brain, and digestive system cancers ${ }^{9-13}$. 
Results from external comparison analyses in the UAW-Ford and UAW-GM cohorts are valuable for characterizing the mortality experience of autoworkers in the U.S. All-cause mortality rates are generally lower than expected while rates tend to be greater for cancerspecific causes. Estimates of lower than expected overall mortality and elevated SMR estimates in shorter-term workers with greater time since hire are indicative of 'healthy worker' biases. The greater deficit in SMR estimates in Black (or other) compared to White workers indicates that healthy worker biases are stronger in this group. While both cohorts are predominantly comprised of workers who never worked in electronics manufacturing, it is common for UAW members, including those employed in Huntsville, to work in a variety of automotive production sectors, as members frequently transfer to multiple plants in their lifetime due to layoffs and closures. Results from these cohorts provide useful information about mortality patterns in the UAW workforce more broadly, and describe the mortality experience of a population with similar insurance, benefits, and socioeconomic characteristics to the study population in Huntsville.

\subsection{Previous studies of mortality in workers manufacturing electronic circuit boards}

Few epidemiological studies have investigated mortality hazards associated with employment in electronic circuit board manufacturing. Two studies have investigated mortality risks in autoworkers with some analyses specific to electronics manufacturing. Two other investigations were conducted in employees who manufactured computer products for IBM. A wider body of literature describes mortality risks associated with electronic semiconductor and capacitor manufacturing, however, these components were not manufactured at the facilities in Huntsville and involve exposure to distinct chemical agents. 


\section{Electronics manufacturing and mortality in autoworkers}

There are few studies that have investigated health hazards associated with employment in automotive electronics manufacturing. Two mortality studies by Park et al. and Brown et al. investigated risks associated with electronics work in UAW members ${ }^{4,5}$. Park et al. conducted a proportional mortality study using national reference proportions among hourly UAW workers at an aerospace electromechanical systems manufacturer. Processes at the facility included the machining and assembly of gyroscopes, accelerometers, and the production of electronic circuit boards. The analysis involved 583 deaths between 1950 and 1986 among workers employed at the facility for at least 10 years. Results indicated an increased proportion of deaths due to all cancers (PMR 1.19, 95\% CI: 0.96, 1.48), brain cancer (PMR 5.15, 95\% CI, 2.07, 10.61), and all lymphopoietic (PMR 1.74, 95\% CI: 0.75, 3.43) cancers. The proportion of deaths due to lung, digestive cancers, heart disease, and respiratory diseases were similar to or below expectation. Brown et al. conducted a case-control study of employment history in the automotive manufacturing industry and prostate cancer mortality. Their analysis included 322 prostate cancer deaths occurring between 1973 and 1987 and 1,288 individually matched controls drawn from the UAW-Ford cohort. They analyzed employment history according to longest worked production sector and used never-workers in a given sector as the referent. They reported a positive association between employment in electronic equipment manufacturing and prostate cancer mortality (OR 2.1, 95\% CI: 1.2, 3.7). The association remained similar after imposing a 10 year truncation of work history (lag) prior to death.

The studies by Park et al. and Brown et al. indicate elevated risk of certain cancers among autoworkers employed in electronics manufacturing compared to the general U.S. population, 
although they are based on a relatively small number of deaths and provide little description of process-specific exposures.

\section{Electronics manufacturing and mortality at IBM}

Two studies have characterized mortality risks among former employees at IBM computer electronics manufacturing facilities ${ }^{14,15}$. Similar to the concern that emerged in Huntsville, both studies were initiated through litigation in response to worker complaints over excess mortality. The first investigation by Clapp consisted of a company-wide proportionate mortality ratio analysis of 31,941 deceased hourly employees who worked $\geq 5$ years and who died between 1969 and $2001^{14}$. The U.S. general population was used for comparison. Overall, Clapp reported a small excess in the proportion of deaths due to all cancers among males (PMR 1.07, 95\% CI: 1.05, 1.09) and females (PMR 1.15, 95\% CI: 1.10, 1.19), while estimates for heart disease, non-malignant respiratory disease, and all external causes of death were either equal to or below expectation for both sexes. A significant excess in the proportion of deaths due to nervous system disorders was reported but a point estimate was not provided. Among decedents with known work history (32\%) who were ever-employed in manufacturing operations and who died of cancer (1,180 men and 302 women), PMRs were elevated (>1.4) in men for rectal, pancreatic, kidney, and brain and nervous system cancer. A small excess was reported for nonHodgkin's lymphoma. Among women, PMRs were elevated for stomach and kidney cancer, as well as for leukemia and lymphopoietic cancers, although estimates in women were imprecise due to the small number of decedents.

The second study was conducted by the National Institute of Occupational Safety and Health (NIOSH) among 34,494 salaried and hourly workers ever-employed between 1969 and 2001 at a specific plant in Endicott, New York ${ }^{15}$. In addition to worker complaints of excess 
mortality at the facility, evidence of soil and groundwater contamination with trichloroethylene and other industrial solvents in the community prompted the New York State Department of Health and Congressional representatives to request an occupational mortality investigation at the facility.

NIOSH's investigation consisted of historical exposure reconstruction and the creation of a department-specific exposure matrix ${ }^{16}$. The facility began manufacturing electronic circuit boards for computers and business machines in the mid 1960's. The manufacture of circuit boards continued as a major process at the facility until 2002. Trichloroethylene was introduced at the facility in the mid 1960's but was discontinued in 1985. Lead was used in solder throughout the facility's history. Of the 34,494 workers in the cohort, an estimated $59 \%$ were ever-exposed to chlorinated solvents, including $24 \%$ to 1,1,1-trichloroethane (methyl chloroform), $15 \%$ to dichloromethane, $12 \%$ to perchloroethylene (PCE), and 9\% to trichloroethylene. A total of $29 \%$ were ever-exposed to lead and $15 \%$ to fiberglass dust. Approximately $21 \%$ of total employed person-time involved exposure to chlorinated solvents, $11 \%$ to lead, and $4 \%$ to fiberglass dust. Annual mean cumulative worker exposure scores were highest from 1974 to 1985 for chlorinated solvents and from 1986 to 1993 for fiberglass and lead. Among solvents, 1,1,1-trichloroethane was responsible for the greatest mean cumulative exposure in all manufacturing eras.

Results of the mortality investigation showed $17 \%$ of the cohort (5,966 individuals) had died after a mean of 25 years of follow-up. SMRs were reported using U.S. general population reference rates. Among male hourly workers, SMRs were below expectation for all causes (SMR 0.76, 95\% CI: $0.73,0.78$ ) and for all cancers (SMR 0.83, 95\% CI: 0.78, 0.88). However, SMRs were elevated for rectal cancer (SMR 1.70, 95\% CI: 1.20, 2.36), mesothelioma (SMR 2.18, 95\% 
CI: 0.88, 4.50), and non-Hodgkin's lymphoma (SMR 1.49, 95\% CI: 1.15, 1.89). SMRs for all causes and all cancers were well below expectation among male salaried workers. Among females, SMRs for all causes and all cancers were similar to those observed in males for both hourly and salaried workers. Among female hourly workers, the SMR was elevated for leukemia only (SMR 1.61, 95\% CI: 0.94, 2.57). The authors reported that SMRs did not change markedly with the use of New York state reference rates or when workers employed less than one year were excluded.

Internal comparisons of mortality were conducted according to duration of employment in specific departments and cumulative exposure scores to specific agents. For analyses by duration, workers employed $\geq 5$ years in specific departments were compared to the rest of the cohort with model adjustment for paycode (i.e. hourly, salaried) and sex. The authors reported that $\geq 5$ years of employment in circuit board and substrate manufacturing departments was associated with an elevated risk of non-chronic lymphocytic leukemia mortality (HR 1.59, 95\% CI: $1.02,2.49)$. No other associations were observed for other causes of death within circuit board manufacturing departments. For comparisons of cumulative exposure score, hazard ratio (HR) estimates were elevated but not significant for trichloroethylene exposure and kidney cancer (HR 1.24, 95\% CI: 0.87, 1.77), trichloroethylene and non-chronic lymphocytic leukemia (HR 1.31, 95\% CI: 0.98, 1.75), and perchlorethylene and non-Hodgkin's lymphoma mortality (HR 1.25, 95\% CI: 0.90, 1.73). A significant, elevated association was found for cumulative perchloroethylene exposure and mortality due to non-malignant diseases of the nervous system (HR 1.31, 95\% CI: 1.01, 1.69).

Results of the NIOSH study are broadly consistent with a prior proportionate cancer mortality ratio analysis at the New York facility published in $2008{ }^{17}$, which reported an excess 
of lymphoma mortality (PCMR 2.20, 95\% CI: 1.01, 4.19) in males, and suggested potential excesses of death due to kidney and brain cancer. However, this analysis was based on a small number of cancer deaths (115) and used reference rates for New York State only.

Overall, NIOSH's investigation at the IBM facility in New York State benefits from a large number of decedents and department-specific exposure ascertainment to several chemical agents. However, the mean age of the cohort at the end of follow-up was only 59, suggesting SMR estimates were biased downward due to 'healthy hire' biases attributable to recency of active employment. With respect to exposure, the NIOSH study is extremely valuable for corroborating worker descriptions of manufacturing processes and exposures of concern at the automotive facilities in Huntsville. Both workplaces involved exposure to fiberglass dust, lead, and chlorinated solvents including trichloroethylene and 1,1,1-trichloroethane. NIOSH investigators also noted an excess of mesothelioma and pleural cancer mortality among early hires at the IBM facility and suggested the potential for workplace exposure to asbestos.

\subsection{Diseases associated with suspected workplace exposures}

Exposures of concern at the Huntsville facilities were identified based on interviews with former workers and published news articles describing soil contamination at Plant 2. Information obtained from these sources was corroborated using results from the NIOSH exposure assessment at the IBM electronics plant in New York State. These exposures are briefly reviewed for their associations with specific diseases. Causes of death of a priori interest based on the exposures of concern at the Huntsville facilities are summarized in Table 2.1. 


\section{Lead}

Lead is a systemic toxicant affecting all major organ systems. Chronic exposure to elevated doses of lead in adults is primarily associated with chronic kidney disease, including impaired renal function or kidney failure, and diseases of the central nervous system, including neurodegenerative diseases and cognitive impairment ${ }^{18,19}$. A large body of evidence has also established a positive association between blood lead levels and various cardiovascular disease endpoints, with the strongest evidence indicating increased risk of hypertension and cerebrovascular disease ${ }^{20-22}$. Defects in cardiac conduction and rhythm have also been documented in populations chronically exposed to lead at low doses ${ }^{23-25}$.

In occupational settings, several studies have described mortality risks among males with elevated lead exposure through employment at lead smelter and battery manufacturing plants. These studies have consistently reported associations between employment and elevated risk of non-malignant kidney disease, cerebrovascular disease, and ischemic heart disease mortality ${ }^{26-}$ 31. A study of 1,990 workers at a U.S. lead smelting plant with extended follow-up and quantitative exposure ascertainment reported an elevated association between cumulative lead exposure and ischemic heart, cerebrovascular, and chronic kidney disease mortality ${ }^{32}$. An external comparison also indicated excess mortality due to amyotrophic lateral sclerosis (ALS), although the estimate was imprecise due to the rarity of the disease. However, a meta-analysis of nine case-control studies of ALS reported a positive association between ALS incidence and prior occupational exposure to lead ${ }^{33}$. Some studies of workers occupationally exposed to lead have reported elevated risk of stomach, lung, or kidney cancer, although these findings may be confounded by exposure to other heavy metals, such as arsenic and cadmium ${ }^{26,28,34,35}$. Overall, there is little evidence that lead exposure is associated with malignant disease ${ }^{36,37}$. 


\section{Chlorinated organic solvents}

Trichloroethylene has been widely studied with respect to its cancer and non-cancer toxicity. A re-evaluation of trichloroethylene by IARC in 2012 resulted in its classification as carcinogenic to humans (Group 1) based on strong epidemiological and animal evidence for kidney cancer and limited evidence for liver cancer and non-Hodgkin's lymphoma ${ }^{38}$. A metaanalysis of epidemiological studies investigating trichloroethylene exposure and cancer risk reported an elevated association for kidney cancer, liver cancer, and non-Hodgkin's lymphoma, although estimates for the latter two cancer sites were subject to issues of study heterogeneity and a weaker exposure-response relationship ${ }^{39}$.

The non-cancer health effects of trichloroethylene include toxicity to several major organ systems. An in-depth toxicological review by the U.S. Environmental Protection Agency (EPA) concluded strong evidence that trichloroethylene exposure is toxic to the immune system, central nervous system, reproductive system, kidney, and liver ${ }^{40}$. Epidemiological and experimental evidence indicated that exposure can cause autoimmune disease (particularly generalized skin disorders), impairment of nerve function, tubular nephropathy, and toxicity to the liver and testes.

Other chlorinated solvents of interest include 1,1,1-trichloroethane and dichloroethane. Both chemicals were last reviewed by IARC in 1979 and classified in a monographs supplement in $1987^{41,42} .1,1,1$-trichloroethane was classified as having inadequate evidence for carcinogenicity in humans and experimental animals (Group 3), and dichloroethane was classified as having inadequate evidence in humans, but sufficient evidence in animals (Group 2B). A toxicological review by the U.S. EPA concluded 1,1,1-trichloroethane is toxic to the 
central nervous system ${ }^{43}$. Chlorinated solvents have been associated with non-malignant liver and nervous system diseases, including neurobehavioral impairment ${ }^{43-46}$.

\section{Asbestos}

The health effects of asbestos exposure have been extensively studied. The latest evaluation by IARC in 2012 classified asbestos as a human carcinogen due to strong evidence for mesothelioma and cancer of the lung, larynx, and ovary (Group 1) ${ }^{47}$. Much of the epidemiological evidence of the cancer risk of asbestos exposure comes from occupational studies of workers with long term or high exposure to asbestos, although there is evidence of elevated risk of malignant lung disease even at low levels. Asbestos exposure also causes nonmalignant lung disease, including fibrosis of the lungs and asbestosis ${ }^{48}$.

\section{Fiberglass dust}

Exposure to man-made vitreous fibers, including fiberglass, was last reviewed for its carcinogenic potential by IARC in 2002 . It was concluded that there was inadequate evidence in humans and limited evidence in experimental animals for the carcinogenicity of glass wool fibers 49. A retrospective cohort study of 32,110 employees at several U.S. fiberglass manufacturing plants from 1945 to 1978 found no excess of mortality due to non-malignant respiratory disease and a small excess of respiratory system cancer compared to national reference rates ${ }^{50}$. There were no excesses observed for other non-malignant causes of death. Internal comparisons of exposure showed little evidence of association with respiratory system cancer. A systematic review of the association between fiber glass exposure and respiratory system cancer published in 2011 concluded no consistent evidence of risk ${ }^{51}$. 
Table 2.1. Causes of death of a priori interest based on suspected workplace exposures at Huntsville facilities

\begin{tabular}{lc}
\hline Cause of death & Exposure \\
\hline Malignant & \\
Kidney cancer & TCE \\
Non-Hodgkin's lymphoma & TCE \\
Respiratory system cancer & Asbestos \\
& \\
Non-Malignant & \\
Hypertension & Lead \\
Cerebrovascular disease & Lead \\
Ischemic heart disease & Lead \\
Cardiac conductive/rhythm disease & Lead \\
Amyotrophic lateral sclerosis (ALS) & Lead \\
Central nervous system disease & Lead, TCE, other solvents \\
Chronic kidney disease & Lead, TCE \\
Liver disease & TCE, other solvents \\
Non-malignant lung disease & Asbestos \\
\hline
\end{tabular}




\section{CHAPTER 3: MATERIALS AND METHODS}

\subsection{Study design}

The specific aims were addressed through a prospective observational study of an occupational cohort. The study population was enumerated for the first time for the purposes of this investigation. All study information was obtained from administrative data sources. Statistical analyses were conducted on the cohort data set to achieve the study aims.

\subsection{Data sources}

There were three data sources that contributed to the enumeration of the study population for this investigation: 1) UAW employment records, 2) UAW-Chrysler pension records, and 3) the UAW pension information system. All of these data sources originated from the UAW, however, the first two have been maintained by a study collaborator at NIOSH since 1994. Data from all three sources were received on October $11^{\text {th }} 2016$.

\section{UAW employment records (magnetic tape storage)}

The study population was first identified in historical employment records collected by the UAW. In 1967, the UAW entered contractual agreements with Chrysler that required the company to provide the UAW with employment records for all UAW members actively employed by Chrysler in the United States. The records were generated by management at the automotive companies through the administrative process for collecting union dues. The records were sent to the UAW biannually on magnetic reel-to-reel tapes. Members of the UAW Health \& Safety Department maintained the tapes in collaboration with UAW Information Technology 
staff. The tapes were last updated in 1993 and subsequently transferred from UAW offices (Solidarity House) in Detroit, Michigan to the Education and Information Division at NIOSH headquarters in Cincinnati, Ohio. Employment records for all years (1967 to 1993) were transferred, except for 1971, as the tape for this year was lost in UAW file management. In 2014, NIOSH initiated the conversion of UAW employment records from magnetic tape storage to a digital format. The conversion was performed by an external data management firm (Iron Mountain) that provided all employment records to NIOSH in a digital file that was later converted to a SAS data set by NIOSH staff.

The newly created digital file contained employment history on approximately 311,000 individuals employed for any duration at any Chrysler-owned plant in the United States from 1967-1970 and 1972-1993. This file is referred to as the Chrysler global work history file. The file contains information on work history for each individual, including year and month of company first hire, plant code of employment (yearly), department of employment (yearly), skilled trade job code, and the year the job code first appeared (up to 1993). The file also lists the social security number, first five letters of the last name, first name initial, birth date, and sex as unique identifiers of each individual. The study population for this investigation was enumerated from this file.

\section{UAW-Chrysler pension records (magnetic tape storage)}

In addition to employment records, a separate agreement required Chrysler to provide company-generated pension records to the UAW. These records were also stored on magnetic reel-to-reel tapes and were created for years 1987 to 1993. The UAW Health \& Safety Department managed these records and transferred them to NIOSH in 1994 along with the employment records. They were digitized in 2014 and converted to a SAS data set file format. 
The file contains pension information for some individuals listed in the Chrysler global work history file, including retirement code, retirement status, last known state of residence, date of death, last plant worked, seniority date, credited service date (date of hire for pension calculation if there were gaps in employment), and date of termination. The file also contains identifiable information including social security number, full first name, middle initial, and full last name. The pension file was linked with the Chrysler global work history file by NIOSH staff using social security number. Name information from the UAW-Chrysler pension records was used to supplement missing or incomplete information in the Chrysler global work history file. However, pension data from this source were available for only $7 \%$ of the study population and several variables had a high proportion of missing data.

\section{UAW pension information system (digital database)}

The UAW pension information system is a computerized database of information on active and inactive UAW members. The pension information system contains demographic, vital status, and employment information on most UAW members who were receiving UAW pension benefits as of 2000 (approximate), or who are actively employed but are not yet receiving pension benefits.

UAW staff at Solidarity House in Detroit, Michigan linked records from their pension information system with the UAW employment and historical pension records provided by NIOSH. The linkage was done to provide additional and updated data on individuals in the historical files. I met with UAW staff at Solidarity House prior to the linkage to obtain details of the linkage process and determine what information was available in the pension system. This linkage was performed in October of 2016. 
Prior to the linkage, records in the system were updated with the latest name, birth date, sex, and race information from company (Chrysler, Ford, General Motors) active employee and pension files, the Local Union Information System (LUIS), and the American Federation of Labor and Congress of Industrial Organizations (AFL-CIO) COPE file (Committee on Political Education). UAW staff also updated the deceased status of records through a query of the most recent version of the Social Security Death Index (SSDI).

Once all updates of the UAW pension information system were complete, the system was able to provide the social security number, full first name, middle initial, full last name, previous first name, previous middle initial, previous last name, birth date, death date, seniority date, sex, race, last known state of residence, SSDI full name, SSDI birth date, and SSDI death date on UAW members listed in the employment and historical pension records held at NIOSH.

\subsection{Enumeration of the study population}

The study population was selected from the UAW employment records contained within the Chrysler global work history file. Any individual with a plant code in their work history that corresponded to any of the Huntsville electronics manufacturing facilities was selected into the study population. The plant codes were provided by the UAW Health \& Safety Department and encompass all Chrysler electronics manufacturing facilities in Huntsville up to 1993. No exclusion criteria or sampling methods were used in selecting the study population. The relationship between data sources used to enumerate the study population is illustrated in Figure

\section{1.}


Figure 3.1. Illustration of the relationship between UAW data sources used to enumerate the study population

$$
\text { Chrysler global work history file }(n=311,000)
$$

All UAW-Chrysler employees nationwide, 1967-1993

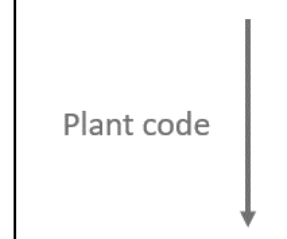

Study population $(n=4,396)$

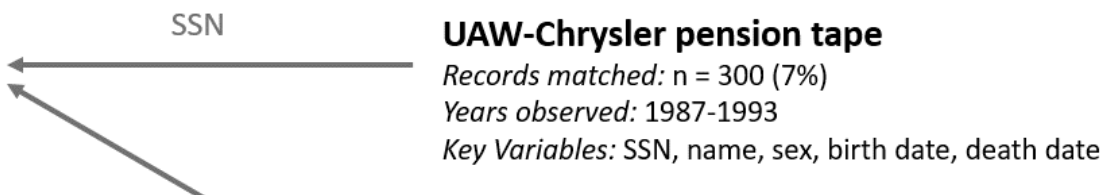

UAW pension information system

Records matched: $\mathrm{n}=3,361(83 \%)$

Years observed: 2000-2016 (approx.)

Key Variables: SSN, name, sex, race, birth date, UAW death date, SSDI death date

A total of 4,396 individuals who were ever-employed at the electronics manufacturing facilities in Huntsville from 1972 to 1993 were selected into the study population from the global work history file. The operational history and number of workers ever-employed at each plant is displayed in Table 3.1. All individuals identified in the study population were searched in the UAW pension information system by UAW staff using the social security number as a unique identifier. The system contained a correct match for 3,631 individuals (83\% of the study population). Once all data had been received at UNC, data from the pension information system were merged with the UAW employment and historical pension records using social security number as a matching variable. The resulting data set was used to accomplish the aims of the investigation. 
Table 3.1. Actual and observed operational history of plant codes at Chrysler electronics manufacturing facilities in Huntsville, Alabama $(\mathrm{n}=4,396)$

\begin{tabular}{lcccc}
\hline Plant code name & $\begin{array}{c}\text { Plant code } \\
\text { start year }\end{array}$ & $\begin{array}{c}\text { Plant code } \\
\text { end year }\end{array}$ & $\begin{array}{c}\text { Observed } \\
\text { start year }\end{array}$ & $\begin{array}{c}\text { Observed } \\
\text { end year }\end{array}$ \\
\hline Huntsville Electronics (original) & 1971 & $1989^{\mathrm{a}}$ & $1972^{\mathrm{b}}$ & 1989 \\
Military-Public Electronics & 1983 & 1989 & 1983 & 1989 \\
New Huntsville Electronics & 1989 & 2010 & 1989 & 1993 \\
\hline
\end{tabular}

${ }^{a}$ Original plants officially ceased operations in 1989, although some production continued intermittently until 2010.

${ }^{\mathrm{b}}$ Operations began in 1971 but work history tape for this year was lost in UAW file management.

\subsection{Data cleaning}

The initial quality of the data set was assessed in several ways. The data set was assessed for duplicate records, social security numbers that did not have exactly 9 digits, and excessive missing data or implausible values for important study variables. No duplicate records or erroneous social security numbers were found in the data set. All birth dates were verified to ensure a correct and consistent format. Implausible birth dates were corrected by specifying the $20^{\text {th }}$ century as the century of birth when year of birth had been parsed using the last two digits only. Work history, including plants and departments worked from 1967-1970 and 1972-1993, was available for all individuals.

The Lexis Nexis 'Accurint' commercial public information database was used to correct missing or discordant information on sex, race, or birth date for a total of 952 individuals. The web-based database was manually searched over a four week period beginning in January 2017. Individuals were searched one at a time using their social security number as a unique identifier. Accurint's voter registration database was used to determine race as listed on voter registration cards. Birth date and sex were determined from the 'People Plus' search, which is based on a 
variety of different public information sources. In situations where sex or birth date information in UAW files was discordant with Accurint, the latter source was given priority if the record was a strong match in Accurint (i.e. name and social security number match, residential address in Huntsville). This was done for a total of 5 records.

The Accurint product provided the sex and birth date for all individuals who were missing this information from UAW sources (95 and 102 individuals, respectively). Race was obtained for $48 \%$ of the 883 individuals missing this information, as some study members were not found in Accurint's voter registration database or did not provide race on their voter registration form. The proportion of White individuals found in the voter registration database (85\% White) was similar to the proportion found in the UAW pension information system $(80 \%$ White).

\subsection{Study population}

The study population consisted of 4,396 unionized men and women ever-employed at the automotive electronics manufacturing facilities in Huntsville, Alabama between 1972 and 1993. The population may exclude workers first hired at the facilities part way through 1993 . Descriptive characteristics of the study population are presented in Table 3.2.

The population includes both hourly and salaried employees, although it was not possible to distinguish workers in each pay grade with the available data. Hourly workers include those who worked on production lines in the manufacturing area of the plants. Salaried workers consist of those employed in clerical, supervisory, or professional (i.e. engineering) occupations. These workers were generally isolated from the production area of the plant, however, many salaried employees in engineering and technical departments were exposed to chemical agents through 
Table 3.2. Descriptive characteristics of the study population of 4,396 UAW hourly and salaried workers ever-employed at Chrysler electronics in Huntsville, Alabama from 1972-1993

Characteristic

\begin{tabular}{|c|c|}
\hline $\mathrm{N}$ & 4,396 \\
\hline Year of birth, median (IQR) & $1949(1940,1955)$ \\
\hline $\begin{array}{l}\text { Sex, n }(\%) \\
\text { Female } \\
\text { Male }\end{array}$ & $\begin{array}{l}2,562(58) \\
1,834(42)\end{array}$ \\
\hline $\begin{array}{l}\text { Race, } \mathrm{n}(\%) \\
\text { White/Caucasian } \\
\text { Black/African-American } \\
\text { Hispanic } \\
\text { Native American/Alaskan Native } \\
\text { Asian/Pacific Islander } \\
\text { Other } \\
\text { Missing }\end{array}$ & $\begin{array}{c}3,170(80) \\
746(19) \\
24(1) \\
6 \\
3 \\
1 \\
446\end{array}$ \\
\hline $\begin{array}{l}\text { Huntsville plants, median (IQR) } \\
\text { Age first worked } \\
\text { Year first worked } \\
\text { Years since first hire } \\
\text { Years of employment }\end{array}$ & $\begin{array}{c}32(26,41) \\
1983(1977,1984) \\
32(28,39) \\
9(4,12)\end{array}$ \\
\hline $\begin{array}{l}\text { Chrysler company, median (IQR) } \\
\text { Age first worked } \\
\text { Year first worked } \\
\text { Years since first hire } \\
\text { Years of employment }\end{array}$ & $\begin{array}{c}30(25,39) \\
1979(1976,1984) \\
33(30,39) \\
10(5,16)\end{array}$ \\
\hline Ever-worked at other Chrysler plants, $\mathrm{n}(\%)$ & $914(21)$ \\
\hline $\begin{array}{l}\text { Last known state of residence, } \mathrm{n}(\%) \\
\text { Alabama } \\
\text { Tennessee } \\
\text { Michigan } \\
\text { Florida } \\
\text { Indiana } \\
\text { Georgia } \\
\text { Illinois } \\
\text { Missouri } \\
\text { Texas } \\
\text { Ohio } \\
\text { Other } \\
\text { Missing }\end{array}$ & $\begin{array}{c}3,338(81) \\
265(6) \\
97(2) \\
70(2) \\
63(2) \\
59(1) \\
35(1) \\
31(1) \\
29(1) \\
22(1) \\
120(3) \\
267\end{array}$ \\
\hline
\end{tabular}

\footnotetext{
${ }^{\mathrm{a}}$ Fewer than 20 individuals live in any one of the states in this category.
} 
smaller-scale manufacturing processes related to product research and development. For this reason, salaried employees were also represented by their own UAW health and safety representative. A news article published in 1986 reported approximately $10 \%$ of employees at Chrysler's automotive electronics facilities in Huntsville were salaried ${ }^{52}$.

\subsection{Exposure ascertainment}

The use of specific industrial agents at the Huntsville facilities was ascertained through interviews with former workers and UAW representatives at the facilities and a news article describing soil contamination at the Plant 2 site ${ }^{7}$. Information obtained from these sources was corroborated using results from a retrospective exposure investigation at an IBM circuit board and computer manufacturing facility in New York State ${ }^{16}$. Given that no job-, department-, or building-specific exposure information was available for this investigation, exposure metrics were based on employment characteristics to serve as proxies for exposure to hazardous agents at the facilities. These characteristics were duration of employment, plant of employment, calendar period of hire, and skilled trade job status.

\section{Duration of employment}

This exposure metric served as a proxy for cumulative, longer-term workplace exposure to hazardous agents at the Huntsville facilities. Duration of employment was determined as the sum of observed years of work at Huntsville plant codes. Individuals had their hire date imputed at January $1^{\text {st }}$ of their first year of employment at the facilities and were assumed to have worked the entire year for subsequent years of observed work. January $1^{\text {st }}$ was chosen to prevent the exclusion of individuals who died the same year they began work and added a trivial amount of person-time to follow-up. The first/last year worked at a given plant was determined as the

first/last year the plant code appears in the work history. Work history for the entire study 
population was unavailable after 1993 and during the first few months that Plant 1 was operational in 1971. For workers actively employed in $1993(n=2,212)$, employment duration was imputed based on age using methods described in Chapter $\mathbf{5}$.

\section{Calendar period of employment}

This exposure metric represented potential exposure contrasts at the facilities based on changes in manufacturing process or workplace conditions over time. Three calendar periods of first hire were compared corresponding to broad eras in manufacturing process: exclusive use of Plant 1 (1972-1976), introduction of Plant 2 and wave solder process (1977-1983), and introduction of the military plant and Plant 3 (1984-1993). Binary calendar year cut points were also used to compare known hires at Plant 1 (< versus $\geq 1977$ ), hires during the earlier half of the observed employment period (< versus $\geq 1983$ ), and hires after the construction of Plant 3 (< versus $\geq 1989$ ). Generally, early calendar periods of employment were interpreted as having greater workplace exposure to hazardous agents based on information obtained from worker interviews. An illustration of the number of study members active per year at the facilities is shown in Figure 3.2.

\section{Plant of employment}

This exposure metric characterized exposure to hazards at specific plant codes at the Huntsville facilities. The codes were created by the UAW for administrative purposes and do not correspond to specific buildings per se, but to one or more buildings comprising a given manufacturing operation. There are three plant codes included in the available work history named Huntsville Electronics, Military-Public Electronics, and New Huntsville Electronics. These codes correspond broadly to the Plant 1 and 2, military plant, and Plant 3 buildings, 
respectively, although actual building-specific work history was not available for this investigation.

Huntsville Electronics corresponds to manufacturing at the original Plant 1 and 2 buildings. These two plants were the only site of automotive electronics manufacturing from 1971 to 1988 . Plant 1 was originally constructed in 1955 and expanded twice in the mid-1970's. Plant 2 was constructed in 1977. Military Public-Electronics refers to the non-automotive electronics manufacturing operation occurring in a small, separate plant from 1983 to 1989. After 1989, this building was not used again and the division was terminated. New Huntsville

Figure 3.2. Number of study members active per year according to plant code at Chrysler electronics facilities in Huntsville, 1972-1993 $(\mathrm{n}=4,396)$

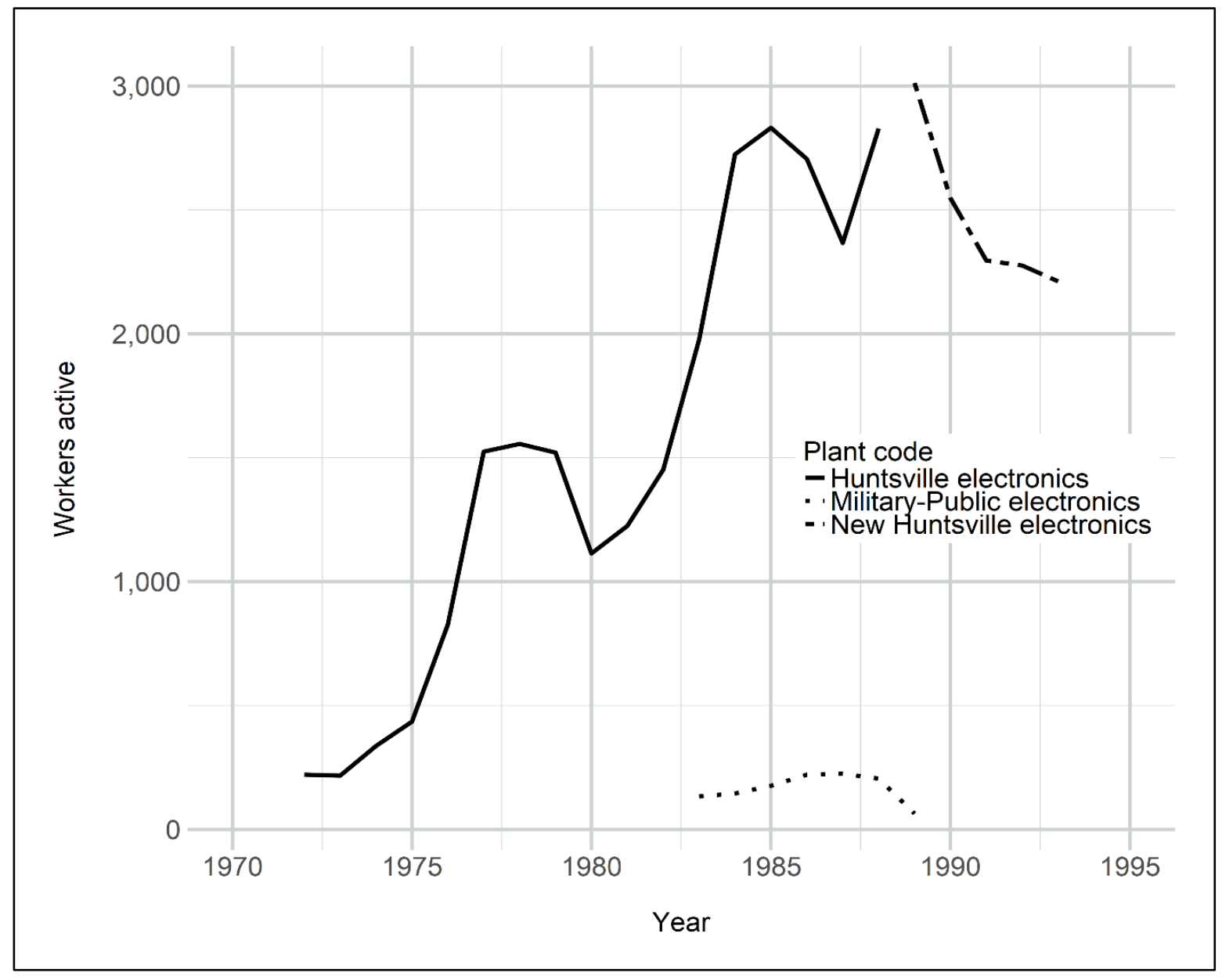


Electronics refers primarily to work at the new facility constructed in a separate area of the city in 1989. Work history at the original Plant 1 and 2 buildings after 1989 is not discernible as all operations adopted the new plant code in this year, although it is estimated that relatively few worked at the original buildings during that time. The majority of the study population had work history at more than one plant code. There were 2,773 individuals (63\% of the study population) ever-employed at both Huntsville Electronics and New Huntsville Electronics. Further, 72\% of the 344 individuals ever-employed at Military-Public Electronics were also ever-employed at the other facilities.

\section{Skilled trade job status}

A skilled tradesperson typically refers to an individual with specialized training in an occupation that involves manual work. At the Huntsville facilities, skilled tradespeople were electricians, machine repairers, carpenters, tool makers, and air conditioning technicians. Skilled trade status was used as an indicator for reduced exposure to manufacturing processes relative to unskilled workers employed full-time on production lines. However, skilled tradespeople were estimated to have greater exposure to asbestos due to their conducting electrical work and construction within plant walls. The available work history contains skilled trade job codes for skilled workers as of 1967 or later and also contains the first year their job code appeared in their work history. Skilled tradespeople at the Huntsville facilities were almost exclusively male $(92 \%)$.

\subsection{Vital status ascertainment}

The vital status of the study population was ascertained from four sources: 1) UAWChrysler pension records, 2) UAW pension information system, 3) the Social Security Death 
Index (SSDI), and 4) the National Death Index (NDI). All four sources provided month and year of death.

\section{UAW-Chrysler pension records (magnetic tape storage)}

Historical UAW-Chrysler pension records identified a total of 24 deceased individuals with death dates from 1987 to 1993 . This source included company pension records for years 1987 to 1993, however, the completeness of decedent reporting during these years was unknown.

\section{UAW pension information system (digital database)}

The UAW pension information system matched with $83 \%(n=3,631)$ of the study population and identified a total of 882 decedents with death dates from 1981 to September of 2016. The pension system indicated deaths reported internally through the UAW's administration of pension benefits and also through queries of the SSDI. However, the UAW suppressed indications of deceased status from the SSDI for individuals with a death date less than three years prior to the latest SSDI search date (October $10^{\text {th }} 2016$ ) for confidentiality reasons. The completeness of the UAW's internal process for ascertaining deaths was unclear. There were 173 individuals identified as deceased in this source who were not identified as such in the SSDI, with the earliest date of death occurring in 1992. Personal communication with UAW staff indicated that the pension system includes most active and inactive members receiving benefits as of approximately 2000. However, the system includes 9 records with a nonSSDI death date prior to this year.

\section{Social Security Death Index}

Vital status was further ascertained through a search of the SSDI which I completed on December $5^{\text {th }}$ 2016. The SSDI search was performed using a batch service provided by 
LexisNexis, whereby identifiable information on all 4,396 individuals in the study population was submitted to LexisNexis for query in the SSDI. Social security number, full name, birth date, and address were match items used to identify decedents. A total of 897 individuals were identified as deceased through this search with death dates from 1973 to September of 2016. LexisNexis provided the death date for individuals identified as deceased, plus full name and residential address history on the entire cohort. All identified decedents matched using their social security number, except for one who matched using name and address only. LexisNexis provided all vital status information obtained from the SSDI up to the most recent version of the index. The SSDI is updated weekly by the Social Security Administration.

The SSDI contains all deaths reported to the Social Security Administration due to a claim for death benefits or the termination of benefits the decedent received when alive. The majority of deaths in the SSDI occurred from the mid-1960's to present. The sensitivity of the SSDI depends primarily on the age at death, with older populations being detected with greater sensitivity. The overall sensitivity of the SSDI is estimated to be approximately $83 \%{ }^{53}$.

\section{National Death Index}

I initiated the NDI search in July of 2017 to verify and complement vital status ascertainment in the SSDI and the UAW pension system, as searching the entire study population in the NDI was prohibited by cost. Broadly, the NDI search was conducted to 1) confirm the deceased status and death date of individuals identified as deceased in the SSDI or UAW sources, and 2) to ascertain the vital status of individuals who did not match whatsoever in the UAW pension information system or in the Lexis Nexis residential history search. The specific criteria used for submitting individuals for search in the NDI and the number of individuals searched is shown in Table 3.3. A total of 1,118 individuals were identified as 
deceased in the NDI with death dates from 1979 to November $12^{\text {th }}$ 2016, including 64 individuals who had not been previously identified as deceased in any other source. Social security number, full name, birth date, sex, race, age at death (where applicable), and last known state of residence were used to identify decedents. Records were identified as 'true matches' if they 1) met the NDI's criteria for being a true match based on overall match score and type of variables matched $(n=1,108)$, or 2$)$ matched perfectly on social security number and $\operatorname{sex}(n=9)$, or 3) matched perfectly on full name, full birth date, sex, and had the social security number unavailable on the death certificate (i.e. potential social security number match) $(n=1)$.

Table 3.3. Criteria for selection and number of individuals submitted to the National Death Index for vital status ascertainment $(n=1,714)$

\begin{tabular}{lc}
\hline Criteria & $\mathrm{N}$ \\
\hline Confirmation of vital status & 1,061 \\
$\quad$ Deceased in any source $\geq 1979$ & \\
Ascertainment of vital status & 23 \\
$\quad$ Non-deceased, non-match in Lexis Nexis address database & 37 \\
$\quad$ Non-deceased, last used address $\leq 10 / 2016$ & 593 \\
Non-deceased, non-match in UAW pension information system & \\
\hline
\end{tabular}

The NDI is a centralized database of death record information obtained from state vital statistics offices as of January $1^{\text {st }} 1979$. It is part of the Centers for Disease Control and Prevention's National Center for Health Statistics and is considered the most complete national record of deaths occurring in the U.S. The overall sensitivity of the NDI is estimated to be between $87 \%$ and $98 \%{ }^{53}$. The NDI search conducted for this investigation included a search of the 2016 early release file, which includes an estimated $92 \%$ of the deaths to be contained in the final 2016 file once reporting from each individual state is complete. The early release file 
contained demographic data for $100 \%$ and cause of death data for $97 \%$ of decedents in Alabama in $2016^{54}$.

\section{Concordance between vital status sources}

The concordance between data sources used to ascertain vital status was satisfactory. Of the 1,134 total individuals identified as deceased, 706 (62\%) were deceased in the SSDI, UAW pension system, and NDI, 348 (31\%) were deceased in the NDI and either the SSDI or the UAW pension system (but not both), 64 (6\%) were identified in the NDI only, and $16(1 \%)$ were identified in the UAW pension system or the SSDI (or both). All 606 decedents identified through the SSDI search in the UAW pension information system were also identified in the SSDI search conducted by LexisNexis. All 24 decedents in the UAW-Chrysler pension records were deceased in all three other sources. Of all sources searched, the latest observed death date was November $12^{\text {th }} 2016$. The calendar years and number of individuals searched in each source used for vital status ascertainment are summarized in Table 3.4. The number of decedents identified in each source is illustrated in Figure 3.3.

Table 3.4. Calendar years of death and number of individuals searched in each data source used for vital status ascertainment

\begin{tabular}{lcc} 
Data source & $\begin{array}{c}\text { Calendar years } \\
\text { available }\end{array}$ & N searched \\
\hline UAW-Chrysler pension records (tape) & $1987-1993$ & Unknown \\
UAW pension information system & $1993-2016$ & 3,631 \\
Social Security Death Index & $1965-2016$ & 4,396 \\
National Death Index & $1979-2016$ & 1,699 \\
\hline
\end{tabular}


Figure 3.3. Number of deaths identified in each data source and concordance between data sources used for vital status ascertainment

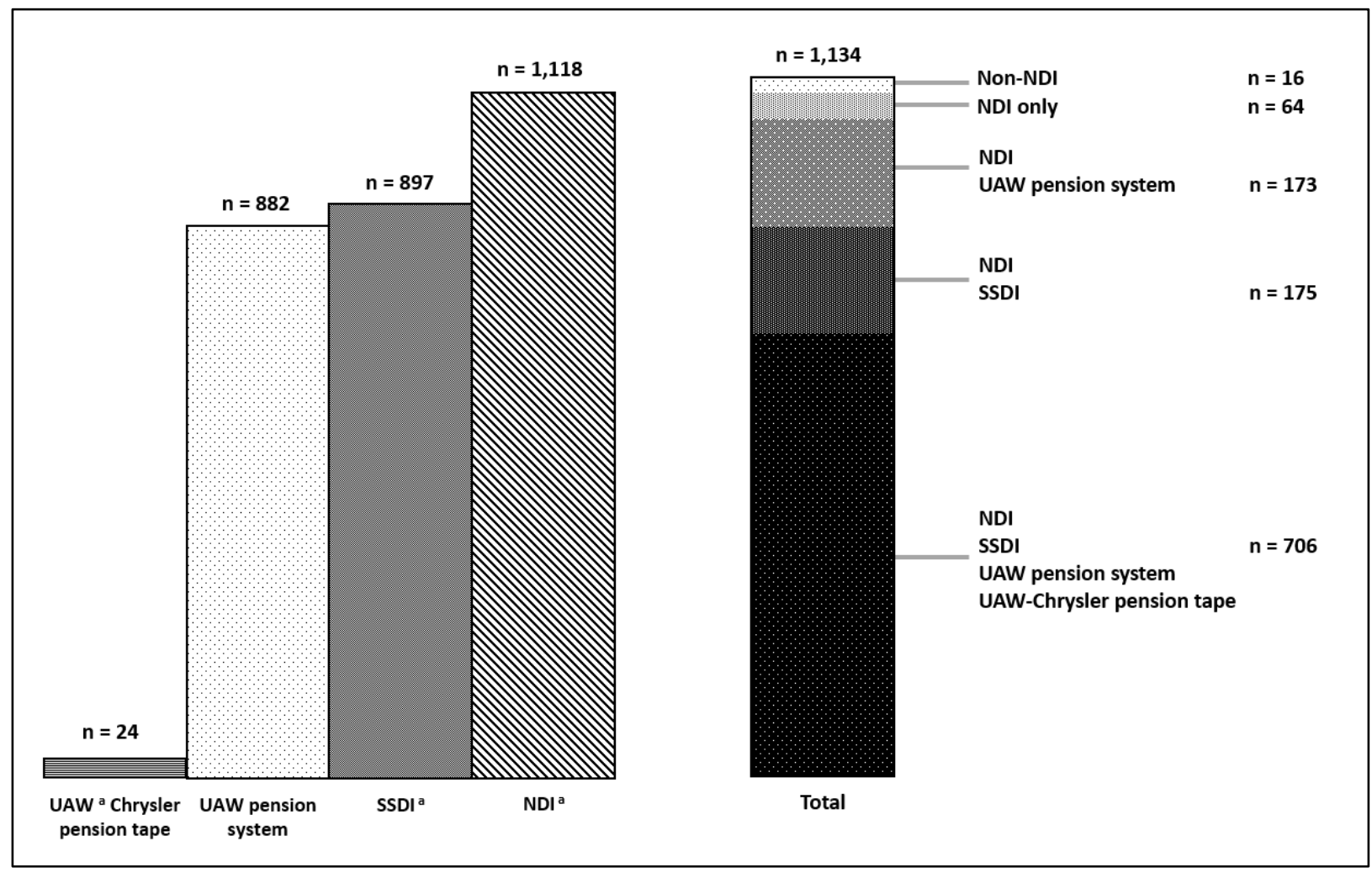

${ }^{\text {a }}$ UAW, United Autoworkers; SSDI, Social Security Death Index; NDI, National Death Index

\subsection{Cause of death ascertainment}

Cause of death was ascertained using the underlying cause of death code listed on the death certificate of individuals identified as deceased as of December $31^{\text {st }} 2016$. Death certificate information was obtained from the NDI for deaths that occurred in 1979 or later and from the Alabama state vital records office for deaths that occurred prior to 1979. Cause of death was ascertained for a total of 1,127 individuals in the study population. The number of deaths in the study population due to specific causes is presented in Table 3.5.

All 1,118 individuals identified as deceased in the NDI had their underlying cause of death code obtained from death certificate information in the digital NDI output. The cause of 
death codes provided by the NDI are classified according to the International Classification of Diseases (ICD) revision in effect at the time of death (ICD-9 or ICD-10). There are 6 individuals identified as deceased in non-NDI sources who did not meet the criteria for being classified as a 'true match' in the NDI. For these records, the cause of death is unknown. It is assumed that these individuals died outside of the U.S. or had an incomplete death certificate. There were 9 individuals identified as deceased prior to 1979 who had their death certificates retrieved from the Alabama state vital records office. I completed this in-person through retrieval services at the Madison County Public Health Department in Huntsville in April of 2017. The social security number, full name, birth date, and death date was used as identifiable information to retrieve physical copies of death certificates. The death certificates listed the underlying cause of death code in effect at the time of death (ICD-8). There was 1 individual identified as deceased prior to 1979 whose death certificate was not found and whose cause of death is unknown. It is assumed that this individual died outside the state of Alabama. Cause of death codes were classified into 119 categories according to the major and minor cause of death classification system established by NIOSH ${ }^{55}$. This system is widely used and was chosen for comparison and consistency with other U.S. occupational mortality studies. 
Table 3.5. Observed number of deaths in the study population due to specific causes according to the NIOSH-119 major and minor cause of death categories

\begin{tabular}{|c|c|}
\hline Cause of death & $\mathrm{N}$ \\
\hline All Causes & 1,134 \\
\hline All malignant neoplasms & 318 \\
\hline Buccal \& pharynx & 4 \\
\hline Other buccal & 1 \\
\hline Pharynx & 3 \\
\hline Digestive \& peritoneum & 63 \\
\hline Esophagus & 10 \\
\hline Stomach & 6 \\
\hline Intestine & 16 \\
\hline Rectum & 4 \\
\hline Biliary, liver, gall bladder & 9 \\
\hline Pancreas & 17 \\
\hline Peritoneum, other, unspecified sites & 1 \\
\hline Respiratory & 100 \\
\hline Larynx & 2 \\
\hline Trachea, bronchus, lung & 96 \\
\hline Other respiratory & 2 \\
\hline Breast & 36 \\
\hline Female genital organs & 18 \\
\hline Cervix & 3 \\
\hline Other \& unspecified parts of uterus & 2 \\
\hline Ovary & 12 \\
\hline Other female genital organs & 1 \\
\hline Male genital organs & 11 \\
\hline Prostate & 11 \\
\hline Urinary organs & 8 \\
\hline Kidney & 1 \\
\hline Bladder \& other urinary organs & 7 \\
\hline Other \& unspecified sites & 47 \\
\hline Bone & 1 \\
\hline Melanoma & 6 \\
\hline Other skin neoplasm & 1 \\
\hline Connective tissue & 1 \\
\hline Brain \& other parts of nervous system & 12 \\
\hline Thyroid gland & 1 \\
\hline Other \& unspecified sites & 25 \\
\hline Lymphatic \& hematopoietic & 31 \\
\hline Non-Hodgkin's lymphoma & 12 \\
\hline Multiple myeloma & 9 \\
\hline Leukemia & 10 \\
\hline Benign \& unspecified neoplasms & 3 \\
\hline Benign neoplasm of the eye, brain, \& nervous system & 2 \\
\hline Other & 1 \\
\hline Heart diseases & 259 \\
\hline Rheumatic heart disease & 2 \\
\hline Hypertension with heart disease & 5 \\
\hline Ischemic heart disease & 130 \\
\hline
\end{tabular}


Table 3.5 continued

Chronic disease of the endocardium $\quad 7$

Cardiomyopathy 5

Conduction disorder $\quad 66$

Other heart diseases $\quad 44$

Other circulatory system diseases $\quad 94$

Cerebrovascular disease $\quad 60$

Hypertension without heart disease $\quad 11$

Disease of the arteries, veins, \& lymphatic vessels 23

Respiratory system diseases $\quad 98$

Pneumonia 21

Chronic Obstructive Pulmonary Disease (COPD) 55

Asthma 2

Asbestosis 1

$\begin{array}{lr}\text { Other respiratory diseases } & 19\end{array}$

Digestive system diseases $\quad 55$

Diseases of the stomach \& duodenum 2

Hernia \& intestinal obstruction 3

Cirrhosis \& other liver disease $\quad 24$

Other digestive system diseases $\quad 26$

Nervous system disorders $\quad 46$

Multiple sclerosis $\quad 4$

Other nervous system diseases $\quad 42$

Diabetes mellitus $\quad 28$

Mental, psychoneurotic, \& personality disorders 23

Alcoholism $\quad 5$

Other mental disorders $\quad 18$

Diseases of the genito-urinary system 25

Acute glomerulonephritis \& renal failure 5

Chronic \& unspecified nephritis \& renal failure $\quad 17$

Other genito-urinary diseases $\quad 3$

Diseases of the musculoskeletal \& connective system 4

Osteomyelitis \& periotitis $\quad 1$

Other musculoskeletal diseases 3

Tuberculosis \& HIV 2

Diseases of blood \& blood forming organs 1

Skin \& subcutaneous diseases 1

Transportation injuries 44

Railway, water \& air transport $\quad 2$

Motor vehicle (other \& unspecified) 28

Other transportation injuries $\quad 14$

Violence 38

Intentional self-harm $\quad 24$

$\begin{array}{ll}\text { Assault \& homicide } & 14\end{array}$

Falls $\quad 7$

Other injury 24

Symptoms \& ill-defined conditions $\quad 24$

Other \& unspecified causes $\quad 40$ 


\subsection{Referent mortality rates}

Aim 1 analyses involved an external comparison of standardized cause-specific mortality rates with the general population. Referent mortality rates for the general population of the U.S. and the state of Alabama were obtained from the Department of Surveillance, Hazard Evaluations, and Field Studies at NIOSH with permission from the National Center for Health Statistics. Mortality rates were provided until 2012 for the U.S. and until 2014 for the state of Alabama. Rates for subsequent years were imputed to equal the most recent year available for all analyses. Referent rates for the state of Alabama were chosen to provide a potentially more comparable reference population with respect to health-related lifestyle characteristics and for identifying state-specific trends in underlying cause of death coding.

\subsection{Effect measures}

Standardized mortality ratio analysis

The first aim of this investigation involved the estimation of standardized mortality ratios (SMRs). The SMR is a summary measure of the mortality experience of a cohort relative to some referent population. It can be interpreted as a ratio of the observed to the expected number of deaths in a given population, where the expected number of deaths equals that which would have been observed had the study population experienced the mortality rate of a given referent population with the same age, sex, and race characteristics over the same calendar years. Binary race was imputed for $10 \%$ of the study population $(n=446)$ according to methods described in

Chapter 4. The general form of the SMR equation used for this study is:

$$
S M R=\frac{\sum_{i} A_{i}}{\sum_{i} P_{i} R_{i}}
$$


Where:

$A=$ Observed number of cause-specific deaths in study population

$P=$ Person-years at risk of death in study population

$R=$ Cause-specific mortality rate in referent population

$i=$ Index for strata of age (5-year groups from 20-24 to $\geq 85$ ), sex (male, female), binary

race (White, Black or other), and calendar year (1972-2016)

\section{Poisson regression analysis}

The second aim of this investigation involved the estimation of mortality rate ratios (RRs). The analytic data set was transformed into a person-year format such that each row corresponded to one person-year of follow-up for a given individual in the study population. Generalized linear models with a Poisson distribution and log-link were used to estimate rate ratios using the transformed person-year dataset. The natural log of person-years in the dataset was used as the offset term. The general form of the crude model used to estimate rate ratios using a binary exposure in this study is:

$$
\ln (E[Y])=\ln (p t)+\beta_{0}+\beta_{1} X_{1}
$$

Where:

$$
\begin{aligned}
& \beta_{0}=\text { Log of the mortality rate among the unexposed } \\
& \beta_{1}=\text { Log of the mortality rate ratio comparing the exposed to the unexposed } \\
& X_{1}=\text { Binary exposure variable of interest } \\
& p t=\text { Person-time of follow-up (offset) }
\end{aligned}
$$




\section{CHAPTER 4: MORTALITY AMONG AUTOWORKERS MANUFACTURING ELECTRONICS IN HUNTSVILLE, ALABAMA: EXTERNAL COMPARISONS OF CAUSE-SPECIFIC MORTALITY}

\subsection{Introduction}

Former employees at automotive electronics manufacturing facilities in Huntsville, Alabama have raised concerns over a suspected excess of mortality among their colleagues. The facilities were closed in 2010, however, public knowledge of soil contamination with chlorinated solvents at one plant site and asbestos contamination of at least one plant building has increased worker's concerns over potential health hazards associated with employment at the facilities. In 2015, local members of the United Autoworkers (UAW) produced an employee-generated list of deceased workers and requested that the UAW Health and Safety Department evaluate a perceived elevated rate of mortality among former employees. The UAW requested epidemiologic support to investigate worker concerns.

The Huntsville facilities primarily manufactured electronic circuit boards for automotive engine, body, and dashboard components for Chrysler and other manufacturers from 1971 to 2010. Interviews with former employees and UAW health and safety representatives at the facilities indicated that workers were exposed to trichloroethylene (TCE), lead fumes from molten solder, fiberglass dust, and asbestos in plant walls. A local news article published in 2010 reported soil at one plant site was contaminated with 1,1,1-trichloroethane ${ }^{7}$. Previous studies among workers employed at electronics and computer manufacturers in the U.S. have indicated exposure to lead-based solder and chlorinated organic solvents, including trichloroethylene and 1,1,1-trichloroethane, to be of particular concern for worker health due to the known toxicity of 
these agents to several major organ systems ${ }^{14-16,18,19,21,43,56,57}$. Previous mortality studies among hourly UAW members in the large UAW-Ford and UAW-GM cohorts reported lower standardized all-cause mortality rates among workers relative to the U.S. general population ${ }^{1,8}$, which is characteristic of 'healthy worker' effects common in occupational studies of mortality 58.

The objective of this study was to investigate concerns about excess mortality among 4,396 hourly and salaried UAW members ever-employed at automotive electronics manufacturing facilities between 1972 and 1993 in Huntsville, Alabama. Cause-specific mortality rates in the study cohort were compared externally with U.S. and Alabama general population rates using standardized mortality ratio analyses. Mortality estimates were stratified according to worker sex, race, and calendar period of first employment with examination of 'healthy worker' effects. This investigation involves the enumeration of a novel cohort with primary ascertainment of mortality and cause of death.

\subsection{Methods}

Study setting

Automotive electronics manufacturing operations began in Huntsville in 1971 at a plant building originally constructed for Chrysler defense and aerospace contracts in the 1950's (Plant 1). This original Plant 1 building was the site of all manufacturing until 1977, when a second plant (Plant 2) was built adjacent. Both Plant 1 and 2 were used as the primary site of manufacturing until 1989, when a large, more modern facility was constructed at a separate site (Plant 3). The majority of the workforce and equipment was transferred to Plant 3 after it opened, although Plant 1 and 2 remained in use for some manufacturing operations. A small manufacturing operation also existed at a fourth plant building to fulfill a military and railway 
electronics contract from 1983 to 1989 . The workforce remained unionized through the UAW until all facilities in Huntsville were permanently closed in 2010.

\section{Study population}

The study cohort includes 4,396 hourly and salaried UAW members employed for any duration at any Chrysler electronics facility in Huntsville between 1972 and 1993. The cohort was enumerated for the purposes of this investigation from national UAW employment records generated through a joint UAW-Chrysler agreement. Individuals were selected into the study cohort from the national records if their work history contained a plant code corresponding to any of the Chrysler electronics facilities in Huntsville during the calendar years for which records were available (1967-1970 and 1972-1993). The employment records used for this investigation were updated biannually and include company work history for the entire study cohort during the observed employment period. The records were accessed in computerized format and included yearly indications of employment at specific Chrysler plant codes and skilled trade job codes. The three available plant codes at the Huntsville facilities correspond to Plant 1 and 2 (combined), the military plant, and Plant 3. The study cohort includes both hourly and salaried UAW members, as it was not possible to distinguish workers in each pay grade with the available data. It is estimated that approximately $10 \%$ of UAW members employed at the Huntsville facilities were salaried employees.

All individual employment records were linked with the most current version of the UAW pension information system at UAW offices (Solidarity House) in Detroit, Michigan to obtain missing birth date, sex, and race information and to verify information provided in the UAW employment records. A total of 3,631 (83\%) individuals in the cohort matched in the UAW pension system using social security number (SSN). A subset of 952 records were 
additionally searched in a commercial public information database (LexisNexis Accurint) to obtain demographic information that remained missing after the pension linkage. The search included consumer/marketing and U.S. voter registration databases and was conducted using complete name and SSN. The search provided the birth date or sex for all individuals and race for $48 \%$ of the 883 individuals missing this information. A separate search of LexisNexis Accurint was also conducted to obtain the last known state of residence of all individuals in the study cohort to improve the search and match criteria of mortality follow-up. There were no exclusions applied to the study cohort based on missing data. The study protocol was approved by the University of North Carolina Institutional Review Board.

\section{Exposure characterization}

An author (N.D.) conducted interviews with former employees and UAW health and safety representatives at the Huntsville facilities. Interviews identified lead, chlorinated solvents, fiberglass dust, conformal coatings, and asbestos as exposures of primary concern. Workers were exposed to lead through various soldering operations, including molten wave solder, hand solder, and solder paste processes. Chlorinated organic solvents, including trichloroethylene and 1,1,1trichloroethane, were used at the facilities for solder degreasing from machinery, tools, and worker's hands. Soil contamination with chlorinated solvents and other industrial agents, including 1,1,1-trichloroethane, was discovered at Plant 2 in the 1980's ${ }^{7}$. Workers also reported particular concern over working conditions at the original Plant 1 building. Primary concerns at Plant 1 included a lack of ventilation in the production area, lack of enclosures or capture systems on wet processing lines, excessive heat, and asbestos in plant walls. A retrospective exposure assessment conducted at an IBM circuit board and computer manufacturing facility in New York state corroborated the presence of trichloroethylene, 1,1,1-trichloroethane, lead-based 
solder, and fiberglass dust exposure in manufacturing processes ${ }^{16}$. The assessment also reported use of tetrachloroethylene and dichloromethane, although it is unknown whether these agents were used at the Huntsville facilities. At the IBM facility, workers were exposed to trichloroethylene <1985 only, and exposure was greatest for 1,1,1-trichloroethane throughout all manufacturing eras from 1969 to 2002 . No quantitative exposure information or industrial hygiene monitoring data were available for this investigation. Job- and department-specific work history information was also unavailable for classifying work history according to specific exposure processes.

\section{Mortality and cause of death ascertainment}

Vital status of the study cohort was ascertained through December $5^{\text {th }}, 2016$ using three sources: the Social Security Death Index (SSDI), the UAW pension information system, and the National Death Index (NDI). The entire cohort was searched for vital status ascertainment in the SSDI through December $5^{\text {th }} 2016$. The UAW pension system provided vital status through the UAW's internal administration of benefits from 1992 to 2016 . A total of 653 individuals who were not identified as deceased and either 1) did not match to the UAW pension system at all or

2) had a missing or inactive residential address were also submitted for additional vital status follow-up in the NDI through December 2016. All sources provided each decedent's full date of death.

Individuals identified as deceased in any source had their cause of death ascertained using the underlying cause of death code listed on the death certificate. Death certificate information was obtained from the NDI for deaths occurring in 1979 or later $(n=1,118)$. For deaths prior to 1979, death certificates were obtained from the Alabama state vital records office $(n=9)$. Both sources provided the underlying cause of death code classified according to the 
International Classification of Diseases (ICD) revision in effect at the time of death. There were 7 individuals identified as deceased by the UAW pension system or SSDI with unknown cause of death. Of these, 6 did not match sufficiently in the NDI and 1 died prior to 1979 without a matching death certificate in Alabama state vital records. These 7 individuals were identified as deceased for analyses ( $<1 \%$ of all decedents), as they were assumed to have died outside the U.S. or Alabama (prior to 1979), or had incomplete identifiable information listed on their death certificate. Individuals not identified as deceased in any source as of December $5^{\text {th }} 2016$ were presumed alive.

\section{Statistical analyses}

Standardized mortality ratio (SMR) analyses comparing cause-specific mortality rates in the study cohort to that of the general population of the U.S. and Alabama were conducted using the National Institute of Occupational Safety and Health's Life Table Analysis System (NIOSH LTAS) ${ }^{59}$. The SMRs for this investigation can be interpreted as a ratio of the observed to the expected number of deaths in the cohort, where the expected equals the number of deaths that would have been observed had the cohort experienced the same mortality rate as a given general population with the same age, sex, and race distribution during the same calendar years. This interpretation also assumes the person-time distribution in the study population would have remained unchanged had workplace exposures been absent ${ }^{60}$.

Person-time at risk began on the date of first employment at the Huntsville facilities and ended on December $5^{\text {th }} 2016$ for those presumed alive or the date of death for those deceased. For all SMRs, first employment dates were imputed at January $1^{\text {st }}$ of the first year of observed work at the facilities. Person-time at risk was stratified by age (5-year groups), calendar period (5-year intervals), binary race (White, Black or other), and sex and multiplied by the 
corresponding mortality rate in the referent populations to generate expected numbers of deaths. 'Black or other' was defined as one racial category for analyses. Referent rates were based on national mortality rates in the U.S. general population from 1972 to 2012 . Given that $80 \%$ of decedents died in Alabama, SMRs were also estimated using referent rates from the general population of Alabama from 1972 to 2014. Alabama rates were used for comparison to the SMRs estimated using national rates and to evaluate differences in trends of underlying cause of death coding in Alabama relative to the U.S. For all calendar years where referent mortality rates were unavailable (2013-2016 for the U.S. and 2015-2016 for Alabama), the rates for the most recent year with available data were repeated.

The SMR calculations are based on race-specific (White, Black or other) mortality rates given that mortality rates in the U.S. vary considerably between these groups. However, race was missing for $10 \%(\mathrm{n}=446)$ of the study cohort. Individuals with missing race were more likely to be born earlier (median year of birth 1943 vs. 1949), first employed earlier (median year of hire 1977 vs. 1983), and more likely to be deceased (59\% vs. $22 \%$ ). SMRs were sensitive to the exclusion of individuals with missing race from analyses (complete case analysis) given the high proportion of deaths in this group. In order to calculate SMRs for the entire cohort, we conducted a sensitivity analysis in which we imputed binary race (White, Black or other) for individuals missing this information. The imputation was conducted using a logistic regression model with covariates that were associated with race among individuals with non-missing race (sex, birth date, skilled trade status, plant ever/never worked, and age of first employment). A single imputation was made for these analyses that assigned White race to $87 \%$ of individuals missing race, resulting in the analytic cohort being $81 \%$ White (compared to $80 \%$ White among those with known race). Estimates of the standard error of our SMRs were not adjusted because the 
proportion missing race was small (10\%). Results of sensitivity analyses for the race imputation method are presented in supplemental Table 4.1, which compares analyses with 1) the exclusion of individuals with missing race, 2) re-imputed race with a lower proportion White (83\%) among those missing race, and 3) re-imputed race with a greater proportion White (91\%) among those missing race.

SMRs using each referent population were stratified by sex and race to evaluate differences in mortality patterns according to these characteristics. Stratification was done using a cross-classification of the sex and race variables. Since building-specific work history was unavailable, SMRs were also stratified according to calendar period of first employment at the facilities to evaluate differences in mortality risk during specific eras of facility operation corresponding to the opening of new plant buildings (<1977 vs. $\geq 1977,<1983$ vs. $\geq 1983,<1989$ vs. $\geq 1989)$. Analyses were also conducted to explore 'healthy worker' effects in the study cohort, as SMR estimates in occupational cohorts typically show substantial deficits during periods of active employment and increase with increasing time since first hire ${ }^{61,62}$. SMRs were estimated using employed versus post-termination person-time and stratified according to time from company first hire to end of follow-up in 10-year intervals. Deaths occurring during employed person-time were those where the year of death was the same as the last calendar year of work.

For all SMRs, cause of death categories are based on the NIOSH-119 underlying cause of death classification scheme. Estimates for all major and minor causes of death were examined with particular focus on causes of a priori interest identified based on known workplace exposures at the Huntsville facilities and other electronics plants in the U.S. with similar manufacturing processes. Causes of death of interest in this study include kidney cancer, lymphatic and hematopoietic malignancies including non-Hodgkin lymphoma, brain and nervous 
system cancer, liver cancer, non-malignant chronic kidney and liver diseases, and nervous system disorders for their association with trichloroethylene and 1,1,1-trichloroethane exposure. Additionally, cardiovascular diseases including hypertension and cerebrovascular disease, chronic kidney disease, and nervous system disorders were of interest for their association with occupational lead exposure. Respiratory system cancer and non-malignant lung disease were of interest due to their being caused by asbestos exposure.

\subsection{Results}

Descriptive characteristics of the study cohort are presented in Table 4.1. The study cohort of 4,396 workers was majority female (58\%), White (80\%), and had a median age of 66 years (Interquartile Range; IQR 59, 73) at the end of follow-up. There were 1,134 individuals identified as deceased (26\% of cohort) and the median age at death was 66 years (IQR 56, 75). The cohort accumulated a total of 143,427 person-years of follow-up with a median of 33 years per individual (IQR 29, 40). The majority (66\%) of observed employed person-time occurred at Plant 1 and 2 between 1972 and 1988. There were 469 (11\%) individuals in the cohort with $\leq 1$ year of observed employment. The median observed time working at the facilities was 9 years (IQR 4, 12). There were 221 workers active during the first observed year of plant operation in 1972 and 2,212 active during the last observed year in 1993.

\section{Mortality in the overall cohort}

Table 4.2 presents estimates of relative cause-specific mortality in the overall cohort using both referent populations. After standardizing to the age, sex, race, and calendar year distribution of the study cohort, the all-cause mortality rate in the study cohort was similar to the U.S. general population referent rate (SMR 1.01, 95\% CI 0.95-1.07). Relative to U.S. referent rates, there was a deficit of all-cancer mortality, however, mortality due to malignant neoplasms 
of the brain and nervous system (12 deaths, SMR 1.31, 95\% CI 0.67-2.28), multiple myeloma (9 deaths, SMR 1.47, 0.67-2.78), and esophageal cancer (10 deaths, SMR 1.22, 95\% CI 0.59, 2.25) showed elevated but imprecise estimates of excess mortality. The number of observed deaths due to ischemic heart disease and hypertension with heart disease was lower than the expected number. However, there was a significant excess of mortality due to cardiac conduction disorders (66 deaths, SMR 3.74, 95\% CI 2.89-4.76) and 'other' heart diseases. There were no excesses of death due cerebrovascular disease or diseases of the arteries, veins, and lymphatic system. There was an indication of excess deaths due to hypertension without heart disease (11 deaths, SMR 1.32, 95\% CI 0.66-2.36). For other causes of death of a priori interest, there was an excess of deaths due to nervous system disorders (46 deaths, SMR 1.24, 95\% CI 0.91-1.65), which included an elevated but highly imprecise estimate for multiple sclerosis. There was also an excess in the number of deaths due to diseases of the genito-urinary system, including chronic and unspecified nephritis and renal failure (17 deaths, SMR 1.22, 95\% CI 0.71-1.95).

SMR estimates using the Alabama referent rates were generally lower than those obtained using the U.S. rates and demonstrated equivalence or deficits between the observed and expected number of deaths for most causes (see Table 4.2). Using the Alabama rates, there was a significant deficit in the all-cause SMR, and SMRs did not indicate excess mortality for several causes observed to be in excess using the U.S. rates, including cardiac conduction disorders, 'other' heart diseases, hypertension without heart disease, nervous system disorders (overall), or diseases of the genito-urinary system. However, there was still a greater than expected number of deaths for malignant neoplasms of the brain and other nervous system sites (SMR 1.15, 95\% CI 0.60-2.01), multiple myeloma (SMR 1.32, 95\% CI 0.60-2.50), esophageal cancer (SMR 1.29, 95\% CI 0.62-2.36), and multiple sclerosis (SMR 2.33, 95\% CI 0.64-5.98). 


\section{Mortality according to sex and race group}

Table 4.3 presents sex-stratified SMR results among White workers using U.S. referent rates. Sex-stratified results for Black (or other) workers are shown in supplemental Table 4.2 since there were only 168 deaths in this group and estimates were highly imprecise. Among White females, there was a small but relatively precise excess of all-cause mortality (SMR 1.08, 95\% CI 0.99-1.18). SMRs were significantly elevated for cardiac conduction disorders and other heart diseases. For causes of a priori interest, there was an excess number of deaths due to nervous system disorders. There were also excesses observed for non-Hodgkin lymphoma and unspecified nephritis and renal failure, although estimates for these causes were imprecise. Among White males, the number of deaths due to all-causes was similar to the expected number. Cause-specific SMRs were significantly elevated for cardiac conduction disorders and 'other' heart diseases. For causes of a priori interest, there was an excess number of deaths due to acute glomerulonephritis and renal failure, 'other' (primarily liver) diseases of the digestive system, and nervous system disorders.

Among Black (or other) individuals, the number of deaths due to all causes was similar to the expected number among Black (or other) females, but showed a large deficit among Black (or other) males using U.S. referent rates (supplemental Table 4.2). Estimates for causes of $a$ priori interest were highly imprecise. However, there were excesses of mortality due to all cancers (combined) and lymphatic and hematopoietic cancer among both Black (or other) females and males. There was some indication of excess mortality due to nervous system disorders and hypertension without heart disease among Black (or other) females and chronic nephritis and renal failure among Black (or other) males. 
Results using Alabama referent rates showed the same pattern in sex- and race- stratified analyses to estimates obtained using U.S. referent rates (not shown). Using the Alabama referent, the all-cause SMR estimate was greatest among White females (SMR 0.92, 95\% CI 0.84-1.01), followed by White males (SMR 0.82, 95\% CI 0.75-0.90), Black (or other) females (SMR 0.75, 95\% CI 0.61-0.91), and Black (or other) males (SMR 0.56, 95\% CI 0.43-0.72). Cause-specific estimates tended to show greater deficits using Alabama versus U.S. referent rates given the elevated mortality rates in the state.

\section{Mortality according to employment characteristics}

Table 4.4 presents SMR results among those hired before and after the construction of Plant 2 in 1977 using U.S. referent rates. Overall, SMR estimates were elevated in the early $(<1977)$ compared to the late $(\geq 1977)$ hire group. In the early hire group, there was a small excess in the number of deaths due to all-causes and a large but imprecise excess of deaths due to brain and other nervous system cancers. There was an excess number of deaths for several causes of a priori interest, including cerebrovascular disease, diseases of the genito-urinary system, and digestive system diseases. In the late hire group, SMR estimates showed deficits or equivalences in mortality for most causes of death with the exception of a moderate excess observed for nervous system disorders. In both groups, the all-cause SMR increased monotonically with increasing time from first hire to end of follow-up. SMRs generally remained elevated in the early hire group relative to the late hire group in all categories of years since first hire, including the $\geq 30$ year category. There was little evidence of differences in relative mortality using other (1983 and 1989) calendar year stratifications (not shown).

Table 4.5 presents SMR results according to observed employed and post-termination person-time using U.S. referent rates. During employment, there were large deficits in mortality 
due to all-causes and for all major cause of death categories. After termination of employment, there was a small but significant excess of all-cause mortality in the study cohort. There were also small but precise estimates indicating excesses of mortality due to cerebrovascular disease, diseases of the digestive system, and nervous system disorders. SMR estimates for nearly all causes of death were greater during the period after termination of employment than during the total at-risk period from first employment to end of follow-up.

\subsection{Discussion}

The overall study cohort exhibited an all-cause mortality rate similar to that of the U.S. general population standardized to the age, sex, race, and calendar-year characteristics of the study cohort. However, the relative all-cause mortality rate in the study cohort is greater than that reported in other UAW-based cohorts, as the company-wide UAW-Ford cohort of nearly 200,000 hourly employees and the UAW-GM cohort of over 45,000 hourly metalworkers in Michigan, both reported small deficits in all-cause mortality relative to the U.S. population with similar lengths of follow-up ${ }^{1,8}$. The greater all-cause SMR estimate in the study cohort relative to the UAW-Ford cohort persisted with stratification according to all sex- and race-specific subgroups except for non-White males, who had similar estimates. Our results also showed that workers hired prior to 1977 at the original Plant 1 building had a greater standardized all-cause mortality rate relative to U.S. referent rates, which is consistent with worker concerns over adverse working conditions and elevated exposure at this facility. Typically, estimates of lowerthan-expected all-cause mortality relative to general population rates are reported in occupational studies due to 'healthy worker' hire effects, whereby relatively healthier individuals are more likely to seek and be offered employment ${ }^{58}$. In this study, however, we did not observe a deficit in all-cause mortality in the overall cohort relative to U.S. referent rates, and we observed small 
excesses of all-cause mortality among women and pre-1977 hires. For mortality due to specific causes of a priori interest based on lead, trichloroethylene, and 1,1,1-trichloroethane exposure, we observed moderate excesses of brain and nervous system cancer mortality and non-malignant nervous system disorder mortality in the study cohort.

Previous studies of mortality hazards associated with electronics manufacturing occupations in the U.S. consist primarily of analyses of employees at IBM facilities ${ }^{14,15,17,63}$. Researchers at NIOSH conducted a mortality investigation among 34,494 workers employed between 1969 and 2001 at an IBM computer manufacturing facility in New York State in response to complaints over chlorinated solvent contamination of soil and groundwater and elevated kidney cancer incidence among town residents ${ }^{15}$. Historical exposure reconstruction estimated that $59 \%$ of the cohort was ever-exposed to chlorinated solvents (mainly trichloroethylene and 1,1,1-trichloroethane) and 29\% was ever-exposed to lead through soldering processes ${ }^{16}$. External comparison results indicated large deficits of mortality due to all causes and all cancers among hourly males and females relative to U.S. referent rates, however, there was a significant excess of deaths due to non-Hodgkin lymphoma (SMR 1.49, 95\% CI 1.15-1.89) among hourly males. Internal comparison results indicated that $\geq 5$ years of employment in a circuit board manufacturing building was significantly associated with an elevated rate of leukemia mortality and that cumulative tetrachloroethylene exposure was significantly associated with elevated rate of nervous system disease mortality. Our results showed no evidence of excess mortality due to non-Hodgkin lymphoma, leukemia, or lymphatic and hematopoietic (overall) cancer mortality, however, we observed a moderate excess of nervous system disorder mortality. Investigators of the IBM cohort suggested that the youth of the cohort and low proportion of 
decedents limited the inferences able to be made from their results, as the mean age of hourly workers surviving to the end of follow-up was only 59 years.

Our findings indicated a moderate excess of non-malignant nervous system disorder mortality in the study cohort compared to U.S. referent rates. Nervous system disorders were of particular a priori interest in this investigation given that both lead and chlorinated solvents are toxic to the central nervous system ${ }^{19,43,56,64,65}$. A review by the U.S. Environmental Protection Agency (EPA) concluded the central nervous system to be the most sensitive target for 1,1,1trichloroethane toxicity in humans ${ }^{43}$. Our estimate of excess nervous system disorder mortality in the overall cohort was precise and close to statistical significance, with an excess of similar magnitude observed in both male and female workers. The excess was concentrated almost exclusively among those hired in 1977 or later, with $25 \%$ of nervous system disorder decedents hired in exactly 1977, when 729 individuals were hired at the facilities presumably to help staff the newly constructed Plant 2 . The excess among those hired in 1977 or later could be attributed to greater mean 1,1,1-trichloroethane exposure through processes at Plant 2, where this chemical was reported to have contaminated soil during the mid-1980's. The observed excess of mortality due to nervous system disorders in the overall cohort was driven by both multiple sclerosis mortality, which showed a large but highly imprecise excess relative to both U.S. and Alabama referent rates, as well as 'other' nervous system diseases, which consisted of a majority of deaths due to Alzheimer's and Parkinson's disease. Our finding of excess nervous system disorder mortality in the study cohort is consistent with results from the company-wide analysis of decedents employed at IBM, where the proportion of nervous system disorder deaths was reported to be in excess compared to the U.S. referent ${ }^{14}$. 
Our results indicated a moderate excess in mortality in the study cohort due to malignant neoplasms of the brain and other parts of the nervous system. Estimates for this cause should be treated with caution since they are based on only 12 deaths due to the rare incidence of these cancers, however, the excess was observed using both referent populations. The excess was substantially more pronounced among those hired before 1977, when overall exposure to plant processes was presumed to be greatest and operations were confined to the original Plant 1 building with more limited worker protections. Several previous studies have shown employment in electronics manufacturing jobs to be associated with elevated risk of brain or nervous system cancer mortality ${ }^{14,63,66,67}$. A company-wide analysis of 31,941 decedents employed for at least 5 years at IBM in the U.S. found a significantly elevated proportion of brain and nervous system cancer deaths among hourly male manufacturing workers relative to the U.S. population ${ }^{14}$. This finding is consistent with results from an analysis of 583 deceased hourly UAW members employed at an aerospace electro-mechanical systems facility, which also reported an elevated proportion of brain and nervous system cancer mortality ${ }^{4}$. A population-based case-control study of 435 male brain cancer decedents in three U.S. states also reported a significantly elevated odds of mortality associated with employment in electronics manufacturing ${ }^{67}$. The odds were greatest for electronics equipment repairers and assemblers, which was the predominant manufacturing process at the Huntsville facilities. Exposure to specific chlorinated solvents used in electronics manufacturing has also been associated with brain or nervous system cancer in other studies ${ }^{68-70}$, including one study that included biological measurements of exposure to three chlorinated solvents and cancer incidence follow-up in Finland ${ }^{71}$, although evidence for this relationship remains inconsistent ${ }^{72}$. 
Our results showed that workers hired prior to 1977 experienced an elevated all-cause mortality rate relative to the U.S. general population and also a greater mortality ratio than those hired during or after 1977 . The finding of elevated mortality in the pre-1977 hire group is consistent with UAW member's concerns over hazards at the original Plant 1 building, which was used exclusively from 1972 to 1977 . Working conditions at Plant 1 were described as being the most adverse, with no ventilation system in the production area and limited protections from lead-solder or chlorinated solvent exposure. At the IBM facility in New York State, mean cumulative exposure in the workforce to trichloroethylene and 1,1,1-trichloroethane was greatest in earlier calendar eras of operation ${ }^{16}$. In the pre-1977 hire group, estimates indicated excess mortality for all major causes of a priori interest with the exception of nervous system disorders. The greater all-cause mortality ratio among pre- versus post-1977 hires persisted after stratification of person-time by number of years from first hire to end of follow-up. While this stratification may not have fully accounted for differences in mean length of follow-up between groups, the observation of elevated mortality in the pre-1977 hire group is consistent with UAW member's descriptions of exposure history at the facilities, and stratification by the median year of hire (1983) did not show any meaningful differences in all-cause or cause-specific relative mortality rates between hire groups. Despite the construction of Plant 2 in 1977 and the more modern Plant 3 in 1989, Plant 1 was used up until the final closure of all facilities in 2010, suggesting a significant portion of the cohort worked in the Plant 1 building throughout the study period.

Other causes of death of note in the cohort include one death due to asbestosis and one death due to toxic effects of non-petroleum solvent exposure, which is a category that includes chlorinated hydrocarbon solvents. Asbestos was reported by UAW members to be present in at 
least one of the original plant buildings. There were also three deaths due to spinal muscular atrophy and related syndromes, which includes amyotrophic lateral sclerosis (ALS). ALS is a nervous system disorder that has been shown to be associated with chronic occupational lead exposure in a meta-analysis ${ }^{33}$, although external comparisons for this cause of death could not be performed due to lack of more specific cause of death data and corresponding referent rates. We did not observe excesses of mortality for causes strongly related to smoking. The rate of death due to trachea, bronchus, and lung cancer and chronic obstructive pulmonary disease (COPD) in the study cohort was the same as the U.S. referent rate, suggesting that patterns and prevalence of smoking in the study cohort were similar to the U.S. average.

Our results showed evidence of 'healthy worker' effects as anticipated. We observed a lower mortality ratio estimate among Black (or other) female and male workers compared to their White female and male counterparts, respectively. This finding is consistent with external comparison results from the UAW-Ford cohort and is potentially due to the larger disparity in mortality between Black (or other) workers and the U.S. general Black (or other) population, who suffer from a greater all-cause mortality rate than the general White population. We also observed a significant excess of all-cause mortality in the cohort after observed termination of employment, which has been shown previously in other occupational cohorts ${ }^{62}$. This estimate is likely conservative given that the actual date of termination was in fact later than the last year of available work history for approximately half the cohort $(\mathrm{n}=2,212)$. Our analysis of excess mortality stratified according to number of years from first hire to end of follow-up showed a monotonic increase in all-cause mortality estimates with increasing time since hire. This is consistent with the phenomenon of worker health status regressing to the general population 
average over time typically observed in occupational cohort studies, which can lead to underestimations of mortality risk associated with exposures at work ${ }^{61}$.

Results obtained using Alabama referent rates were subject to a stronger 'healthy worker' effect than those using U.S. referent rates. We observed large deficits in all-cause and causespecific mortality relative to Alabama referent rates, which was anticipated given that Alabama has had one of the highest age-adjusted all-cause mortality rates and one of the lowest median house hold incomes in the U.S. since at least the early 2000 's ${ }^{73,74}$. These characteristics make the Alabama general population a problematic comparison group, as individuals in the study cohort who are able to maintain employment in a unionized occupation with above average health insurance, wages, and retirement benefits may be at a considerable mortality advantage relative to the Alabama average. Further, at least $21 \%$ of the study cohort worked at other nonHuntsville Chrysler plants, suggesting a sizeable proportion of the cohort may possess healthrelated lifestyle behaviors more characteristic of populations from other regions of the U.S. For these reasons, Alabama was considered a less suitable comparison population for the study cohort and results obtained using U.S. referent rates were used as the focus for analyses and discussion. Estimates obtained using Alabama referent rates were more useful for evaluating state-specific cause of death coding practices, as a large majority (80\%) of decedents died in Alabama.

Cardiovascular diseases were of a priori interest in this study given that lead causes hypertension even at low levels of exposure and has been associated with stroke, ischemic heart disease, and peripheral arterial disease ${ }^{21}$. Cardiac arrhythmias and other more acute cardiac effects have also been associated with occupational exposure to chlorinated solvents, including 1,1,1-trichloroethane and trichloroethylene ${ }^{46}$. However, the interpretation of results for 
cardiovascular diseases in this study is hampered by the elevated baseline incidence of hypertension and cardiovascular disease mortality in the southeast U.S. and atypical coding practices for certain cardiovascular causes of death in this region ${ }^{75}$. We found a statistically significant threefold increase in cardiac conduction disorder mortality (a broad category of disorders including cardiac arrest) in the study cohort relative to U.S. referent rates, but this excess disappeared entirely when compared to referent rates in Alabama. Alabama is a large outlier in the U.S. for age-adjusted rates of cardiac conduction disorder mortality ${ }^{73}$. The observed excess of cardiac conduction disorders is likely a result of cause of death coding practices in Alabama, as the proportion of cardiac conduction disorder deaths among decedents who died in Alabama was significantly greater than that among decedents who died in other states (7\% versus $0.8 \%$ respectively). We also observed a significant excess of mortality for 'other' heart diseases relative to the U.S. referent rates that showed a deficit relative to Alabama rates, which may also be attributed to Alabama-specific coding practices. In addition, hypertension has been shown to be underreported as an underlying cause of death on death certificates across the U.S. ${ }^{76}$. Characterization of cardiovascular disease risks, including hypertension and stroke, may be better conducted through internal comparisons to improve the interpretability of results.

Our results showed little evidence of excess mortality for the a priori causes of interest of lymphatic and hematopoietic cancer, kidney diseases, and liver diseases. Estimates for several minor causes in these disease categories were too imprecise to make inferences. The International Agency for Research on Cancer (IARC) monograph on chlorinated solvents concluded that trichloroethylene exposure causes kidney cancer and has been associated with non-Hodgkin lymphoma and liver cancer in several studies ${ }^{38,40}$. We observed only one kidney 
cancer death and estimates indicated a significant deficit of deaths due to this cause in all analyses. There was also no excess of deaths due to non-Hodgkin lymphoma. These findings could be explained by either a low prevalence of trichloroethylene exposure or an inadequate length of follow-up, as the median age at death in the U.S. for both kidney cancer and nonHodgkin lymphoma is 5 and 10 years greater than the median age of the cohort (66 years), respectively ${ }^{77,78}$. Our results did suggest a moderate excess of deaths due to multiple myeloma using both referent populations, although estimates were based on only 9 deaths and were highly imprecise. Several well-designed studies have shown chlorinated solvent exposure to be associated with risk of multiple myeloma, with the strongest relationship purported for 1,1,1trichloroethane exposure ${ }^{71,79-82}$. Diseases of the kidney and liver were of a priori interest as lead and trichloroethylene are toxic to the kidney, and trichloroethylene and 1,1,1-trichloroethane have demonstrated liver toxicity ${ }^{18,43,45,56}$. Estimates were suggestive of excess mortality for acute glomerulonephritis and renal failure relative to both the U.S. and Alabama referent rates, but were highly imprecise. There was little indication of excess mortality due to malignant or non-malignant liver diseases in the cohort.

For causes of death not of a priori interest, we observed elevated mortality rates due to esophageal cancer and transportation injuries. Estimates for esophageal cancer suggested an excess of death due to this cause relative to both the U.S. and Alabama referent rates, although the estimate was based on only 10 deaths and was imprecise. Previous studies indicate a limited and inconsistent relationship between chlorinated solvent exposure and esophageal cancer, although studies among dry cleaning workers have reported more consistent associations specific to tetrachloroethylene exposure ${ }^{46,79}$. Overall there is little evidence that exposure to fiberglass dust or asbestos is associated with esophageal cancer ${ }^{47,51}$. There was a large and significant 
excess of mortality due to transportation injuries in the cohort relative to U.S. referent rates. The estimate was attenuated but still suggestive of an excess relative to Alabama referent rates. The excess of transportation injury mortality could be attributed to acute balance and coordination impairment caused by neurotoxic effects of lead and chlorinated solvents in the workplace. Transportation injury mortality was previously observed to be in significant excess among workers at a lead smelter in Idaho relative to U.S. referent rates ${ }^{32}$.

The primary limitation of this study is the lack of exposure assessment. We were unable to identify job- or department-specific work history or distinguish between hourly and salaried employees with available data. In general, there was good concordance between sources used to ascertain the presence of specific exposures at the facilities, but the prevalence and intensity of exposures in the cohort over time remains unknown. This limited the interpretation of our results for specific causes of interest and reduced our ability to compare findings with other studies in similar cohorts. Given that salaried workers likely had lower average exposure compared to their hourly counterparts, the inability to identify salaried workers in analyses may have biased our estimates toward the null value, making our assessment of mortality risks in the cohort more conservative. A second limitation of this study is the lack of ascertainment of disease incidence. The use of mortality outcomes underestimated the actual burden of disease in the cohort for several diseases of interest, particularly those that are less often fatal or less likely to be reported as the underlying cause of death on death certificates. Additionally, the misclassification of cause of death coding, particularly for deaths potentially misclassified as being due to cardiovascular diseases in Alabama, may have biased our mortality ratio estimates for other causes downward. Several cause-specific estimates may have also been biased downward due to 'healthy worker' effects common with the use of general population reference rates. The primary strengths of this 
study include the use of multiple sources for vital status ascertainment and complete work history records of individuals ever-employed at the facilities for an extended period. The use of multiple vital status sources allowed for the verification of deceased status and improved the overall sensitivity of vital status follow-up throughout the entire risk period of the study. The use of complete work history records precluded selection biases due to gaps in available data and included work history over a 21-year period during the earliest years of facility operation when exposures were estimated to be most intense. The cohort was followed for a mean of 33 years with sufficient time to observe mortality due to most causes of interest and without excessive influence from 'healthy worker' effect related to recency of active employment.

\section{Conclusion}

This investigation involved the enumeration of a novel cohort of UAW members employed at automotive electronics manufacturing facilities in Huntsville, Alabama between 1972 and 1993. Workers at the facilities were exposed to industrial agents with known toxicity and carcinogenicity and results suggest they experienced greater all-cause mortality rates relative to other large UAW cohorts. The observed excesses of all-cause and cause specific mortality among pre-1977 hires are consistent with worker concerns over particularly adverse working conditions at the Plant 1 building. Among female workers, the observed excesses of mortality may indicate that women were more likely than men to hold non-skilled or non-salaried jobs with greater exposure to production processes. The study cohort experienced an elevated rate of mortality due to brain and nervous system cancers as well as nervous system disorders relative to the U.S. referent, which is consistent with previous studies of workers with occupational exposure to lead and chlorinated solvents. We observed one death caused by asbestos exposure and one death caused by non-petroleum solvent poisoning. The observed excesses of all-cause 
mortality among subgroups of the study cohort and excesses of malignant and non-malignant nervous system diseases warrant further investigation to assess hazards associated with specific exposures at the facilities. 
Table 4.1. Descriptive characteristics of 4,396 hourly and salaried UAW members ever-employed at automotive electronics manufacturing facilities from 1972-1993 in Huntsville, Alabama

\begin{tabular}{|c|c|}
\hline Characteristic & \\
\hline $\mathrm{N}$ & 4,396 \\
\hline Year of birth, median (IQR) & $1949(1940,1955)$ \\
\hline $\operatorname{Sex}(\%)$ & \\
\hline Female & $2,562(58)$ \\
\hline Male & $1,834(42)$ \\
\hline Race $(\%)$ & \\
\hline White/Caucasian & $3,170(80)$ \\
\hline Black/African-American & $746(19)$ \\
\hline Hispanic & $24(1)$ \\
\hline Other & 10 \\
\hline Missing & 446 \\
\hline Vital status at end of follow-up, n (\%) & \\
\hline Presumed alive & $3,262(74)$ \\
\hline Deceased & $1,134(26)$ \\
\hline Cause of death known & $1,127(99)$ \\
\hline Cause of death unknown & $7(1)$ \\
\hline Person-years of follow-up, median (IQR) & $33(29,40)$ \\
\hline Person-years of follow-up, cumulative & 143,427 \\
\hline Age at end of follow-up, median (IQR) & $66(59,73)$ \\
\hline Age at death, median (IQR) & $66(56,75)$ \\
\hline Person-years of employment, Huntsville, cumulative (\%) & $39,381(100)$ \\
\hline Huntsville electronics (1972-1988) & $25,866(66)$ \\
\hline Military-Public electronics (1983-1989) & $1,169(3)$ \\
\hline New Huntsville electronics (1989-1993) & $12,346(31)$ \\
\hline Calendar period of hire, $\mathrm{n}(\%)$ & \\
\hline $1972-1978$ & $1,720(39)$ \\
\hline $1979-1985$ & $1,995(45)$ \\
\hline $1986-1993$ & $681(15)$ \\
\hline Age at first hire, median (IQR) & $32(25,41)$ \\
\hline Year of first hire, median (IQR) & $1983(1977,1984)$ \\
\hline Years of employment, median (IQR) & $9(4,12)$ \\
\hline Ever-worked at other Chrysler plant (\%) & $914(21)$ \\
\hline
\end{tabular}

IQR: Interquartile Range 
Table 4.2. Standardized mortality ratios comparing cause-specific mortality among 4,396 UAW members ever-employed from 1972-1993 to U.S. and Alabama referent rates ${ }^{\text {a }}$

\begin{tabular}{|c|c|c|c|c|c|c|c|}
\hline \multirow[b]{2}{*}{ Cause of death } & \multirow[b]{2}{*}{ Obs } & \multicolumn{3}{|c|}{ U.S. } & \multicolumn{3}{|c|}{ Alabama } \\
\hline & & Exp & SMR & $95 \% \mathrm{CI}$ & Exp & SMR & $95 \% \mathrm{CI}$ \\
\hline All Causes & 1,134 & 1128.0 & 1.01 & $0.95,1.07$ & 1365.9 & 0.83 & $0.78,0.88$ \\
\hline All Cancers & 318 & 340.7 & 0.93 & $0.83,1.04$ & 373.1 & 0.85 & $0.76,0.95$ \\
\hline MN buccal \& pharynx & 4 & 5.5 & 0.72 & $0.20,1.85$ & 5.8 & 0.69 & $0.19,1.77$ \\
\hline MN digestive \& peritoneum & 63 & 78.0 & 0.81 & $0.62,1.03$ & 77.3 & 0.82 & $0.63,1.04$ \\
\hline MN esophagus & 10 & 8.2 & 1.22 & $0.59,2.25$ & 7.8 & 1.29 & $0.62,2.36$ \\
\hline MN liver, biliary passages, gall bladder & 9 & 11.9 & 0.76 & $0.35,1.43$ & 11.9 & 0.75 & $0.34,1.43$ \\
\hline MN respiratory & 100 & 104.6 & 0.96 & $0.78,1.16$ & 126.1 & 0.79 & $0.65,0.96$ \\
\hline MN of trachea, bronchus, lung & 96 & 101.3 & 0.95 & $0.77,1.16$ & 122.7 & 0.78 & $0.63,0.96$ \\
\hline MN breast & 36 & 33.2 & 1.09 & $0.76,1.50$ & 33.1 & 1.09 & $0.76,1.51$ \\
\hline MN female genital organs & 18 & 20.2 & 0.89 & $0.53,1.41$ & 19.9 & 0.91 & $0.54,1.43$ \\
\hline MN male genital organs & 11 & 10.6 & 1.03 & $0.52,1.85$ & 11.4 & 0.97 & $0.48,1.73$ \\
\hline MN urinary & 8 & 13.9 & 0.58 & $0.25,1.14$ & 12.9 & 0.62 & $0.27,1.22$ \\
\hline MN kidney & 1 & 7.7 & 0.13 & $0,0.72$ & 7.4 & 0.14 & $0,0.75$ \\
\hline MN bladder \& other urinary site & 7 & 6.1 & 1.14 & $0.46,2.35$ & 5.5 & 1.27 & $0.51,2.63$ \\
\hline MN other \& unspecified site & 47 & 44.3 & 1.06 & $0.78,1.41$ & 54.8 & 0.86 & $0.63,1.14$ \\
\hline MN brain \& other nervous system & 12 & 9.2 & 1.31 & $0.67,2.28$ & 10.4 & 1.15 & $0.60,2.01$ \\
\hline MN lymphatic \& hematopoietic & 31 & 30.5 & 1.02 & $0.69,1.44$ & 31.9 & 0.97 & $0.66,1.38$ \\
\hline Non-Hodgkin's lymphoma & 12 & 11.9 & 1.01 & $0.52,1.76$ & 12.1 & 0.99 & $0.51,1.73$ \\
\hline Multiple myeloma & 9 & 6.1 & 1.47 & $0.67,2.78$ & 6.8 & 1.32 & $0.60,2.50$ \\
\hline Leukemia & 10 & 11.4 & 0.88 & $0.42,1.61$ & 12.1 & 0.83 & $0.4,1.52$ \\
\hline Benign \& unspecified neoplasms & 3 & 4.1 & 0.72 & $0.15,2.12$ & 4.6 & 0.65 & $0.13,1.91$ \\
\hline Heart diseases & 259 & 264.4 & 0.98 & $0.86,1.11$ & 338.2 & 0.77 & $0.68,0.86$ \\
\hline Hypertension with heart disease & 5 & 14.6 & 0.34 & $0.11,0.80$ & 11.1 & 0.45 & $0.15,1.05$ \\
\hline Ischemic heart disease & 130 & 190.4 & 0.68 & $0.57,0.81$ & 189.8 & 0.68 & $0.57,0.81$ \\
\hline Conduction disorder & 66 & 17.6 & 3.74 & $2.89,4.76$ & 67.4 & 0.98 & $0.76,1.25$ \\
\hline Other heart diseases & 44 & 20.5 & 2.15 & $1.56,2.89$ & 50.6 & 0.87 & $0.63,1.17$ \\
\hline Other diseases of the circulatory system & 94 & 83.3 & 1.13 & $0.91,1.38$ & 107.3 & 0.88 & $0.71,1.07$ \\
\hline Cerebrovascular disease & 60 & 52.4 & 1.14 & $0.87,1.47$ & 68.5 & 0.88 & $0.67,1.13$ \\
\hline Hypertension without heart disease & 11 & 8.4 & 1.32 & $0.66,2.36$ & 10.7 & 1.03 & $0.51,1.85$ \\
\hline Diseases of the arteries, veins, lymph & 23 & 22.5 & 1.02 & $0.65,1.54$ & 28.1 & 0.82 & $0.52,1.23$ \\
\hline Diseases of the genito-urinary system & 25 & 22.4 & 1.12 & $0.72,1.65$ & 31.1 & 0.80 & $0.52,1.19$ \\
\hline Acute glomerulonephritis \& renal failure & 5 & 2.7 & 1.86 & $0.60,4.33$ & 4.2 & 1.19 & $0.39,2.78$ \\
\hline Chronic nephritis \& renal failure & 17 & 14.0 & 1.22 & $0.71,1.95$ & 19.7 & 0.86 & $0.50,1.38$ \\
\hline Diseases of the digestive system & 55 & 50.2 & 1.10 & $0.83,1.43$ & 56.2 & 0.98 & $0.74,1.27$ \\
\hline Cirrhosis \& other liver diseases & 24 & 24.0 & 1.00 & $0.64,1.49$ & 23.9 & 1.00 & $0.64,1.49$ \\
\hline Other diseases of the digestive system & 26 & 21.5 & 1.21 & $0.79,1.77$ & 27.0 & 0.96 & $0.63,1.41$ \\
\hline Diseases of the respiratory system & 98 & 94.3 & 1.04 & $0.84,1.27$ & 120.7 & 0.81 & $0.66,0.99$ \\
\hline Chronic obstructive pulmonary disorder & 55 & 56.1 & 0.98 & $0.74,1.28$ & 75.9 & 0.72 & $0.55,0.94$ \\
\hline Asbestosis & 1 & 0.2 & 5.61 & $0.14,31.3$ & 0.4 & 2.65 & $0.07,14.8$ \\
\hline Nervous system disorders & 46 & 37.2 & 1.24 & $0.91,1.65$ & 45.4 & 1.01 & $0.74,1.35$ \\
\hline Multiple sclerosis & 4 & 2.7 & 1.50 & $0.41,3.85$ & 1.7 & 2.33 & $0.64,5.98$ \\
\hline
\end{tabular}




\begin{tabular}{|c|c|c|c|c|c|c|c|}
\hline \multirow{2}{*}{ (Table 4.2 continued) } & \multirow[b]{2}{*}{ Obs } & \multicolumn{3}{|c|}{ U.S. } & \multicolumn{3}{|c|}{ Alabama } \\
\hline & & $\operatorname{Exp}$ & SMR & $95 \% \mathrm{CI}$ & Exp & SMR & $95 \% \mathrm{CI}$ \\
\hline Other nervous system diseases & 42 & 34.5 & 1.22 & $0.88,1.64$ & 43.7 & 0.96 & $0.69,1.30$ \\
\hline Mental \& psychiatric disorders & 23 & 26.7 & 0.86 & $0.55,1.29$ & 32.9 & 0.70 & $0.44,1.05$ \\
\hline Diabetes mellitus & 28 & 35.9 & 0.78 & $0.52,1.13$ & 38.6 & 0.73 & $0.48,1.05$ \\
\hline Musculoskeletal \& connective tissue diseases & 4 & 6.0 & 0.67 & $0.18,1.71$ & 6.5 & 0.61 & $0.17,1.57$ \\
\hline Diseases of skin \& subcutaneous tissue & 1 & 1.6 & 0.63 & $0.02,3.50$ & 1.8 & 0.57 & $0.01,3.15$ \\
\hline Diseases of blood \& blood forming organs & 1 & 5.5 & 0.18 & $0,1.01$ & 6.9 & 0.14 & $0,0.81$ \\
\hline Tuberculosis \& HIV & 2 & 13.5 & 0.15 & $0.02,0.54$ & 7.1 & 0.28 & $0.03,1.01$ \\
\hline Transportation injuries & 44 & 24.0 & 1.83 & $1.33,2.46$ & 36.3 & 1.21 & $0.88,1.63$ \\
\hline Falls & 7 & 8.0 & 0.88 & $0.35,1.81$ & 5.3 & 1.31 & $0.53,2.70$ \\
\hline Other injury & 24 & 25.0 & 0.96 & $0.62,1.43$ & 31.8 & 0.75 & $0.48,1.12$ \\
\hline Violence & 38 & 30.2 & 1.26 & $0.89,1.73$ & 36.2 & 1.05 & $0.74,1.44$ \\
\hline Intentional self-harm & 24 & 20.0 & 1.20 & $0.77,1.78$ & 22.1 & 1.09 & $0.70,1.61$ \\
\hline Symptoms \& ill-defined conditions & 24 & 13.6 & 1.76 & $1.13,2.62$ & 37.6 & 0.64 & $0.41,0.95$ \\
\hline Other \& unspecified causes & 40 & 41.6 & 0.96 & $0.69,1.31$ & 48.3 & 0.83 & $0.59,1.13$ \\
\hline
\end{tabular}

Obs: Observed number of deaths in study cohort; Exp: Expected number of deaths in study cohort based on general population rates; MN: Malignant neoplasm; SMR: Standardized Mortality Ratio; CI, Confidence Interval.

${ }^{\mathrm{a}}$ Referent rates are standardized according to the age, sex, race, and calendar year distribution of the study cohort. 
Table 4.3. Standardized mortality ratios comparing mortality due to select causes of death among White female and White male UAW members ever-employed from 1972-1993 to U.S. referent rates ${ }^{\text {a }}$ (estimates for Black or other females and males shown in supplemental Table S4.2)

\begin{tabular}{|c|c|c|c|c|c|c|}
\hline \multirow[b]{2}{*}{ Cause of death } & \multicolumn{3}{|c|}{ White females } & \multicolumn{3}{|c|}{ White males } \\
\hline & Obs & SMR & $95 \% \mathrm{CI}$ & Obs & SMR & $95 \% \mathrm{CI}$ \\
\hline All Causes & 475 & 1.08 & $0.99,1.18$ & 491 & 0.99 & $0.90,1.08$ \\
\hline All Cancers & 135 & 0.92 & $0.77,1.09$ & 122 & 0.86 & $0.72,1.03$ \\
\hline MN urinary & 2 & 0.48 & $0.06,1.74$ & 6 & 0.73 & $0.27,1.59$ \\
\hline MN other \& unspecified site & 16 & 0.90 & $0.52,1.47$ & 25 & 1.18 & $0.76,1.74$ \\
\hline MN brain \& other nervous system & 7 & 1.76 & $0.71,3.63$ & 4 & 0.90 & $0.24,2.30$ \\
\hline MN lymphatic \& hemaopoietic & 9 & 0.75 & $0.34,1.42$ & 14 & 0.97 & $0.53,1.64$ \\
\hline Non-Hodgkin's lymphoma & 6 & 1.23 & $0.45,2.68$ & 5 & 0.86 & $0.28,2.02$ \\
\hline Heart diseases & 101 & 1.16 & $0.94,1.41$ & 132 & 0.99 & $0.83,1.17$ \\
\hline Ischemic heart disease & 45 & 0.76 & $0.55,1.01$ & 73 & 0.70 & $0.55,0.89$ \\
\hline Conduction disorder & 23 & 3.35 & $2.12,5.02$ & 36 & 4.81 & $3.37,6.65$ \\
\hline Other heart diseases & 22 & 2.56 & $1.60,3.87$ & 16 & 1.89 & $1.08,3.07$ \\
\hline Other circulatory system diseases & 41 & 1.17 & $0.84,1.59$ & 37 & 1.21 & $0.85,1.66$ \\
\hline Cerebrovascular disease & 29 & 1.28 & $0.85,1.83$ & 20 & 1.08 & $0.66,1.66$ \\
\hline Diseases of the genito-urinary system & 10 & 1.12 & $0.54,2.06$ & 9 & 1.13 & $0.52,2.14$ \\
\hline Acute glomerulonephritis \& renal failure & 1 & 0.89 & $0.02,4.93$ & 4 & 3.72 & $1.01,9.51$ \\
\hline Chronic nephritis \& renal failure & 8 & 1.59 & $0.69,3.13$ & 4 & 0.79 & $0.22,2.02$ \\
\hline Diseases of the digestive system & 21 & 1.13 & $0.70,1.73$ & 27 & 1.17 & $0.77,1.71$ \\
\hline Cirrhosis \& other liver diseases & 9 & 1.23 & $0.56,2.33$ & 11 & 0.88 & $0.44,1.58$ \\
\hline Other diseases of the digestive system & 10 & 1.10 & $0.53,2.02$ & 15 & 1.73 & $0.97,2.86$ \\
\hline Nervous system disorders & 25 & 1.33 & $0.86,1.96$ & 18 & 1.25 & $0.74,1.98$ \\
\hline Multiple sclerosis & 3 & 1.90 & $0.39,5.55$ & 1 & 1.39 & $0.04,7.73$ \\
\hline Other nervous system diseases & 22 & 1.28 & $0.80,1.93$ & 17 & 1.25 & $0.73,1.99$ \\
\hline Transportation injuries & 16 & 2.42 & $1.38,3.93$ & 21 & 1.57 & $0.97,2.41$ \\
\hline
\end{tabular}


Table 4.4. Standardized mortality ratios comparing mortality due to select causes of death among 4,396 UAW members to U.S. referent rates according to hire period and years since first hire ${ }^{\mathrm{a}}$

\begin{tabular}{|c|c|c|c|c|c|c|c|c|c|c|c|}
\hline \multirow{3}{*}{ Cause of death } & \multicolumn{8}{|c|}{ Years since first hire to end of follow-up } & \multirow{2}{*}{\multicolumn{3}{|c|}{ Overall }} \\
\hline & \multicolumn{2}{|c|}{$<10$} & \multicolumn{2}{|c|}{10 to $<20$} & \multicolumn{2}{|c|}{20 to $<30$} & \multicolumn{2}{|c|}{$\geq 30$} & & & \\
\hline & Obs & SMR & Obs & SMR & Obs & SMR & Obs & SMR & Obs & SMR & $95 \% \mathrm{CI}$ \\
\hline \multicolumn{12}{|l|}{ First hired <1977 $(n=905)$} \\
\hline All Causes & 26 & 0.85 & 57 & 1.05 & 97 & 1.07 & 199 & 1.18 & 379 & 1.10 & $0.99,1.22$ \\
\hline All Cancers & 9 & 1.13 & 14 & 0.79 & 28 & 0.95 & 51 & 1.10 & 102 & 1.00 & $0.82,1.22$ \\
\hline MN other \& unspecified site & 1 & 0.89 & 3 & 1.32 & 6 & 1.65 & 13 & 2.26 & 23 & 1.80 & $1.14,2.7$ \\
\hline MN brain \& other nervous & 1 & 3.41 & - & - & 2 & 2.80 & 3 & 3.04 & 6 & 2.40 & $0.88,5.23$ \\
\hline Non-Hodgkin’s lymphoma & - & - & - & - & 2 & 1.80 & 2 & 1.20 & 4 & 1.10 & $0.30,2.81$ \\
\hline Heart diseases & 3 & 0.37 & 21 & 1.39 & 30 & 1.25 & 40 & 0.99 & 94 & 1.07 & $0.87,1.31$ \\
\hline Cerebrovascular disease & - & - & - & - & 7 & 1.49 & 17 & 1.85 & 24 & 1.37 & $0.88,2.04$ \\
\hline Diseases of the genitourinary system & - & - & 2 & 3.19 & 3 & 1.82 & 6 & 1.33 & 11 & 1.55 & $0.77,2.78$ \\
\hline Diseases of the digestive system & 1 & 0.52 & 4 & 1.53 & 5 & 1.34 & 9 & 1.48 & 19 & 1.32 & $0.8,2.07$ \\
\hline Nervous system disorders & - & - & 1 & 1.33 & 1 & 0.45 & 11 & 1.25 & 13 & 1.07 & $0.57,1.83$ \\
\hline \multicolumn{12}{|l|}{ First hired $\geq 1977(n=3,491)$} \\
\hline All Causes & 63 & 0.63 & 167 & 0.91 & 314 & 1.04 & 211 & 1.07 & 755 & 0.96 & $0.90,1.04$ \\
\hline All Cancers & 17 & 0.64 & 55 & 0.93 & 91 & 0.95 & 53 & 0.91 & 216 & 0.90 & $0.79,1.03$ \\
\hline MN other \& unspecified site & 2 & 0.49 & 8 & 1.01 & 8 & 0.65 & 6 & 0.83 & 24 & 0.76 & $0.49,1.13$ \\
\hline MN brain \& other nervous & - & - & 3 & 1.66 & 1 & 0.40 & 2 & 1.47 & 6 & 0.90 & $0.33,1.96$ \\
\hline Non-Hodgkin's lymphoma & - & - & 4 & 1.85 & 4 & 1.27 & - & - & 8 & 0.97 & $0.42,1.90$ \\
\hline Heart diseases & 15 & 0.71 & 35 & 0.81 & 69 & 1.01 & 46 & 1.04 & 165 & 0.93 & $0.8,1.09$ \\
\hline Cerebrovascular disease & 2 & 0.57 & 6 & 0.79 & 16 & 1.16 & 12 & 1.21 & 36 & 1.03 & $0.72,1.43$ \\
\hline Diseases of the genitourinary system & 1 & 1.04 & 1 & 0.37 & 5 & 0.76 & 7 & 1.38 & 14 & 0.91 & $0.5,1.53$ \\
\hline Diseases of the digestive system & - & - & 7 & 0.78 & 20 & 1.46 & 9 & 1.14 & 36 & 1.00 & $0.7,1.39$ \\
\hline Nervous system disorders & - & - & 3 & 0.84 & 10 & 0.95 & 20 & 2.10 & 33 & 1.32 & $0.91,1.85$ \\
\hline
\end{tabular}

Obs: Observed number of deaths in the study cohort; MN: Malignant neoplasm; SMR: Standardized Mortality Ratio; CI, Confidence Interval.

${ }^{a}$ Referent rates are standardized according to the age, sex, race, and calendar year distribution of the study cohort. 
Table 4.5. Standardized mortality ratios comparing mortality due to select causes of death among 4,396 UAW members to U.S. referent rates according to employment status ${ }^{\text {a }}$

\begin{tabular}{|c|c|c|c|c|c|c|}
\hline \multirow{2}{*}{ Cause of death } & \multicolumn{3}{|c|}{ Employed } & \multicolumn{3}{|c|}{ Post-termination } \\
\hline & Obs & SMR & $95 \% \mathrm{CI}$ & Obs & SMR & $95 \% \mathrm{CI}$ \\
\hline All Causes & 67 & 0.51 & $0.39,0.64$ & 1,067 & 1.07 & $1.01,1.14$ \\
\hline All Cancers & 16 & 0.43 & $0.25,0.70$ & 302 & 0.99 & $0.89,1.11$ \\
\hline MN other \& unspecified site & 2 & 0.37 & $0.05,1.35$ & 45 & 1.16 & $0.84,1.55$ \\
\hline MN brain \& other nervous & 1 & 0.74 & $0.02,4.14$ & 11 & 1.40 & $0.70,2.51$ \\
\hline Heart diseases & 20 & 0.68 & $0.42,1.05$ & 239 & 1.02 & $0.89,1.15$ \\
\hline Conduction disorder & 4 & 1.93 & $0.53,4.94$ & 62 & 3.98 & $3.05,5.10$ \\
\hline Cerebrovascular disease & - & - & - & 60 & 1.27 & $0.97,1.63$ \\
\hline Diseases of the genitourinary system & - & - & - & 25 & 1.19 & $0.77,1.75$ \\
\hline Diseases of the digestive system & 1 & 0.13 & $0,0.75$ & 54 & 1.26 & $0.95,1.65$ \\
\hline Nervous system disorders & - & - & - & 46 & 1.30 & $0.95,1.74$ \\
\hline
\end{tabular}

Obs: Observed number of deaths in study cohort; SMR: Standardized Mortality Ratio; CI, Confidence Interval.

${ }^{\mathrm{a}}$ Referent rates are standardized according to the age, sex, race, and calendar year distribution of the study cohort.

Supplemental Table S4.1. Sensitivity analyses for race imputation methods on overall standardized mortality ratio estimates using U.S. referent rates ${ }^{\text {a }}$

\begin{tabular}{|c|c|c|c|c|c|c|c|c|}
\hline \multirow{3}{*}{ Cause of death } & \multirow{2}{*}{\multicolumn{3}{|c|}{$\begin{array}{l}\text { Excluded missing race } \\
\qquad(\mathrm{n}=3,950)\end{array}$}} & \multirow[b]{3}{*}{ Obs } & \multicolumn{4}{|c|}{ Imputed missing race } \\
\hline & & & & & \multicolumn{2}{|c|}{$83 \%$ White $^{b}$} & \multicolumn{2}{|c|}{$91 \%$ White $^{b}$} \\
\hline & Obs & SMR & $95 \% \mathrm{CI}$ & & SMR & $95 \% \mathrm{CI}$ & SMR & $95 \% \mathrm{CI}$ \\
\hline All Causes & 873 & 0.87 & $0.81,0.93$ & 1,134 & 1.00 & $0.95,1.06$ & 1.01 & $0.95,1.07$ \\
\hline All Cancers & 246 & 0.81 & $0.71,0.91$ & 318 & 0.93 & $0.83,1.04$ & 0.93 & $0.83,1.04$ \\
\hline Heart diseases & 195 & 0.85 & $0.73,0.97$ & 259 & 0.98 & $0.86,1.10$ & 0.98 & $0.86,1.11$ \\
\hline Cerebrovascular disease & 50 & 1.08 & $0.80,1.42$ & 60 & 1.14 & $0.87,1.47$ & 1.15 & $0.87,1.47$ \\
\hline Diseases of the genitourinary system & 18 & 0.89 & $0.53,1.41$ & 25 & 1.11 & $0.72,1.64$ & 1.12 & $0.72,1.65$ \\
\hline Diseases of the digestive system & 40 & 0.89 & $0.64,1.21$ & 55 & 1.09 & $0.82,1.42$ & 1.10 & $0.83,1.43$ \\
\hline Nervous system disorders & 40 & 1.20 & $0.84,1.65$ & 46 & 1.24 & $0.91,1.65$ & 1.24 & $0.91,1.65$ \\
\hline
\end{tabular}


Supplemental Table S4.2. Standardized mortality ratios comparing mortality due to select causes of death among Black (or other) female and male UAW members ever-employed from 1972-1993 to U.S. referent rates ${ }^{\text {a }}$

\begin{tabular}{|c|c|c|c|c|c|c|}
\hline \multirow[b]{2}{*}{ Cause of death } & \multicolumn{3}{|c|}{ Black (or other) females } & \multicolumn{3}{|c|}{ Black (or other) males } \\
\hline & Obs & SMR & $95 \% \mathrm{CI}$ & Obs & SMR & $95 \% \mathrm{CI}$ \\
\hline All Causes & 105 & 0.96 & $0.78,1.16$ & 63 & 0.75 & $0.58,0.96$ \\
\hline All Cancers & 38 & 1.17 & $0.83,1.61$ & 23 & 1.13 & $0.71,1.69$ \\
\hline MN urinary & - & - & - & - & - & - \\
\hline MN other \& unspecified site & 4 & 1.26 & $0.34,3.23$ & 2 & 0.89 & $0.11,3.2$ \\
\hline MN brain \& other nervous & 1 & 2.29 & $0.06,12.74$ & - & - & - \\
\hline MN lymphatic \& hemaopoietic & 4 & 1.66 & $0.45,4.24$ & 4 & 2.40 & $0.65,6.14$ \\
\hline Non-Hodgkin's lymphoma & - & - & - & 1 & 1.80 & $0.05,10.01$ \\
\hline Multiple myeloma & 3 & 3.67 & $0.76,10.71$ & 2 & 4.07 & $0.49,14.70$ \\
\hline Heart diseases & 15 & 0.65 & $0.36,1.07$ & 11 & 0.54 & $0.27,0.97$ \\
\hline Ischemic heart disease & 7 & 0.50 & $0.20,1.03$ & 5 & 0.37 & $0.12,0.87$ \\
\hline Conduction disorder & 2 & 1.04 & $0.13,3.77$ & 5 & 3.67 & $1.19,8.55$ \\
\hline Other heart diseases & 5 & 2.50 & $0.81,5.83$ & 1 & 0.72 & $0.02,4.02$ \\
\hline Other circulatory system diseases & 11 & 1.00 & $0.50,1.79$ & 5 & 0.76 & $0.25,1.77$ \\
\hline Cerebrovascular disease & 8 & 1.16 & $0.50,2.29$ & 3 & 0.71 & $0.15,2.08$ \\
\hline Hypertension without heart disease & 3 & 1.96 & $0.40,5.74$ & 2 & 2.15 & $0.26,7.78$ \\
\hline Diseases of the genito-urinary system & 3 & 0.86 & $0.18,2.52$ & 3 & 1.49 & $0.31,4.35$ \\
\hline Chronic \& unspecified nephritis, renal failure & 2 & 0.83 & $0.10,2.98$ & 3 & 2.11 & $0.43,6.16$ \\
\hline Diseases of the digestive system & 3 & 0.64 & $0.13,1.88$ & 4 & 1.01 & $0.27,2.58$ \\
\hline Cirrhosis \& other liver diseases & 2 & 0.97 & $0.12,3.51$ & 2 & 0.95 & $0.11,3.43$ \\
\hline Other diseases of the digestive system & - & - & - & 1 & 0.66 & $0.02,3.66$ \\
\hline Nervous system disorders & 3 & 1.14 & $0.24,3.34$ & - & - & - \\
\hline Other nervous system diseases & 3 & 1.28 & $0.26,3.75$ & - & - & - \\
\hline Transportation injuries & 4 & 2.33 & $0.64,5.97$ & 3 & 1.29 & $0.27,3.77$ \\
\hline
\end{tabular}




\section{CHAPTER 5: EMPLOYMENT CHARACTERISTICS AND CAUSE-SPECIFIC MORTALITY AT AUTOMOTIVE ELECTRONICS MANUFACTURING FACILITIES IN HUNTSVILLE, ALABAMA}

\subsection{Introduction}

Former employees at automotive electronics manufacturing facilities in Huntsville, Alabama have raised concerns over exposure to hazardous agents and a suspected excess of mortality among their colleagues. The facilities primarily manufactured electronic circuit boards for automotive engine, body, and dashboard components from 1971 to 2010. Evidence of soil contamination with chlorinated organic solvents at one plant site, in addition to asbestos contamination of one plant building, exacerbated worker concerns about potential health hazards associated with employment at the facilities. In 2015, local union representatives voiced these concerns with the United Autoworkers (UAW) Health and Safety Department, who requested the support of epidemiologists to conduct a mortality investigation. This study was initiated in response to these concerns.

Interviews with former employees and UAW health and safety representatives at the Huntsville facilities indicated that workers were exposed to chlorinated solvents including trichloroethylene (TCE), lead-based solder, fiberglass dust, and asbestos. Workers reported working conditions to be particularly adverse at the original plant building due to a lack of plant ventilation and lack of enclosures on wet processing lines. A previous exposure assessment at an IBM electronics and computer manufacturing facility in New York State indicated worker exposure to lead through soldering processes and several chlorinated solvents, including

trichloroethylene and 1,1,1-trichloroethane ${ }^{16}$. These agents are of particular concern for worker 
health due to their known toxicity to the central nervous, circulatory, and digestive systems 18,19,21,40,43,56. The most recent evaluation by the International Agency for Research on Cancer (IARC) also concluded that trichloroethylene exposure causes kidney cancer and has been associated with liver cancer and non-Hodgkin lymphoma ${ }^{38}$.

The objective of this study was to investigate concerns over exposure to hazardous agents and mortality risk among 4,396 hourly and salaried UAW members ever-employed at automotive electronics manufacturing facilities between 1972 and 1993 in Huntsville, Alabama. Workers reported particular concern over adverse working conditions in the original plant building (Plant 1), which was the only building in use prior to 1977. We compared cause-specific mortality rates within the study cohort according to employment characteristics representing potential contrasts in exposure to facility processes, including skilled trade job status, calendar period of hire, and plant and duration of work. Causes of death related to exposures of concern, namely trichloroethylene, 1,1,1-trichloroethane, lead, and asbestos, were the focus of analyses. Kaplan-Meier survival analysis was conducted to estimate overall survival according to employment characteristics over time.

\subsection{Methods}

Study population

The study cohort includes 4,396 hourly and salaried UAW members employed for any duration at Chrysler electronics facilities in Huntsville from 1972 to 1993. The cohort was enumerated from UAW employment records generated through a joint UAW-Chrysler agreement. The employment records were updated biannually and were available for the entire study cohort for years 1967-1970 and 1972-1993. Employment records provided a yearly indication of employment at Chrysler plant codes in the U.S. in addition to skilled trade job 
status and personal identifiable information. Missing or conflicting demographic information (sex, birth date, or race) on the study cohort was corrected through a linkage with the current UAW pension information system at UAW offices (Solidarity House) in Detroit, Michigan and searches of a commercial public information database (LexisNexis Accurint). A separate search of LexisNexis Accurint was also conducted to obtain the last known state of residence of the full study cohort to improve the search and match criteria of mortality follow-up. The study cohort includes both hourly and salaried UAW members, as it was not possible to distinguish workers in each pay grade with available data. Approximately $10 \%$ of the study cohort consists of salaried members. The study protocol was approved by the University of North Carolina Institutional Review Board.

\section{Exposure characterization}

The first plant building (Plant 1) was originally constructed in the 1950s for the manufacture of electronics for guided missile and aerospace projects. Automotive electronics manufacturing began at Plant 1 in 1971. The Plant 1 building was expanded twice in 1972 and 1974. A second plant (Plant 2) was constructed adjacent to Plant 1 in 1977. The size of the workforce at Plant 1 and 2 increased substantially between 1980 and 1985 as production requirements increased. Plant 1 and 2 were the primary site of manufacturing operations until 1989, when a large, more modern facility was constructed at a separate site (Plant 3). Much of the workforce and equipment was transferred to Plant 3 after it opened, although Plant 1 and 2 remained active for some operations. A small manufacturing operation with similar processes also existed at a fourth plant in the same industrial park as Plant 1 and 2 to fulfill a military and railway electronics contract from 1983 to 1989 . Plant codes in the employment records correspond to one or more buildings active during given calendar eras, and do not represent 
building-specific work history. Three plant codes were available that correspond predominantly to the Plant 1 and 2 (combined), military plant, and Plant 3 buildings. The workforce remained unionized through the UAW until all facilities in Huntsville were permanently closed in 2010.

The facilities primarily manufactured printed circuit boards for vehicle engine, dashboard, and body electronic components. Circuit board manufacturing processes generally involved cutting the board substrate from fiberglass sheets, assembly and insertion of semiconductors (manufactured elsewhere) onto boards, and soldering board components using lead-based solder through hand-solder, solder-paste, and wave solder processes. Chlorinated organic solvents, including trichloroethylene and 1,1,1-trichloroethane, were used at the facilities as degreasers to remove excess solder from circuit boards, tools, and machinery. Circuit boards also received conformal coating application for weather and heat protection. The boards were generally wired in enclosures and shipped to other facilities.

An author (N.D.) conducted interviews with former employees and UAW health and safety representatives at the facilities to identify exposures of concern. The primary concerns included exposure to fiberglass dust, conformal coatings, lead-based solder, chlorinated solvents, and asbestos. Workers were exposed to fiberglass dust through circuit board cutting processes. Lead exposure occurred through various soldering operations, including dermal exposure to solder paste and inhalation of solder fumes from attendant jobs at wave solder machines, which is an automated soldering process involving circuit boards passing over a tub of molten solder. Wave solder machines were introduced into the plants in approximately the early 1980s and constituted a major part of production processes until 2010. Workers were exposed to chlorinated solvents through solder degreasing processes, which involved spraying solvents in enclosed areas, scrubbing boards with solvents during circuit board repair, and using solvents to wash 
excess solder from hands and tools. Workers reported use of trichloroethylene and 1,1,1trichloroethane at the facilities. In the 1980s, soil at Plant 2 was contaminated from a chlorinated solvent spill, preventing employees from using a recreational baseball field at the plant site. A news article published in 2010 confirmed that soil was contaminated with 1,1,1-trichloroethane and other chemicals ${ }^{7}$. Workers also reported particular concern over working conditions at the original Plant 1 building used exclusively prior to 1977 . Primary concerns at Plant 1 were due to a lack of ventilation in the production area, lack of enclosures or capture systems on wet processing lines, and excessive heat. Asbestos was discovered at the original plants and workers reported concern over asbestos exposure when plant walls were opened for electrical work.

Exposure to agents of concern at the Huntsville facilities is corroborated by a retrospective exposure assessment conducted at an IBM circuit board and computer part manufacturing facility in New York State ${ }^{16}$. The assessment reported worker exposure to several chlorinated solvents (including trichloroethylene and 1,1,1-trichloroethane), lead-based solder, and fiberglass dust through manufacturing processes. At the IBM facility, workers were exposed to trichloroethylene <1985 only, and exposure was greatest for 1,1,1-trichloroethane throughout all manufacturing eras from 1969 to 2002 . However, no quantitative exposure information or industrial hygiene monitoring data were available for this investigation. Job-, department-, and building-specific work history information was also unavailable for classifying work history according to specific exposure processes.

\section{Mortality and cause of death ascertainment}

Vital status of the study cohort was ascertained through December $5^{\text {th }}, 2016$ using three sources: the Social Security Death Index (SSDI), the UAW pension information system, and the National Death Index (NDI). The entire cohort was searched for vital status ascertainment in the 
SSDI through December $5^{\text {th }} 2016$. The UAW pension system provided vital status through the UAW's internal administration of benefits from 1992 to 2016. A total of 653 individuals who were not identified as deceased and either 1) did not match to the UAW pension system or 2) had a missing or inactive residential address in LexisNexis Accurint were also submitted for additional vital status follow-up in the NDI through December 2016.

Individuals identified as deceased in any of the three sources used for vital status ascertainment had their cause of death ascertained using the underlying cause of death code listed on the death certificate. Multiple cause of death codes were also ascertained from death certificates which describe contributing causes of death. Death certificate information was obtained from the NDI for deaths occurring in 1979 or later $(\mathrm{n}=1,118)$ and from the Alabama state vital records office for deaths occurring prior to $1979(n=9)$. Both sources provided the underlying cause of death code classified according to the International Classification of Diseases (ICD) revision in effect at the time of death. There were 7 individuals identified as deceased with unknown cause of death due to their not matching in the NDI or in Alabama state vital records. Individuals not identified as deceased in any source as of December $5^{\text {th }} 2016$ were presumed alive.

Cause of death codes were categorized according to the NIOSH-119 cause of death classification scheme. Estimates for all major and minor underlying cause of death categories were examined with particular focus on causes of a priori interest. Multiple cause of death codes were also examined for diseases less commonly reported as the underlying cause of death, such as hypertension ${ }^{76}$. Causes of death of a priori interest in this investigation include those related to trichloroethylene, 1,1,1-trichloroethane, lead, and asbestos exposure, in addition to causes identified to be in excess through external comparison analyses of this cohort reported elsewhere 
83. Lymphatic and hematopoietic malignancies, brain and nervous system cancer, digestive system and liver diseases, chronic kidney diseases, and nervous system disorders were of interest for their association with trichloroethylene and 1,1,1-trichloroethane exposure. Cardiovascular diseases including hypertension and cerebrovascular disease, chronic kidney diseases, and nervous system disorders were of interest for their association with occupational lead exposure. Respiratory system cancer was of interest due to it being caused by asbestos exposure.

\section{Statistical analyses}

Rate ratios (RR) were calculated to compare mortality rates according to employment characteristics. Poisson regression models were used to estimate RRs for all-cause and causespecific mortality adjusted for age, sex, and year of birth to control birth cohort trends in mortality throughout the follow-up period. Adjustment variables were chosen a priori from measured variables that were associated with mortality and potentially associated with exposures of interest. Various specifications of adjustment variables were fit in models estimating rates for all-cause, all-cancer, cardiovascular disease, lung cancer, and nervous system disorder mortality. In general, the set of adjustment variables selected was the one that maximized model fit based on the Akaike Information Criterion (AIC), although a more parsimonious adjustment set was favored when change in the AIC was minimal $(<1 \%)$ and both models yielded identical point estimates. The same covariates were adjusted for regardless of the cause of death assessed during the model selection process for consistency in interpretation. Final models were adjusted for a binary indicator for sex, age using a linear and quadratic term, and year of birth using a linear term. Person-time at risk began at the start of the year of first employment at the Huntsville facilities. Follow-up ended on the earliest of the death date, age 85, or December $5^{\text {th }} 2016$. Individuals were censored at age 85 to limit bias due to excess person-time introduced by 
misclassification of individuals incorrectly presumed alive and because cause of death coding among decedents aged $>85$ is subject to greater misclassification ${ }^{84}$.

The person-time and events were categorized according to duration of employment, calendar period of hire, plant code of employment, and skilled trade job status to create potential exposure contrasts for comparison. Duration of employment at Huntsville facilities was categorized in $\leq 5,>5-15$, and $>15$ year categories. Given that UAW information on work history was unavailable after 1993, and that plant operations continued through 2010 and study followup extends into 2016, we imputed termination dates for cohort members still actively employed in $1993(\mathrm{n}=2,212)$. The imputed termination dates were based on estimates of the age-specific hazard of termination observed within the cohort prior to 1993. Based on the estimated agespecific probability of termination observed in the cohort, workers still active in 1993 were randomly assigned active or terminated employment status each year from 1994 until the earliest of facility closure (2010), retirement age (65), or death. The random assignment was repeated 25 times and parameter estimates and standard errors obtained from each replication of imputed termination dates were combined using the MIANALYZE procedure in SAS version 9.4. Sensitivity analyses for this imputation method are shown in supplemental Table 5.1.

To evaluate worker concerns over hazards at the Plant 1 building, we assessed mortality rates among those known to have worked at Plant 1 through their hire at the Huntsville facilities prior to 1977 when Plant 1 was the only building in operation. Hire period was categorized into a three-level variable corresponding to broad changes in manufacturing process: exclusive use of Plant 1 (1972-1976), construction of Plant 2 and growth of the workforce (1977-1983), and beginning of the military operation and construction of Plant 3 (1984-1993). Skilled trade job status was determined by the presence of a skilled trade job code in any year of an individual's 
work history (ever versus never). This variable was specified as a time-fixed covariate for consistency with other exposures and yielded identical results to a time-varying specification, as less than $2 \%$ of person-time in the 'ever-skilled' category consisted of non-skilled work. Skilled trade jobs at the facilities consisted primarily of electricians, machine repairers, carpenters, tool makers, and air conditioning technicians. Each exposure variable used in analyses was modeled individually for its association with mortality without inclusion of other exposure terms. Analyses were stratified by sex for the most common causes of death to evaluate differences in mortality estimates between males and females. To evaluate any influence of the 'healthy worker' survivor effect on results, all analyses were repeated with short-term workers (employed $<3$ years) excluded and with stratification by employed versus post-termination person-time ${ }^{85}$.

Kaplan-Meier survival analysis was used to compare overall survival throughout the follow-up period according to calendar period of hire. The purpose of this analysis was to evaluate Plant 1 mortality risks by comparing the mortality experience of individuals known to have worked at Plant 1 with the rest of the cohort. For this analysis, individuals not observed to be deceased were censored at the end of the follow-up period. The Kaplan-Meier survival estimators were compared using the log-rank test at a significance level of $\alpha=0.05$. All statistical analyses were conducted in SAS version 9.4.

\subsection{Results}

The study cohort of 4,396 workers was predominantly female (58\%), White (80\%), and had a median age of 66 years (Interquartile Range; IQR 59, 73) at the end of follow-up. The cohort accumulated 143,427 person-years of follow-up with a median of 33 years per worker (IQR 29, 40). There were 1,134 individuals identified as deceased (26\% of cohort) and the median age at death was 66 years (IQR 56, 75). Censoring at age 85 excluded 63 deaths and 414 
person-years of follow-up from regression analyses. Skilled trade persons were almost exclusively male (92\%). Descriptive characteristics of the study cohort are presented in Table 5.1 .

All-cause, all-cancer, and cardiovascular disease mortality

Table 5.2 presents results for all-cause mortality and for the two leading major cause of death categories, all-cancer and cardiovascular disease mortality. Never-employment in a skilled trade job was associated with an elevated adjusted all-cause ( $\mathrm{RR}=1.26$; 95\% CI: 1.06, 1.51), allcancer $(\mathrm{RR}=1.43 ; 95 \% \mathrm{CI}: 1.01,2.03)$, and cardiovascular disease $(\mathrm{RR}=1.52 ; 95 \% \mathrm{CI}: 1.10$, 2.09) mortality rate relative to ever-employment in the skilled trades. Workers hired $<1977$ had higher adjusted all-cause $(\mathrm{RR}=1.29 ; 95 \% \mathrm{CI}: 1.09,1.52)$ and cardiovascular disease $(\mathrm{RR}=$ 1.38; $95 \%$ CI: $1.03,1.86)$ mortality rates relative to $1984-1993$ hires. There was a small elevation in the adjusted all-cancer mortality rate among <1977 versus 1984-1993 hires, which was observed almost exclusively among males in sex-stratified analyses. The association between $<1977$ hire and elevated adjusted all-cause and cardiovascular disease mortality rates was similar among both male and female workers. Longer duration of employment was associated with a lower adjusted all-cause mortality rate and this pattern persisted for all-cancer and cardiovascular disease mortality.

Results from the Kaplan-Meier all-cause mortality survival analysis are presented in Figure 5.1. This figure illustrates overall survival during follow-up in three groups stratified by calendar period of first hire. Individuals hired <1977 exhibited reduced overall survival throughout the entire follow-up period relative to the other hire groups, with a greater decline in relative survival after 15 years of follow-up. Survival in the 1977-1983 and 1984-1993 hire groups was similar throughout the follow-up period. The estimated survival probability after 33 
years of follow-up in the 1972-1976, 1977-1983, and 1984-1993 hire groups was 75\%, 80\%, and $81 \%$, respectively. The log-rank test indicated a significant difference between the survival curves $(p<0.01)$ and the test statistic was unaffected by censoring the entire cohort at the time of the first censoring event at 24.9 years of follow-up.

\section{Cancer mortality}

Table 5.3 presents results for three categories of malignant causes of death. There was no evidence of an association between any employment characteristics and trachea, bronchus, and lung cancer mortality in the overall cohort, with the exception of 1977-1983 hire, where a small elevation in mortality was indicated relative to the $1984-1993$ hire group ( $\mathrm{RR}=1.21 ; 95 \% \mathrm{CI}$ : $0.73,1.99)$. For lymphatic and hematopoietic cancer mortality, there was a suggestion of an association between $>15$ versus $\leq 5$ years of employment and death due to this cause, although this estimate was imprecise $(\mathrm{RR}=1.90 ; 95 \% \mathrm{CI}$ : 0.69, 5.28). Results for brain and nervous system cancer mortality were imprecise given that estimates were based on only 12 deaths. However, there was a suggestion of a strong association between $<1977$ hire and an elevated adjusted rate of brain and nervous system cancer mortality relative to later hire. There was no evidence of an association between any of the employment characteristics and digestive or urinary organ cancer mortality (not shown), although estimates for urinary organ cancer were based on only 10 deaths and were imprecise.

\section{Non-cancer mortality}

Table 5.4 presents results for cerebrovascular, nervous system, and digestive system diseases. Pre-1977 hire was associated with an elevated adjusted rate of cerebrovascular $(\mathrm{RR}=$ 1.58; 95\% CI: $0.75,3.29)$ and digestive system disease mortality (RR $=2.31 ; 95 \%$ CI: 1.04 , 5.10) relative to $1984-1993$ hire. However, <1977 hire appeared to be associated with a reduced 
adjusted rate of nervous system disease mortality relative to the 1984-1993 hire group, with some indication of an elevated adjusted rate in the 1977-1983 hire group. Those employed for $>15$ versus $\leq 5$ years exhibited a small elevation in the adjusted nervous system disease mortality rate $(\mathrm{RR}=1.37 ; 95 \% \mathrm{CI}: 0.64,2.95)$, although this estimate was imprecise. Table $\mathbf{5 . 5}$ presents results for genitourinary diseases coded using the underlying cause of death and also for kidney diseases coded using multiple cause of death codes. There was a suggestion of a positive association between <1977 versus 1984-1993 hire and genitourinary disease mortality, but the estimate was imprecise. Longer duration of employment appeared to be associated with a reduced adjusted mortality rate for chronic nephritis and renal failure.

Sensitivity analyses of the 'healthy worker' survivor effect

Table 5.6 presents results of sensitivity analyses in which we excluded the 640 workers who were employed for $<3$ years, as a simple evaluation of 'healthy worker' survivor bias (which may occur if workers with longer-term employment tend to be healthier than short-term workers). For all-cause, all-cancer, and cardiovascular disease mortality, estimates of association between ever versus never skilled trade job status and <1977 versus 1984-1993 hire were slightly higher with the exclusion of short-term workers relative to estimates obtained using the full cohort shown in Table 5.2. Estimates describing the association between duration of employment and all-cause, all-cancer, and cardiovascular disease mortality remained nearly identical to estimates obtained using the full cohort, as all estimates increased only slightly. Estimates for the association between duration of employment and all-cause, all-cancer, and cardiovascular disease mortality did not change meaningfully with restriction to inactive (posttermination of employment) person-time of follow-up. 


\subsection{Discussion}

Workers expressed concern over adverse working conditions and exposure to chemical hazards at the original Plant 1 building. Given that building-specific work history was unavailable for this investigation, we investigated the mortality experience of workers hired prior to 1977 when Plant 1 was the only building in operation. Summary age-, sex-, and birth yearadjusted rate ratios showed that pre-1977 hires had a significantly elevated all-cause and cardiovascular disease mortality rate compared to later hires, and this relationship persisted among both males and females in stratified analyses. Survival analyses also illustrated elevated mortality among pre-1977 hires relative to other hire groups throughout the follow-up period. Survival distributions are unlikely to be confounded by sex or age, as workers in each hire group (earliest to latest) had a median age at hire of 32 (IQR 25-42), 31 (IQR 25-39), and 32 (IQR 2641) years and $56 \%, 58 \%$, and $60 \%$ of them were female, respectively. Smoking is also unlikely to be a positive confounder of the relationship between pre-1977 hire and mortality, as pre-1977 hires exhibited a lower adjusted lung cancer mortality rate than later hires. While it is unknown if the pre-1977 hires experienced greater cumulative mean exposure to lead or chlorinated solvents than later hires, $34 \%$ of workers active in 1976 were observed to be employed in the same department code five years later, suggesting that many pre-1977 hires may have remained at Plant 1 for several years even after the opening of Plant 2. In light of this, and the control for confounding by age and sex and the absence of indirect evidence of positive confounding by smoking, the elevated all-cause mortality rate among pre-1977 hires appears consistent with worker concerns over elevated exposures to agents with known toxicity at Plant 1.

We observed elevated rates of mortality among pre-1977 hires for some specific causes that were of a priori interest based on their association with lead and chlorinated solvent 
exposure. Pre-1977 hires exhibited greater adjusted rates of cerebrovascular and digestive system (primarily liver) disease mortality, which is consistent with concerns over elevated exposure to lead and chlorinated solvents in the Plant 1 building or during earlier calendar years of facility operation when process exposures were presumed to be greatest. Chronic lead exposure has been shown to cause hypertension even at low levels and has been associated with other cardiovascular diseases including cerebrovascular disease, ischemic heart disease, and peripheral arterial disease ${ }^{21}$. Diseases of the liver were of interest due to exposure to chlorinated solvents, as both trichloroethylene and 1,1,1-trichloroethane have demonstrated liver toxicity ${ }^{43,45,56}$. Results for hypertension (without heart disease) were too imprecise to make inferences and multiple cause of death analyses for hypertension indicated little evidence of an association with pre-1977 hire (not shown).

The elevated all-cause mortality rate among pre-1977 hires appears to be explained primarily by non-malignant causes of death, as the all-cancer mortality rate was closer to that among later hires than other causes. However, a strong but highly imprecise association was suggested between pre-1977 hire and brain and nervous system cancer mortality, which was a cause of death of interest based on results from previous studies that have shown employment in electronics manufacturing to be associated with elevated risk of this disease ${ }^{14,63,66,67}$. Exposure to specific chlorinated solvents used in electronics manufacturing has also been associated with brain or nervous system cancer in other studies ${ }^{68-70}$, and there is some limited evidence suggesting lead exposure may be related to risk of certain brain cancers ${ }^{36}$. Half of the 12 deaths in the cohort due to brain and nervous system cancer mortality occurred in pre-1977 hires and results from external comparison analyses in the study cohort reported elsewhere indicated deaths due to this cause to be in excess relative to U.S. and Alabama general population rates ${ }^{83}$. 
Non-malignant nervous system disorder mortality was of particular interest in this investigation given that both lead and some chlorinated solvents are known to be toxic to the central nervous system ${ }^{19,43,56,64,65}$. The central nervous system is considered the most sensitive organ system for 1,1,1-trichloroethane toxicity in humans ${ }^{43}$. Our results indicated that pre-1977 hires exhibited a lower adjusted nervous system disorder mortality rate than all other hires, and the rate was greatest among those hired during the 1977-1983 period. Of those who died of nervous system disorders, $25 \%$ were hired in exactly 1977, when 729 individuals were hired at the facilities presumably to meet growing workforce requirements at the newly constructed Plant 2. The elevated nervous system disorder mortality rate among 1977-1983 hires could be attributed to greater mean 1,1,1-trichloroethane exposure among those hired at Plant 2, where this chemical was reported to have contaminated soil during the mid-1980s, or elevated lead exposure from wave solder processes introduced during this time. Results from a company-wide analysis of 31,941 decedents formerly employed at IBM in computer electronics manufacturing jobs showed a significantly elevated proportion of deaths due to nervous system disorders ${ }^{14}$. A study of 34,494 workers employed between 1969 and 2001 at a single IBM computer manufacturing facility in New York state reported an association between cumulative tetrachloroethylene exposure and nervous system disorder mortality ${ }^{15}$, although it is unknown whether this specific solvent was used at the facilities in Huntsville. A previous external comparison analysis of the study cohort found nervous system disorder mortality to be in excess relative to U.S. and Alabama general population rates ${ }^{83}$.

Lymphatic and hematopoietic cancer was of interest in this investigation because several studies have reported trichloroethylene and 1,1,1-trichloroethane exposure to be associated with these malignancies, particularly non-Hodgkin lymphoma and to a lesser extent multiple myeloma 
39,40,71,79-81,86. Trichloroethylene was classified as a human carcinogen by IARC in part for evidence of its association with non-Hodgkin lymphoma ${ }^{38}$. Our results indicated a potential association between duration of employment and mortality due to lymphatic and hematopoietic cancer. Estimates were imprecise, however, the adjusted rate among those employed more than 15 years was approximately 1.6 to 2 times the rate among those employed 5 years or less, as this estimate varied somewhat with different imputation iterations (shown in supplemental Table 5.1). Similar to this finding, results from the mortality investigation among employees at an IBM facility in New York state showed that 5 or more years of employment in a circuit board manufacturing building was associated with an elevated risk of leukemia mortality $(\mathrm{HR}=1.59$, $95 \%$ CI: $1.02,2.49){ }^{15}$. Our results showed no evidence of elevated lymphatic and hematopoietic cancer mortality (combined) in any of the hire groups. Given that trichloroethylene exposure has been associated with non-Hodgkin lymphoma mortality and was likely used at the facilities during earlier calendar years of operation, the null findings for this cause could be explained by either a low prevalence of trichloroethylene exposure or an inadequate length of follow-up to observe a sufficient number of cases. There were too few cases to make inference about nonHodgkin lymphoma mortality alone, although the estimate comparing pre- versus $\geq 1977$ hires was suggestive of a positive relationship $(\mathrm{RR}=1.24,95 \% \mathrm{CI}: 0.35,4.37)$.

Our findings showed that individuals not employed in skilled trades exhibited a significantly elevated all-cause mortality rate and elevated rates for several major causes of death relative to those employed in skilled trades. Skilled trade job status was used as an indicator of potential exposure since those employed in skilled trades were presumed to have less contact with production processes relative to hourly unskilled workers. While findings of elevated mortality among non-skilled trade workers is consistent with this assumption, this relationship 
may be confounded by socioeconomic status for all-cause mortality and for specific causes more strongly patterned by wealth and education, such as cancer and heart disease. Those employed in skilled trades generally possess greater education, training, and earn a higher wage than unskilled workers. Further, it was not possible to distinguish hourly and salaried workers with available data in this investigation. Workers identified as 'never' employed in skilled trade jobs therefore include all salaried workers in addition to unskilled hourly workers employed full time in production jobs. Salaried workers only comprised an estimated $10 \%$ of the study cohort, however, their inclusion in the never-skilled category may bias estimates toward the null as salaried workers likely had lower exposure to plant processes and attained greater education and income relative to unskilled workers. Skilled trade workers were also almost exclusively male $(92 \%)$. Previous results from external comparison analyses in this cohort showed female workers exhibited excesses of all cause and cause-specific mortality relative to the U.S. general population ${ }^{83}$, suggesting women may have been more likely to work in unskilled production jobs with greater mean exposure relative to men who were more likely to work in skilled trade and potentially salaried positions.

We observed little evidence of elevated mortality in the cohort due to respiratory cancer or kidney diseases. Respiratory cancers were of interest due to worker concerns over asbestos. We observed one death due to asbestosis and no deaths due to mesothelioma. Our results showed no consistent patterns of an association between respiratory system cancer mortality and any employment characteristics, suggesting our finding of elevated mortality among early hires is not unduly confounded by smoking. Results from previous external comparison analyses indicated no excess of lung cancer mortality in the overall cohort relative to U.S. and Alabama general population rates ${ }^{83}$. Kidney diseases were of interest as lead and chlorinated solvents are toxic to 
renal organs and trichloroethylene exposure causes kidney cancer ${ }^{18,38,43,56}$. There was a suggestion of elevated genitourinary disease mortality among pre-1977 hires and never-skilled workers which is consistent with presumed elevated exposure to lead or chlorinated solvents in these groups, but the imprecision of estimates prevented meaningful inference. Analyses using multiple cause of death coding for acute glomerulonephritis and chronic nephritis and renal failure showed few patterns of association with any employment characteristics. There was one observed death due to kidney cancer which prevented any comparisons of mortality due to this cause. Risk of kidney diseases in the cohort may be more suitable for evaluation with additional mortality follow-up and exposure assessment in the future.

\section{Strengths and limitations}

This study was limited by the lack of individual exposure information in the cohort. Available data precluded the ascertainment of job-, department-, or building-specific work history, which limited the interpretability of findings of elevated mortality for specific causes among subgroups. In general, there was good concordance between sources used to ascertain the presence of specific exposures at the facilities, but the prevalence and intensity of exposures in the cohort over time remains unknown. The inclusion of salaried employees in analyses may have also biased our estimates toward the null given that they likely experienced reduced mean exposure to plant processes relative to hourly workers. A second major limitation of this study was the reliance on mortality outcomes. Cause of death coding on death certificates is subject to misclassification and has low sensitivity for the ascertainment of the incidence of chronic diseases of interest, particularly those that are less often fatal. However, it is typically infeasible to study disease incidence in retrospective studies in the U.S. given the unavailability of centralized medical data. This study had a number of strengths, including the use of multiple 
sources of vital status ascertainment and relatively complete work history records of individuals employed at the facilities for an extended period. These features improved the overall sensitivity of vital status follow-up throughout the full study period and precluded major selection biases due to gaps in available data. Available work history included a 21-year period of facility operation during the earliest calendar years when exposures were estimated to be greatest.

\section{Conclusion}

This investigation was initiated in response to worker concerns over elevated mortality risk and exposure to known toxic and carcinogenic agents at automotive electronics manufacturing facilities. It involved the enumeration of a new cohort with primary ascertainment of mortality and cause of death. Our finding of elevated mortality among early hires (prior to 1977) was consistent with worker concerns over adverse working conditions at the original plant building. Future investigations of this type should consider greater emphasis on documenting the presence of exposures in the workplace. Despite the limitations of this study, union records provided a valuable resource for constructing an occupational cohort to address worker health concerns and to provide insights into the health hazards of electronics manufacturing more broadly. The results of this study warrant further investigation into the non-fatal incidence of diseases related to workplace exposures among workers at the facilities. 
Table 5.1. Descriptive characteristics of 4,396 hourly and salaried UAW members ever-employed at automotive electronics manufacturing facilities between 1972-1993 in Huntsville, Alabama

Characteristic

\begin{tabular}{|c|c|}
\hline $\mathrm{N}$ & 4,396 \\
\hline Year of birth, median (IQR) & $1949(1940,1955)$ \\
\hline $\begin{array}{l}\text { Sex }(\%) \\
\text { Female } \\
\text { Male }\end{array}$ & $\begin{array}{l}2,562(58) \\
1,834(42)\end{array}$ \\
\hline $\begin{array}{l}\text { Race }(\%) \\
\text { White/Caucasian } \\
\text { Black/African-American } \\
\text { Hispanic } \\
\text { Other } \\
\text { Missing }\end{array}$ & $\begin{array}{c}3,170(80) \\
746(19) \\
24(1) \\
10 \\
446\end{array}$ \\
\hline $\begin{array}{l}\text { Vital status at end of follow-up, } \mathrm{n}(\%) \\
\text { Presumed alive } \\
\text { Deceased } \\
\quad \text { Cause of death unknown }\end{array}$ & $\begin{array}{c}3,262(74) \\
1,134(26) \\
7\end{array}$ \\
\hline Person-years of follow-up, median (IQR) & $33(29,40)$ \\
\hline Person-years of follow-up, cumulative & 143,427 \\
\hline Age at end of follow-up, median (IQR) & $66(59,73)$ \\
\hline Age at death, median (IQR) & $66(56,75)$ \\
\hline $\begin{array}{l}\text { Person-years of employment by Huntsville plant code, } \\
\text { cumulative (\%) } \\
\text { Huntsville electronics (1972-1988) } \\
\text { Military-Public electronics (1983-1989) } \\
\text { New Huntsville electronics (1989-1993) }\end{array}$ & $\begin{array}{c}39,381(100) \\
25,866(66) \\
1,169(3) \\
12,346(31)\end{array}$ \\
\hline $\begin{array}{l}\text { Calendar period of hire, } \mathrm{n}(\%) \\
\text { 1972-1976 } \\
1977-1983 \\
1984-1993\end{array}$ & $\begin{array}{c}905(21) \\
1,717(39) \\
1,774(40)\end{array}$ \\
\hline Age at first hire, median (IQR) & $32(25,41)$ \\
\hline Year of first hire, median (IQR) & $1983(1977,1984)$ \\
\hline Years of employment, median (IQR) & $9(4,12)$ \\
\hline Ever-worked at other Chrysler plant (\%) & $914(21)$ \\
\hline $\begin{array}{l}\text { Skilled trade status, n (\%) } \\
\text { Ever skilled } \\
\text { Never skilled }\end{array}$ & $\begin{array}{c}617(14) \\
3,779(86)\end{array}$ \\
\hline
\end{tabular}

IQR: Interquartile Range 
Table 5.2. Rate ratios for all-cause, all-cancer, and cardiovascular disease mortality according to employment characteristics overall and according to sex among 4,396 hourly and salaried UAW members ever-employed at automotive electronics manufacturing facilities in Huntsville, Alabama, between 1972-1993

\begin{tabular}{|c|c|c|c|c|c|c|c|c|c|c|}
\hline \multirow{2}{*}{$\begin{array}{l}\text { Employment } \\
\text { characteristics }\end{array}$} & \multirow[b]{2}{*}{$\begin{array}{c}\text { Person- } \\
\text { years }\end{array}$} & \multicolumn{3}{|c|}{ All causes } & \multicolumn{3}{|c|}{ All cancers } & \multicolumn{3}{|c|}{ Cardiovascular disease } \\
\hline & & $\mathrm{n}$ & $\mathrm{RR}^{\mathrm{a}}$ & $95 \% \mathrm{CI}$ & $\mathrm{n}$ & $\mathrm{RR}^{\mathrm{a}}$ & $95 \% \mathrm{CI}$ & $\mathrm{n}$ & $\mathrm{RR}^{\mathrm{a}}$ & $95 \% \mathrm{CI}$ \\
\hline \multicolumn{11}{|l|}{ Overall } \\
\hline \multicolumn{11}{|c|}{ Duration of work (yrs) ${ }^{b}$} \\
\hline$\leq 5$ & 39,851 & 295 & 1 & & 79 & 1 & & 87 & 1 & \\
\hline$>5-15$ & 46,638 & 403 & 0.88 & $0.75,1.03$ & 119 & 0.90 & $0.67,1.21$ & 131 & 0.93 & $0.70,1.23$ \\
\hline$>15$ & 56,532 & 373 & 0.83 & $0.71,0.97$ & 113 & 0.92 & $0.69,1.23$ & 112 & 0.85 & $0.64,1.13$ \\
\hline \multicolumn{11}{|c|}{ Skilled trade status } \\
\hline Ever skilled & 19,378 & 178 & 1 & & 45 & 1 & & 54 & 1 & \\
\hline Never skilled & 123,643 & 893 & 1.26 & $1.06,1.51$ & 269 & 1.43 & $1.01,2.03$ & 276 & 1.52 & $1.10,2.09$ \\
\hline \multicolumn{11}{|c|}{ Calendar period of hire } \\
\hline 1984-1993 & 52,030 & 297 & 1 & & 85 & 1 & & 86 & 1 & \\
\hline $1977-1983$ & 58,183 & 425 & 1.09 & $0.94,1.26$ & 125 & 1.05 & $0.80,1.39$ & 125 & 1.06 & $0.80,1.40$ \\
\hline $1972-1976$ & 32,807 & 349 & 1.29 & $1.09,1.52$ & 101 & 1.16 & $0.85,1.58$ & 119 & 1.38 & $1.03,1.86$ \\
\hline \multicolumn{11}{|c|}{ Worked at Plant 1 or 2} \\
\hline Never & 13,800 & 87 & 1 & & 27 & 1 & & 29 & 1 & \\
\hline Ever & 129,221 & 984 & 1.05 & $0.84,1.31$ & 284 & 0.88 & $0.58,1.31$ & 301 & 0.93 & $0.63,1.37$ \\
\hline \multicolumn{11}{|l|}{ Female } \\
\hline \multicolumn{11}{|c|}{ Duration of work (yrs) ${ }^{b}$} \\
\hline$\leq 5$ & 22,907 & 151 & 1 & & 41 & 1 & & 41 & 1 & \\
\hline$>5-15$ & 26,269 & 196 & 0.88 & $0.70,1.09$ & 67 & 1.04 & $0.70,1.55$ & 53 & 0.84 & $0.55,1.28$ \\
\hline$>15$ & 36,006 & 196 & 0.73 & $0.59,0.90$ & 62 & 0.82 & $0.55,1.22$ & 59 & 0.78 & $0.53,1.17$ \\
\hline \multicolumn{11}{|c|}{ Skilled trade status } \\
\hline Ever skilled & 1,610 & 7 & 1 & & 1 & 1 & & 3 & 1 & \\
\hline Never skilled & 83,571 & 536 & 1.07 & $0.51,2.26$ & 169 & 2.26 & $0.32,16.1$ & 150 & 0.66 & $0.21,2.06$ \\
\hline \multicolumn{11}{|c|}{ Calendar period of hire } \\
\hline $1984-1993$ & 31,811 & 156 & 1 & & 49 & 1 & & 40 & 1 & \\
\hline $1977-1983$ & 34,514 & 212 & 0.99 & $0.80,1.22$ & 70 & 0.95 & $0.66,1.39$ & 60 & 1.03 & $0.69,1.55$ \\
\hline $1972-1976$ & 18,858 & 175 & 1.24 & $0.99,1.57$ & 51 & 0.99 & $0.65,1.51$ & 53 & 1.35 & $0.87,2.09$ \\
\hline \multicolumn{11}{|c|}{ Worked at Plant 1 or 2} \\
\hline Never & 6,460 & 29 & 1 & & 8 & 1 & & 9 & 1 & \\
\hline Ever & 78,722 & 514 & 0.99 & $0.67,1.44$ & 162 & 1.00 & $0.49,2.05$ & 144 & 0.80 & $0.40,1.59$ \\
\hline \multicolumn{11}{|l|}{ Male } \\
\hline \multicolumn{11}{|c|}{ Duration of work (yrs) ${ }^{b}$} \\
\hline$\leq 5$ & 16,944 & 144 & 1 & & 38 & 1 & & 46 & 1 & \\
\hline$>5-15$ & 20,369 & 207 & 0.90 & $0.72,1.12$ & 52 & 0.77 & $0.50,1.19$ & 78 & 1.02 & $0.70,1.49$ \\
\hline$>15$ & 20,526 & 177 & 0.98 & $0.78,1.23$ & 51 & 1.12 & $0.73,1.73$ & 53 & 0.93 & $0.62,1.39$ \\
\hline \multicolumn{11}{|c|}{ Skilled trade status } \\
\hline Ever skilled & 17,768 & 171 & 1 & & 44 & 1 & & 51 & 1 & \\
\hline Never skilled & 40,072 & 357 & 1.30 & $1.08,1.57$ & 97 & 1.46 & $1.02,2.10$ & 126 & 1.62 & $1.17,2.25$ \\
\hline \multicolumn{11}{|c|}{ Calendar period of hire } \\
\hline 1984-1993 & 20,220 & 141 & 1 & & 36 & 1 & & 46 & 1 & \\
\hline $1977-1983$ & 23,670 & 213 & 1.21 & $0.98,1.50$ & 55 & 1.20 & $0.79,1.84$ & 65 & 1.09 & $0.75,1.60$ \\
\hline $1972-1976$ & 13,950 & 174 & 1.35 & $1.06,1.70$ & 50 & 1.40 & $0.89,2.21$ & 66 & 1.41 & $0.94,2.11$ \\
\hline \multicolumn{11}{|c|}{ Worked at Plant 1 or 2} \\
\hline Never & 7,340 & 58 & 1 & & 19 & 1 & & 20 & 1 & \\
\hline Ever & 50,499 & 470 & 1.07 & $0.81,1.41$ & 122 & 0.81 & $0.50,1.34$ & 157 & 0.97 & $0.60,1.56$ \\
\hline
\end{tabular}

RR: Rate Ratio; CI: Confidence Interval

${ }^{a}$ Rate ratio estimates are adjusted for a linear and quadratic age term, year of birth, and sex. Sex-stratified models are adjusted for a linear and quadratic age term and year of birth.

${ }^{\mathrm{b}}$ Duration of work imputed for workers active at the Huntsville facilities in $1993(\mathrm{n}=2,212)$. Reported rate ratios and confidence intervals are combined estimates obtained from twenty five imputed iterations of work duration. 
Figure 5.1. Kaplan-Meier estimated overall survival proportion according to calendar period of first hire among UAW members employed at Huntsville electronics, 1972-1993 $(\mathrm{n}=4,396)^{\mathrm{a}}$

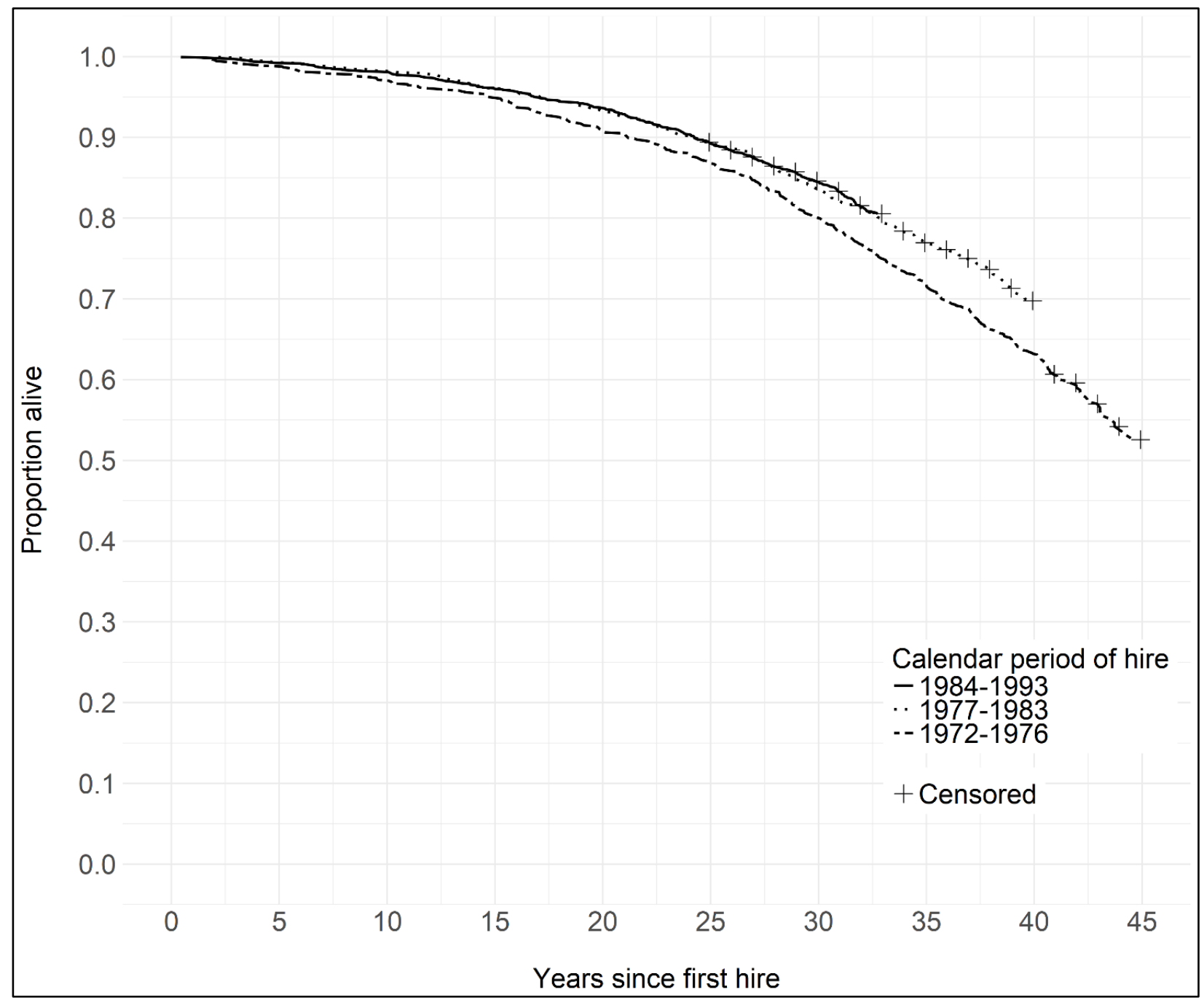

${ }^{a}$ Number of deaths per hire group: 379 (1972-1976); 448 (1977-1983); 307 (1984-1993). 
Table 5.3. Rate ratios for select malignant causes of death according to employment characteristics among 4,396 hourly and salaried UAW members ever-employed at automotive electronics manufacturing facilities in Huntsville, Alabama, between 1972-1993

\begin{tabular}{|c|c|c|c|c|c|c|c|c|c|c|}
\hline \multirow{2}{*}{$\begin{array}{l}\text { Employment } \\
\text { characteristics }\end{array}$} & \multirow[b]{2}{*}{$\begin{array}{c}\text { Person- } \\
\text { years }\end{array}$} & \multicolumn{3}{|c|}{$\begin{array}{c}\text { Trachea, bronchus, } \& \\
\text { lung cancer }\end{array}$} & \multicolumn{3}{|c|}{$\begin{array}{l}\text { Lymphatic \& } \\
\text { hematopoietic cancer }\end{array}$} & \multicolumn{3}{|c|}{$\begin{array}{c}\text { Brain \& nervous system } \\
\text { cancer }\end{array}$} \\
\hline & & $\mathrm{n}$ & $\mathrm{RR}^{\mathrm{a}}$ & $95 \% \mathrm{CI}$ & $\mathrm{n}$ & $\mathrm{RR}^{\mathrm{a}}$ & $95 \% \mathrm{CI}$ & $\mathrm{n}$ & $\mathrm{RR}^{\mathrm{a}}$ & $95 \% \mathrm{CI}$ \\
\hline \multicolumn{11}{|l|}{ Overall } \\
\hline \multicolumn{11}{|c|}{ Duration of work (yrs) ${ }^{b}$} \\
\hline$\leq 5$ & 39,851 & 21 & 1 & & 5 & 1 & & 2 & 1 & \\
\hline$>5-15$ & 46,638 & 37 & 1.01 & $0.58,1.77$ & 11 & 1.31 & $0.45,3.84$ & 5 & 1.58 & $0.29,8.68$ \\
\hline$>15$ & 56,532 & 37 & 1.16 & $0.68,1.99$ & 15 & 1.90 & $0.69,5.28$ & 5 & 1.69 & $0.33,8.68$ \\
\hline \multicolumn{11}{|c|}{ Skilled trade status } \\
\hline Ever skilled & 19,378 & 19 & 1 & & 6 & 1 & & 2 & 1 & \\
\hline Never skilled & 123,643 & 76 & 0.97 & $0.55,1.74$ & 25 & 1.33 & $0.50,3.52$ & 10 & 0.66 & $0.11,4.05$ \\
\hline \multicolumn{11}{|c|}{ Calendar period of hire } \\
\hline 1984-1993 & 52,030 & 25 & 1 & & 9 & 1 & & 2 & 1 & \\
\hline $1977-1983$ & 58,183 & 43 & 1.21 & $0.73,1.99$ & 12 & 0.95 & $0.40,2.29$ & 4 & 1.73 & $0.31,9.62$ \\
\hline $1972-1976$ & 32,807 & 27 & 1.00 & $0.57,1.78$ & 10 & 1.03 & $0.39,2.69$ & 6 & 4.52 & $0.83,24.5$ \\
\hline \multicolumn{11}{|c|}{ Worked at Plant 1 or 2} \\
\hline Never & 13,800 & 10 & 1 & & 3 & 1 & & 0 & 1 & \\
\hline Ever & 129,221 & 85 & 0.71 & $0.36,1.40$ & 28 & 0.86 & $0.25,2.92$ & 12 & $>99$ & \\
\hline
\end{tabular}

RR: Rate Ratio; CI: Confidence Interval

${ }^{a}$ Rate ratio estimates are adjusted for a linear and quadratic age term, year of birth, and sex.

$\mathrm{b}$ Duration of work imputed for workers active at the Huntsville facilities in $1993(\mathrm{n}=2,212)$. Reported rate ratios and confidence intervals are combined estimates obtained from twenty five imputed iterations of work duration. 
Table 5.4. Rate ratios for mortality due to select chronic diseases according to employment characteristics among 4,396 hourly and salaried UAW members ever-employed at automotive electronics manufacturing facilities in Huntsville, Alabama, between 1972-1993

\begin{tabular}{|c|c|c|c|c|c|c|c|c|c|c|}
\hline \multirow{2}{*}{$\begin{array}{l}\text { Employment } \\
\text { characteristics }\end{array}$} & \multirow[b]{2}{*}{$\begin{array}{c}\text { Person- } \\
\text { years }\end{array}$} & \multicolumn{3}{|c|}{$\begin{array}{c}\text { Cerebrovascular } \\
\text { disease }\end{array}$} & \multicolumn{3}{|c|}{$\begin{array}{l}\text { Nervous system } \\
\text { disorders }\end{array}$} & \multicolumn{3}{|c|}{$\begin{array}{c}\text { Digestive system } \\
\text { diseases }\end{array}$} \\
\hline & & $\mathrm{n}$ & $\mathrm{RR}^{\mathrm{a}}$ & $95 \% \mathrm{CI}$ & $\mathrm{n}$ & $\mathrm{RR}^{\mathrm{a}}$ & $95 \% \mathrm{CI}$ & $\mathrm{n}$ & $\mathrm{RR}^{\mathrm{a}}$ & $95 \% \mathrm{CI}$ \\
\hline \multicolumn{11}{|l|}{ Overall } \\
\hline \multicolumn{11}{|c|}{ Duration of work (yrs) ${ }^{b}$} \\
\hline$\leq 5$ & 39,851 & 12 & 1 & & 10 & 1 & & 15 & 1 & \\
\hline$>5-15$ & 46,638 & 20 & 1.05 & $0.50,2.20$ & 9 & 0.62 & $0.25,1.54$ & 16 & 0.75 & $0.36,1.54$ \\
\hline$>15$ & 56,532 & 21 & 1.15 & $0.56,2.36$ & 22 & 1.37 & $0.64,2.95$ & 22 & 0.90 & $0.45,1.77$ \\
\hline \multicolumn{11}{|c|}{ Skilled trade status } \\
\hline Ever skilled & 19,378 & 5 & 1 & & 5 & 1 & & 12 & 1 & \\
\hline Never skilled & 123,643 & 48 & 1.87 & $0.68,5.14$ & 36 & 1.67 & $0.59,4.70$ & 41 & 0.91 & $0.44,1.85$ \\
\hline \multicolumn{11}{|c|}{ Calendar period of hire } \\
\hline 1984-1993 & 52,030 & 14 & 1 & & 12 & 1 & & 11 & 1 & \\
\hline $1977-1983$ & 58,183 & 20 & 1.10 & $0.55,2.20$ & 19 & 1.16 & $0.56,2.42$ & 25 & 1.99 & $0.97,4.08$ \\
\hline $1972-1976$ & 32,807 & 19 & 1.58 & $0.75,3.29$ & 10 & 0.88 & $0.37,2.13$ & 17 & 2.31 & $1.04,5.10$ \\
\hline \multicolumn{11}{|c|}{ Worked at Plant 1 or 2} \\
\hline Never & 13,800 & 5 & 1 & & 2 & 1 & & 2 & 1 & \\
\hline Ever & 129,221 & 48 & 0.79 & $0.31,2.04$ & 39 & 1.70 & $0.40,7.19$ & 51 & 3.13 & $0.75,12.98$ \\
\hline
\end{tabular}

RR: Rate Ratio; CI: Confidence Interval

${ }^{a}$ Rate ratio estimates are adjusted for a linear and quadratic age term, year of birth, and sex.

b Duration of work imputed for workers active at the Huntsville facilities in $1993(\mathrm{n}=2,212)$. Reported rate ratios and confidence intervals are combined estimates obtained from twenty five imputed iterations of work duration. 
Table 5.5. Rate ratios for mortality due to genitourinary and renal diseases according to employment characteristics among 4,396 hourly and salaried UAW members ever-employed at automotive electronics manufacturing facilities in Huntsville, Alabama, between 1972-1993

\begin{tabular}{|c|c|c|c|c|c|c|c|c|c|c|}
\hline \multirow{2}{*}{$\begin{array}{l}\text { Employment } \\
\text { characteristics }\end{array}$} & \multirow[b]{2}{*}{$\begin{array}{l}\text { Person- } \\
\text { years }\end{array}$} & \multicolumn{3}{|c|}{ Genitourinary diseases } & \multicolumn{3}{|c|}{$\begin{array}{l}\text { Acute glomerulonephritis } \\
\text { \& renal failure } \\
\text { (multiple cause) }\end{array}$} & \multicolumn{3}{|c|}{$\begin{array}{c}\text { Chronic nephritis \& renal } \\
\text { failure } \\
\text { (multiple cause) }\end{array}$} \\
\hline & & $\mathrm{n}$ & $\mathrm{RR}^{\mathrm{a}}$ & $95 \% \mathrm{CI}$ & $\mathrm{n}$ & $\mathrm{RR}^{\mathrm{a}}$ & $95 \% \mathrm{CI}$ & $\mathrm{n}$ & $\mathrm{RR}^{\mathrm{a}}$ & $95 \% \mathrm{CI}$ \\
\hline \multicolumn{11}{|l|}{ Overall } \\
\hline \multicolumn{11}{|c|}{ Duration of work (yrs) ${ }^{b}$} \\
\hline$\leq 5$ & 39,851 & 7 & 1 & & 7 & 1 & & 19 & 1 & \\
\hline$>5-15$ & 46,638 & 8 & 0.75 & $0.27,2.09$ & 10 & 0.91 & $0.34,2.46$ & 23 & 0.80 & $0.43,1.49$ \\
\hline$>15$ & 56,532 & 6 & 0.48 & $0.15,1.52$ & 7 & 0.68 & $0.23,1.98$ & 22 & 0.66 & $0.35,1.25$ \\
\hline \multicolumn{11}{|l|}{ Skilled trade status } \\
\hline Ever skilled & 19,378 & 3 & 1 & & 7 & 1 & & 9 & 1 & \\
\hline Never skilled & 123,643 & 18 & 1.80 & $0.48,6.75$ & 17 & 0.90 & $0.34,2.36$ & 55 & 1.43 & $0.65,3.14$ \\
\hline \multicolumn{11}{|c|}{ Calendar period of hire } \\
\hline 1984-1993 & 52,030 & 5 & 1 & & 5 & 1 & & 19 & 1 & \\
\hline $1977-1983$ & 58,183 & 8 & 1.18 & $0.38,3.65$ & 13 & 2.14 & $0.75,6.05$ & 24 & 0.91 & $0.49,1.67$ \\
\hline $1972-1976$ & 32,807 & 8 & 1.66 & $0.52,5.34$ & 6 & 1.49 & $0.44,5.09$ & 21 & 1.10 & $0.57,2.12$ \\
\hline \multicolumn{11}{|c|}{ Worked at Plant 1 or 2} \\
\hline Never & 13,800 & 3 & 1 & & 2 & 1 & & 8 & 1 & \\
\hline Ever & 129,221 & 18 & 0.54 & $0.15,1.92$ & 22 & 1.34 & $0.31,5.84$ & 56 & 0.57 & $0.27,1.24$ \\
\hline
\end{tabular}

RR: Rate Ratio; CI: Confidence Interval

${ }^{\text {a }}$ Rate ratio estimates are adjusted for a linear and quadratic age term, year of birth, and sex.

${ }^{b}$ Duration of work imputed for workers active at the Huntsville facilities in $1993(\mathrm{n}=2,212)$. Reported rate ratios and confidence intervals are combined estimates obtained from twenty five imputed iterations of work duration. 
Table 5.6. Evaluation of 'healthy worker' effect with exclusion of short-term workers and stratification according to active versus inactive person-time in estimates of mortality rate ratios according to employment characteristics in the study cohort $(n=4,396)$

\begin{tabular}{|c|c|c|c|c|c|c|c|c|c|c|}
\hline \multirow{2}{*}{$\begin{array}{l}\text { Employment } \\
\text { characteristics }\end{array}$} & \multirow[b]{2}{*}{$\begin{array}{c}\text { Person- } \\
\text { years }\end{array}$} & \multicolumn{3}{|c|}{ All causes } & \multicolumn{3}{|c|}{ All cancers } & \multicolumn{3}{|c|}{ Cardiovascular disease } \\
\hline & & $\mathrm{n}$ & $\mathrm{RR}^{\mathrm{a}}$ & $95 \% \mathrm{CI}$ & $\mathrm{n}$ & $\mathrm{RR}^{\mathrm{a}}$ & $95 \% \mathrm{CI}$ & $\mathrm{n}$ & $\mathrm{RR}^{\mathrm{a}}$ & $95 \% \mathrm{CI}$ \\
\hline \multicolumn{11}{|l|}{ Worked $\geq 3$ years $b$} \\
\hline \multicolumn{11}{|c|}{ Duration of work (yrs) } \\
\hline $3-5$ & 20,863 & 159 & 1 & & 42 & 1 & & 47 & 1 & \\
\hline$>5-15$ & 46,638 & 403 & 0.91 & $0.76,1.10$ & 119 & 0.96 & $0.67,1.37$ & 131 & 0.98 & $0.70,1.39$ \\
\hline$>15$ & 56,532 & 373 & 0.86 & $0.71,1.04$ & 113 & 0.96 & $0.67,1.38$ & 112 & 0.90 & $0.64,1.28$ \\
\hline \multicolumn{11}{|c|}{ Skilled trade status } \\
\hline Ever skilled & 17,481 & 158 & 1 & & 40 & 1 & & 49 & 1 & \\
\hline Never skilled & 106,552 & 777 & 1.33 & $1.10,1.60$ & 234 & 1.52 & $1.05,2.19$ & 241 & 1.53 & $1.10,2.13$ \\
\hline \multicolumn{11}{|c|}{ Calendar period of hire } \\
\hline 1984-1993 & 41,150 & 238 & 1 & & 70 & 1 & & 70 & 1 & \\
\hline $1977-1983$ & 53,316 & 380 & 1.13 & $0.96,1.33$ & 112 & 1.10 & $0.81,1.48$ & 113 & 1.11 & $0.82,1.49$ \\
\hline $1972-1976$ & 29,567 & 317 & 1.37 & $1.15,1.64$ & 92 & 1.24 & $0.89,1.72$ & 107 & 1.44 & $1.05,1.98$ \\
\hline \multicolumn{11}{|c|}{ Worked at Plant 1 or 2} \\
\hline Never & 7,517 & 55 & 1 & & 19 & 1 & & 20 & 1 & \\
\hline Ever & 116,517 & 880 & 1.14 & $0.87,1.50$ & 255 & 0.89 & $0.54,1.44$ & 270 & 0.98 & $0.62,1.55$ \\
\hline \multicolumn{11}{|c|}{ Active employment ${ }^{\text {b }}$} \\
\hline \multicolumn{11}{|c|}{ Duration of work (yrs) } \\
\hline$\leq 5$ & 4,619 & 24 & 1 & & 6 & 1 & & 4 & 1 & \\
\hline$>5-15$ & 16,668 & 67 & 0.29 & $0.18,0.48$ & 19 & 0.27 & $0.11,0.71$ & 22 & 0.48 & $0.16,1.44$ \\
\hline$>15$ & 36,388 & 137 & 0.09 & $0.05,0.15$ & 44 & 0.07 & $0.03,0.21$ & 44 & 0.17 & $0.05,0.53$ \\
\hline \multicolumn{11}{|c|}{ Inactive employment ${ }^{b}$} \\
\hline \multicolumn{11}{|c|}{ Duration of work (yrs) } \\
\hline$\leq 5$ & 35,232 & 271 & 1 & & 73 & 1 & & 83 & 1 & \\
\hline$>5-15$ & 29,970 & 336 & 0.88 & $0.75,1.04$ & 100 & 0.88 & $0.64,1.20$ & 109 & 0.89 & $0.66,1.20$ \\
\hline$>15$ & 20,144 & 236 & 0.85 & $0.70,1.02$ & 69 & 0.88 & $0.62,1.25$ & 68 & 0.79 & $0.57,1.12$ \\
\hline
\end{tabular}

RR: Rate Ratio; CI: Confidence Interval

${ }^{a}$ Rate ratio estimates are adjusted for a linear and quadratic age term, year of birth, and sex.

${ }^{\mathrm{b}}$ Duration of work imputed for workers active at the Huntsville facilities in $1993(\mathrm{n}=2,212)$. Reported rate ratios and confidence intervals are combined estimates obtained from twenty five imputed iterations of work duration. 
Supplemental Table 5.1. Sensitivity analysis for the imputation of employment duration for all cause and lymphatic \& hematopoietic cancer mortality

\begin{tabular}{|c|c|c|c|c|}
\hline & \multicolumn{2}{|c|}{ All causes } & \multicolumn{2}{|c|}{$\begin{array}{c}\text { Lymphatic \& } \\
\text { hematopoietic cancer }\end{array}$} \\
\hline & $\mathrm{RR}^{\mathrm{a}}$ & $95 \% \mathrm{CI}$ & $\mathrm{RR}^{\mathrm{a}}$ & $95 \% \mathrm{CI}$ \\
\hline \multicolumn{5}{|c|}{ Full work history $(n=1,965)^{b}$} \\
\hline \multicolumn{5}{|c|}{ Duration of work (yrs) } \\
\hline$\leq 5$ & 1 & & 1 & \\
\hline$>5-15$ & 1.09 & $0.91,1.30$ & 1.57 & $0.49,5.01$ \\
\hline$>15$ & 1.01 & $0.72,1.43$ & 2.74 & $0.51,14.6$ \\
\hline \multicolumn{5}{|c|}{ Imputation $1^{\mathrm{c}}$} \\
\hline \multicolumn{5}{|c|}{ Duration of work (yrs) } \\
\hline$\leq 5$ & 1 & & 1 & \\
\hline$>5-15$ & 0.91 & $0.78,1.05$ & 1.35 & $0.47,3.91$ \\
\hline$>15$ & 0.81 & $0.70,0.95$ & 1.94 & $0.70,5.36$ \\
\hline \multicolumn{5}{|c|}{ Imputation $2^{\mathrm{c}}$} \\
\hline \multicolumn{5}{|c|}{ Duration of work (yrs) } \\
\hline$\leq 5$ & 1 & & 1 & \\
\hline$>5-15$ & 0.89 & $0.77,1.04$ & 1.24 & $0.42,3.65$ \\
\hline$>15$ & 0.83 & $0.71,0.96$ & 2.06 & $0.75,5.66$ \\
\hline \multicolumn{5}{|c|}{ Imputation $3^{c}$} \\
\hline \multicolumn{5}{|c|}{ Duration of work (yrs) } \\
\hline$\leq 5$ & 1 & & 1 & \\
\hline$>5-15$ & 0.89 & $0.77,1.04$ & 1.03 & $0.37,2.84$ \\
\hline$>15$ & 0.82 & $0.70,0.95$ & 1.61 & $0.62,4.18$ \\
\hline \multicolumn{5}{|c|}{ Imputation $4^{\mathrm{c}}$} \\
\hline \multicolumn{5}{|c|}{ Duration of work (yrs) } \\
\hline$\leq 5$ & 1 & & 1 & \\
\hline$>5-15$ & 0.89 & $0.76,1.03$ & 1.02 & $0.37,2.83$ \\
\hline$>15$ & 0.84 & $0.72,0.97$ & 1.65 & $0.64,4.29$ \\
\hline \multicolumn{5}{|c|}{ Imputation $5^{\mathrm{c}}$} \\
\hline \multicolumn{5}{|c|}{ Duration of work (yrs) } \\
\hline$\leq 5$ & 1 & & 1 & \\
\hline$>5-15$ & 0.89 & $0.77,1.04$ & 1.44 & $0.50,4.10$ \\
\hline$>15$ & 0.82 & $0.70,0.95$ & 1.82 & $0.65,5.08$ \\
\hline
\end{tabular}

RR: Rate Ratio; CI: Confidence Interval

${ }^{a}$ Rate ratio estimates are adjusted for a linear and quadratic age term, year of birth, and sex

b Includes workers with an observed termination year only

${ }^{\mathrm{c}}$ One of twenty five imputation iterations using a randomly generated number seed for worker selection from Bernoulli distribution of estimated termination probabilities 


\section{CHAPTER 6: DISCUSSION}

\subsection{Fulfillment of the specific aims}

This work was initiated in response to concerns over elevated mortality among individuals formerly employed at automotive electronics manufacturing facilities. The concern arose through the efforts of former employees who, after noticing an alarming number of deaths among their colleagues, began compiling a list of those deceased on social media. The initiative gained momentum, in part due to the continued organization of workers through UAW Local 1413 and Local 1929 after the facilities were closed, but also through publicized knowledge of toxic contamination of plant soil and a class-action asbestos lawsuit among former employees. As the number of contributors to the list increased, the initiative became successful in raising awareness of worker concerns. The list garnered significant attention after it was shared on social media forums for ongoing union negotiations at other plants. Once representatives at the UAW health and safety offices in Detroit, Michigan were notified, epidemiologic support was requested to investigate worker concerns.

The overarching objective of this investigation was to address worker concerns by describing their mortality experience and comparing it to what it might have been had they not been exposed to hazardous agents at the facilities. Broadly, the specific aims were to 1) compare standardized mortality rates among a cohort of workers to general population rates, and 2) compare mortality rates within the cohort according to employment characteristics that were proxies of exposure. 
Accomplishing the study objective first required the enumeration of a cohort of workers employed at the facilities. This effort was, in many ways, an extension of that initiated by concerned workers who began recording a list of the names, job titles, and death dates of deceased colleagues. I enumerated a relatively complete roster of UAW members employed at the facilities during the first 21 years that it was operational, then identified those on the roster who were deceased using systematic methods. This created a novel cohort which formalized worker's efforts to track deaths in a more rigorous and comprehensive way. It allowed for the estimation of more informative measures of health hazards, such as mortality rates and survival over time. It also allowed for the ascertainment of demographic and employment characteristics of workers, in addition to disease-specific information that preceded mortality among decedents. These features of the new cohort not only expanded and improved the initiative started by workers, but permitted scientific inquiry into the existence of excess mortality and its relation to harmful exposures. The creation of this cohort was in itself a significant accomplishment for fulfilling the aims of the investigation. The cohort will be shared with the UAW for analyses that may advance the investigation throughout the future.

This investigation accomplished an informal exposure assessment process that explicitly identified harmful agents at the facilities and lent credibility to worker concerns over their exposure to them. Worker concerns over mortality were largely driven by their awareness of having been exposed to toxic substances, however, this awareness was vague and non-specific. Through interviews conducted with workers and UAW health and safety representatives, it was apparent that they were not sufficiently informed about the agents they were exposed to. Many expressed that they knew the agents they worked with were potentially dangerous, but their understanding of the severity of the health risks was unclear, and some exhibited difficulty 
recalling the specific names of chemicals to which they were exposed. From this perspective, it becomes easier to understand why worker concerns arose out of general alarm over elevated mortality rather than due to the occurrence of specific diseases. Through the synthesis of information from worker interviews, news articles, and previous exposure investigations at other electronics facilities, I was able to generate indirect but compelling evidence of exposure. I explicitly identified the presence of trichloroethylene, 1,1,1-trichloroethane, lead, and asbestos in their workplace. This investigation described the known health effects of these toxic and carcinogenic agents, which supports workers by showing that their concerns over harmful exposures are justified. Although an analysis of the association between specific exposures and mortality was infeasible, the informal exposure assessment process was valuable for accomplishing the overall objective of the investigation. This process provided workers with scientifically vetted documentation of harmful exposures at the facilities for the first time.

A primary aim of the investigation was to compare mortality rates among workers to the general population using standardized mortality ratios as described in Chapter 4. The standardized mortality ratio is a simple and intuitive measure of relative mortality that contributed some evidence toward answering a fundamental question of the investigation: did working at the facilities cause workers to experience a greater risk of disease and death compared to having never worked there? The analysis compared the number of deaths observed among workers to the number that would have been observed had they experienced the same mortality rate as the general population, after accounting for basic demographic characteristics. Using the U.S. general population referent, which was determined to be a more comparable reference population than Alabama due to the excessive poverty and mortality in the state, our findings showed that estimates of relative all-cause mortality in the study cohort were greater 
than anticipated based on results from the large UAW-Ford cohort among White women, Black (or other) women, and Black (or other) men. I observed estimates indicating modest excesses in all-cause mortality among female workers and all workers hired at the original Plant 1 building prior to 1977. Cause-specific mortality estimates showed a moderate excess of nervous system disorder mortality, which was a cause of death of strong a priori interest based on its relation to lead and chlorinated organic solvents (specifically 1,1,1-trichloroethane), which are central nervous system toxins known to have been used extensively in facility processes. Brain and nervous system cancer mortality, although rare, showed a moderate excess and has been associated with electronics manufacturing occupations and chlorinated solvent exposure in several other studies. For other a priori causes of interest, I observed no evidence of an excess of kidney cancer, lymphatic and hematopoietic cancer, or liver disease mortality, and some indication of excess mortality for non-malignant renal disease mortality. Notably, the evaluation of causes of death in this analysis revealed one death in the cohort caused by asbestos exposure and one death caused by non-petroleum solvent poisoning, which were two agents of concern potentially related to exposure at the facilities.

Internal comparison analyses described in Chapter 5 were valuable for validating the finding of excess mortality among pre-1977 hires observed in external comparisons. Pre-1977 hires experienced an elevated adjusted all-cause mortality rate relative to later hires, in addition to reduced overall survival throughout the entire follow-up period. This finding does not appear to be explained by differences in age, sex, or smoking prevalence between hire groups and was observed among both male and female workers. Elevated mortality among pre-1977 hires is consistent with worker concerns over adverse working conditions at the Plant 1 building, which was originally constructed in the 1950's and served as the sole site of manufacturing until 1977, 
when Plant 2 was constructed and the size of the workforce nearly doubled. With respect to specific causes, nervous system disorder (e.g. Alzheimer's and Parkinson's disease) mortality was most common among those hired in 1977 or later, which could suggest greater mean exposure to nervous system toxins at the Plant 2 building, or that exposure increased during this manufacturing era at both plant buildings overall. During interviews with workers and UAW representatives, complaints over the lack of ventilation and excessive fumes at Plant 1 were common. The results of internal comparison analyses were successful in providing some evidence to validate worker's experience of elevated exposure to known toxic and carcinogenic agents in the Plant 1 building.

The objective of this investigation implicitly involved the elucidation of a causal relationship between exposure and disease that cannot be ignored. The complaint was presented as concern over elevated mortality, but this concern was based on the fear that exposure in the workplace caused premature death and disease that would not have occurred otherwise. Simply characterizing mortality patterns among workers is therefore insufficient for addressing the underlying nature of the concern. Addressing the underlying question of causality would require an assessment of whether exposure at the facilities caused diseases in workers that would not have occurred had the exposures been absent, Despite the study's accomplishments, results provided little evidence toward making conclusive statements about the likelihood of causality between exposure and disease. The reasons for this pertain to three major shortcomings of the work, which are common in epidemiological studies of plant workers and often impracticable to overcome. Namely, the shortcomings are the lack of 1) process-specific exposure information, 2) ascertainment of disease incidence, and 3) adequate statistical precision for several diseases of $a$ priori interest. 
Ascertainment of individual exposure information was not feasible and constituted the most salient shortcoming of the investigation. Significant efforts were made to find UAW documents to identify department codes in the available work history records. However, the UAW Local 1413 and Local 1929 destroyed all work-related documentation when the facilities closed and none of the interviewees could locate personal documents among colleagues containing necessary information. As a result, I was unable to create an exposure matrix for assessment of individual process-specific exposure based on job title, department code, or plant building. This precluded the identification of a clear reference group of 'unexposed' workers for comparison, forcing reliance on general population reference rates and broad employment characteristics to make inferences about the relationship between exposure and disease. The sparsity of exposure information made findings difficult to interpret. Findings were susceptible to a variety of interpretations, and I was only capable of describing whether results were broadly consistent with worker concerns or not. The lack of individual exposure data was a shortcoming of the research that not only limited the interpretability of our findings, but also significantly detracted from our ability to provide evidence toward any causal questions implicit in the objective of the investigation.

Another shortcoming of this work was the use of cause-specific mortality as an outcome, which was a weak instrument for ascertaining the incidence of disease among workers. Despite the investigation being initiated in response to complaints over excess mortality, these complaints were driven by an underlying concern over the incidence of disease caused by exposure, which I was unable to ascertain. I was only able to describe disease incidence in individuals who had already died, and even among decedents, I had access to underlying disease information written on only one line of their death certificate, which was additionally subject to 
misclassification that obscured potentially important patterns of disease. Several diseases of $a$ priori interest (e.g. renal) are also especially underrepresented by cause of death reporting on death certificates which led to underestimations of the true incidence of important diseases. The use of mortality outcomes therefore provided a crude and incomplete snapshot of disease burden in the study population. Ascertaining the incidence of diseases in the entire cohort would have been a superior method for associating exposure with specific diseases and would have bolstered the fulfillment of the objective of the investigation. However, the lack of disease incidence information is a common limitation in occupational studies in the U.S. given that no populationbased registries exist for accessing health record information. Obtaining disease incidence data would have required company cooperation or the administration of a survey questionnaire. This was entirely unfeasible given the scope of the research and may have still provided incomplete disease information of potentially limited value.

The use of mortality outcomes in this investigation is closely related to another shortcoming of the research pertaining to statistical precision. Our findings for several causes of death of a priori interest were based on a small number of cases with weak precision. The lack of precision for many causes necessitated the evaluation of broader cause of death categories that were less clearly related to exposures of concern. This was particularly apparent in internal comparison analyses, where I was unable to reliably compare mortality rates for several causes of interest. The lack of adequate statistical precision limited our ability to make meaningful inferences from our results which detracted from the success of the investigation. While statistical precision is an issue that can affect all epidemiological studies, it was an especially important shortcoming of this one given its applied nature. The objective of this study cannot be replicated elsewhere as it is applicable to the experience of workers at the Huntsville facilities 
only. The inconclusive results will remain for important diseases of interest unless mortality follow-up in the study population is updated in the future.

\subsection{Future investigations with the UAW}

This study represents a substantial contribution to the objective of addressing the concerns of UAW members employed at automotive manufacturing facilities. As an investigation initiated in response to a complaint raised by a group of workers and their union, it succeeded in fulfilling the specific aims in a relatively short period of time and for very little cost. The UAW may use the results of this investigation to support advocacy efforts in future health and safety contract negotiations with automotive corporations. Despite the successes of this work, its shortcomings highlight important limitations of mortality studies for investigating concerns over exposure and disease in the workplace that should be considered before pursuing similar investigations in the future. Mortality studies are common for conducting occupational disease investigations in a workforce given their practical convenience, but they are not necessarily a good approach for satisfying the needs of workers.

The strength of a given mortality study for investigating worker concerns depends significantly on the availability of data. There is an understandable temptation for researchers to conduct the best possible study with whatever information is available. However, as described in the previous section, the lack of important study information can greatly limit the potential for a mortality study to produce meaningful results, or worse, eliminate this potential before the analysis even begins. Obtaining individual exposure and disease information is often infeasible, and enumerated cohorts can suffer from multiple biases pertaining to the incompleteness of historical records or insufficient follow-up time and sample size to observe diseases of concern. For plants that have already closed, securing necessary data to avoid these limitations is even 
more challenging. The Huntsville investigation was possible only because of the unlikely availability of employment records at NIOSH that would have otherwise been destroyed, as the UAW was unable to provide any data for this investigation with the exception of limited pension information. Despite the best intentions of researchers and collaborators, deficiencies in the availability of historical data can lead to mortality studies with null or equivocal findings.

This aspect of mortality studies is problematic for workers who have valid concerns over exposure to agents that are known to cause harm. A study using deficient information can produce null results that appear to invalidate worker concerns, even when those concerns are warranted. When disseminating results from such a study, workers may mistakenly interpret the null results as evidence that the exposures carried no risk. Results may also invite inappropriate conclusions about the absence of harm by uninformed or intentionally deceiving commentators. Given that results from mortality studies may be used as evidence in litigation, labor negotiations, or worker compensation claims, mortality studies limited by deficiencies in available data can undermine attempts at protecting worker health and safety. A mortality study at an IBM facility in New York State provides a good example of this problem. State government officials requested that NIOSH conduct a study of workers at an electronics manufacturing facility in response to concerns over contamination of local soil and groundwater with chlorinated solvents. Investigators were given extensive access to company records and were able to conduct a detailed process-specific exposure assessment of nearly 35,000 workers exposed to a variety of toxic agents with follow-up for cause of death and testicular cancer incidence. Overall the results of their investigation showed little conclusive evidence of harm and the authors concluded that "few significant exposure-outcome relations were observed, but risks from occupational exposures cannot be ruled out due to data limitations and the relative 
youth of the cohort" ${ }^{15}$. The IBM investigation highlights the limited value of mortality studies for addressing worker concerns, even when researchers have considerable resources at their disposal.

There are two solutions to this problem that can alleviate the shortcomings of mortality studies for investigating health and safety concerns at a specific facility. The first is to abandon efforts at attempting to link exposures to disease at all. The need to associate exposure with disease places extraordinary burden on workers and researchers to provide evidence of relationships that may not be discernible with available data. Even in situations where comprehensive company and union data are accessible, appropriately ascertaining the incidence of diseases of interest is often impracticable. An alternative strategy for addressing worker concerns is to simply document exposure to toxic agents in the workplace and use this evidence as the basis for advocacy and compensation efforts. This strategy leverages the abundant evidence already produced by epidemiologists and toxicologists describing health risks associated with exposure. Documenting exposure to hazardous agents in the workplace is a considerably more attainable goal than attempting to identify exposure-disease relationships, as process-specific exposures can be shown through industrial hygiene records, plant environmental impact assessments, material safety data sheets (MSDS), and worker testimony. Documenting and emphasizing evidence of harmful exposure in the workplace is a potentially more viable approach than conducting mortality studies for addressing worker concerns. Obviously, this approach is only viable when the health risks of exposure are already well understood, or if there is agreement in the absence of established evidence that exposure presents an unacceptable hazard to worker health. 
The second solution involves empowering workers to better understand the utility and limitations of mortality studies for investigating their concerns using community-based participatory research (CBPR) methods. This approach emphasizes the importance of developing worker-driven research questions, involving workers in every step of the research process, and acknowledging worker expertise over exposure and disease. It is important to communicate to workers that the results of a given study may not support their concerns. Workers should be informed that there are a myriad of reasons why mortality studies can fail to detect associations between exposure and disease, and that null or equivocal findings should not necessarily be interpreted as evidence that invalidates their concerns over toxic exposure. Workers and union representatives should be taught to recognize the utility of mortality studies for providing potentially useful information while understanding their limitations. This will improve the way study results are used to advocate for advancements in protections or compensation for workers. Future investigations with the UAW should be evaluated in the earliest stages of study design to determine whether a mortality study represents the best approach for accomplishing objectives.

\subsection{Conclusion}

Worker concerns over elevated mortality and exposure to several hazardous agents at automotive electronics manufacturing facilities in Huntsville, Alabama were addressed through the enumeration of a novel UAW cohort and cause-specific mortality analyses using a cost and time efficient study design. This work identified excesses of all-cause and nervous system disease mortality in the cohort and elevated mortality among workers hired prior to 1977 at the original plant building. Mortality investigations of this type are limited by deficiencies in available exposure and disease information. Future investigations of this type should consider greater emphasis on documenting the presence of toxic exposures in the workplace and 
collaborating more closely with workers to develop research objectives better aligned with their interests. 


\section{REFERENCES}

1. Delzell E, Brown DA, Matthews R. Mortality among hourly motor vehicle manufacturing workers. J Occup Environ Med. 2003;45(8):813-830.

2. Friesen MC, Betenia N, Costello S, Eisen EA. Metalworking fluid exposure and cancer risk in a retrospective cohort of female autoworkers. Cancer Causes Control. 2012;23(7):1075-1082.

3. Eisen EA, Bardin J, Gore R, Woskie SR, Hallock MF, Monson RR. Exposure-response models based on extended follow-up of a cohort mortality study in the automobile industry. Scand J Work Environ Health. 2001;27(4):240-249.

4. Park RM, Silverstein MA, Green MA, Mirer FE. Brain cancer mortality at a manufacturer of aerospace electromechanical systems. Am J Ind Med. 1990;17(5):537552.

5. Brown DA, Delzell E. Motor vehicle manufacturing and prostate cancer. Am J Ind Med. 2000;38(1):59-70.

6. Zatz D, Webster J. Missiles and Aerospace: Chrysler Electronics in Huntsville, Alabama. 2012. https://www.allpar.com/corporate/factories/huntsville.html.

7. Lowry B. State school board slows Huntsville building purchase over toxic soil. 2010. http://blog.al.com/breaking/2010/06/state_school_board_slows_hunts.html.

8. Eisen EA, Tolbert PE, Monson RR, Smith TJ. Mortality studies of machining fluid exposure in the automobile industry I: A standardized mortality ratio analysis. Am J Ind Med. 1992;22(6):809-824.

9. Vena JE, Sultz HA, Fiedler RC, Barnes RE. Mortality of workers in an automobile engine and parts manufacturing complex. Br J Ind Med. 1985;42(2):85-93.

10. Park R, Krebs J, Mirer F. Mortality at an automotive stamping and assembly complex. Am J Ind Med. 1994;26(4):449-463.

11. Park RM, Mirer FE. A survey of mortality at two automotive engine manufacturing plants. Am J Ind Med. 1996;30(6):664-673.

12. Park RM. Mortality at an automotive engine foundry and machining complex. J Occup Environ Med. 2001;43(5):483-493. 
13. Rotimi C, Austin H, Delzell E, Day C, Macaluso M, Honda Y. Retrospective follow-up study of foundry and engine plant workers. Am J Ind Med. 1993;24(4):485-498.

14. Clapp RW. Mortality among US employees of a large computer manufacturing company: 1969-2001. Environ Health. 2006;5:30.

15. Silver SR, Pinkerton LE, Fleming DA, et al. Retrospective cohort study of a microelectronics and business machine facility. Am J Ind Med. 2014;57(4):412-424.

16. Fleming DA, Woskie SR, Jones JH, Silver SR, Luo L, Bertke SJ. Retrospective assessment of exposure to chemicals for a microelectronics and business machine manufacturing facility. J Occup Environ Hyg. 2014;11(5):292-305.

17. Clapp RW, Hoffman K. Cancer mortality in IBM Endicott plant workers, 1969-2001: an update on a NY production plant. Environ Health. 2008;7:13.

18. Ekong EB, Jaar BG, Weaver VM. Lead-related nephrotoxicity: a review of the epidemiologic evidence. Kidney Int. 2006;70(12):2074-2084.

19. Sanders T, Liu Y, Buchner V, Tchounwou PB. Neurotoxic effects and biomarkers of lead exposure: a review. Rev Environ Health. 2009;24(1):15-45.

20. Nawrot TS, Thijs L, Den Hond EM, Roels HA, Staessen JA. An epidemiological reappraisal of the association between blood pressure and blood lead: a meta-analysis. $J$ Hum Hypertens. 2002;16(2):123-131.

21. Navas-Acien A, Guallar E, Silbergeld EK, Rothenberg SJ. Lead exposure and cardiovascular disease - A systematic review. Environ Health Perspect. 2007;115(3):472482 .

22. Hertz-Picciotto I, Croft J. Review of the relation between blood lead and blood pressure. Epidemiol Rev. 1993;15(2):352-373.

23. Cheng Y, Schwartz J, Vokonas PS, Weiss ST, Aro A, Hu H. Electrocardiographic conduction disturbances in association with low-level lead exposure (the Normative Aging Study). Am J Cardiol. 1998;82(5):594-599.

24. Bockelmann I, Pfister EA, McGauran N, Robra BP. Assessing the suitability of crosssectional and longitudinal cardiac rhythm tests with regard to identifying effects of occupational chronic lead exposure. J Occup Environ Med. 2002;44(1):59-65.

25. Kirkby H, Gyntelberg F. Blood pressure and other cardiovascular risk factors of longterm exposure to lead. Scand J Work Environ Health. 1985;11(1):15-19. 
26. Gerhardsson L, Hagmar L, Rylander L, Skerfving S. Mortality and cancer incidence among secondary lead smelter workers. Occup Environ Med. 1995;52(10):667-672.

27. McMichael AJ, Johnson HM. Long-term mortality profile of heavily-exposed lead smelter workers. J Occup Med. 1982;24(5):375-378.

28. Gerhardsson L, Lundstrom NG, Nordberg G, Wall S. Mortality and lead exposure: a retrospective cohort study of Swedish smelter workers. Br J Ind Med. 1986;43(10):707712.

29. Cooper WC, Wong O, Kheifets L. Mortality among employees of lead battery plants and lead-producing plants, 1947-1980. Scand J Work Environ Health. 1985;11(5):331-345.

30. Malcolm D, Barnett HA. A mortality study of lead workers 1925-76. Br J Ind Med. 1982;39(4):404-410.

31. Fanning D. A mortality study of lead workers, 1926-1985. Arch Environ Health. 1988;43(3):247-251.

32. Bertke SJ, Lehman EJ, Wurzelbacher SJ, Hein MJ. Mortality of lead smelter workers: A follow-up study with exposure assessment. Am J Ind Med. 2016;59(11):979-986.

33. Wang MD, Gomes J, Cashman NR, Little J, Krewski D. A meta-analysis of observational studies of the association between chronic occupational exposure to lead and amyotrophic lateral sclerosis. J Occup Environ Med. 2014;56(12):1235-1242.

34. Wong O, Harris F. Cancer mortality study of employees at lead battery plants and lead smelters, 1947-1995. Am J Ind Med. 2000;38(3):255-270.

35. Lundstrom NG, Nordberg G, Englyst V, et al. Cumulative lead exposure in relation to mortality and lung cancer morbidity in a cohort of primary smelter workers. Scand $J$ Work Environ Health. 1997;23(1):24-30.

36. Steenland K, Boffetta P. Lead and cancer in humans: where are we now? Am J Ind Med. 2000;38(3):295-299.

37. Fu H, Boffetta P. Cancer and occupational exposure to inorganic lead compounds - a metaanalysis of published data. Occup Environ Med. 1995;52(2):73-81.

38. International Agency for Research on Cancer. Monographs on the evaluation of carcinogenic risks to humans: Trichloroethylene, tetrachloroethylene, and some other chlorinated solvents. 2014;106. https://monographs.iarc.fr/iarc-monographs-on-theevaluation-of-carcinogenic-risks-to-humans-10/. 
39. Scott CS, Jinot J. Trichloroethylene and cancer: systematic and quantitative review of epidemiologic evidence for identifying hazards. Int J Environ Res Public Health. 2011;8(11):4238-4272.

40. Chiu WA, Jinot J, Scott CS, et al. Human health effects of trichloroethylene: key findings and scientific issues. Environ Health Perspect. 2013;121(3):303-311.

41. International Agency for Research on Cancer. Monographs supplement 7: 1,1,1Trichloroethane. 1987. https://monographs.iarc.fr/ENG/Monographs/vol71/mono7138.pdf.

42. International Agency for Research on Cancer. Monographs supplement 7: 1,2Dichloroethane. 1987. https://monographs.iarc.fr/ENG/Monographs/vol71/mono7121.pdf.

43. U.S. Environmental Protection Agency. Toxicological review of 1,1,1-trichloroethane. 2007. https://cfpub.epa.gov/ncea/iris/iris_documents/documents/toxreviews/0197tr.pdf.

44. Baker EL. A review of recent research on health effects of human occupational exposure to organic solvents. A critical review. J Occup Med. 1994;36(10):1079-1092.

45. Brautbar N, Williams J. Industrial solvents and liver toxicity: Risk assessment, risk factors and mechanisms. Intl J Hyg Environ Health. 2002;205(6):479-491.

46. Ruder AM. Potential health effects of occupational chlorinated solvent exposure. Ann NY Acad Sci. 2006;1076:207-227.

47. International Agency for Research on Cancer. Monographs on the evaluation of carcinogenic risks to humans: Arsenic, metals, fibres, and dusts. 2012;100C. https://monographs.iarc.fr/iarc-monographs-on-the-evaluation-of-carcinogenic-risks-tohumans-19/.

48. Becklake MR, Bagatin E, Neder JA. Asbestos-related diseases of the lungs and pleura: uses, trends and management over the last century. Int J Tuberc Lung Dis. 2007;11(4):356-369.

49. International Agency for Research on Cancer. Monographs on the evaluation of carcinogenic risks to humans: Man-made vitreous fibres 2002;81. https://monographs.iarc.fr/iarc-monographs-on-the-evaluation-of-carcinogenic-risks-tohumans-40/. 
50. Marsh GM, Youk AO, Stone RA, et al. Historical cohort study of US man-made vitreous fiber production workers: I. 1992 Fiberglass cohort follow-up: Initial findings. J Occup Environ Med. 2001;43(9):741-756.

51. Marsh GM, Buchanich JM, Youk AO. Fiber glass exposure and human respiratory system cancer risk: Lack of evidence persists since 2001 IARC re-evaluation. Reg Toxicol Pharmacol. 2011;60(1):84-92.

52. UPI.com. Chrysler Corp announced Thursday tentative plans to invest more... 1986; http://www.upi.com/Archives/1986/03/06/Chrysler-Corp-announced-Thursday-tentativeplans-to-invest-more/9739510469200/?spt=su. Accessed 7/15/2017.

53. Cowper DC, Kubal JD, Maynard C, Hynes DM. A primer and comparative review of major US mortality databases. Ann Epidemiol. 2002;12(7):462-468.

54. National Death Index. NDI Early Release: Completion Status. 2017; https://www.cdc.gov/nchs/ndi/completion_status.htm\#modalIdString_CDCTable_0.

55. National Institute of Occupational Safety and Health. NIOSH-119 ICD Codes by Category, 1960-2007. 2017; https://www.cdc.gov/niosh/ltas/pdf/niosh-119-table2007.pdf.

56. U.S. Environmental Protection Agency. Toxicological review of trichloroethylene. 2011. https://cfpub.epa.gov/ncea/iris/iris_documents/documents/toxreviews/0199tr/0199tr.pdf.

57. Guha N, Loomis D, Grosse Y, et al. Carcinogenicity of trichloroethylene, tetrachloroethylene, some other chlorinated solvents, and their metabolites. Lancet Oncol. 2012;13(12):1192-1193.

58. Pearce N, Checkoway H, Kriebel D. Bias in occupational epidemiology studies. Occ Environ Med. 2007;64(8):562-568.

59. Schubauer-Berigan MK, Hein MJ, Raudabaugh WM, et al. Update of the NIOSH life table analysis system: a person-years analysis program for the windows computing environment. Am J Ind Med. 2011;54(12):915-924.

60. Richardson DB, Keil AP, Cole SR, MacLehose RF. Observed and Expected Mortality in Cohort Studies. Am J Epidemiol. 2017:1-8.

61. Pearce N. Methodological problems of time-related variables in occupational cohort studies. Rev Epidemiol Sante Publique. 1992;40 Suppl 1:S43-54. 
62. Steenland K, Stayner L. The importance of employment status in occupational cohort mortality studies. Epidemiology. 1991;2(6):418-423.

63. Beall C, Bender TJ, Cheng H, et al. Mortality among semiconductor and storage devicemanufacturing workers. J Occup Environ Med. 2005;47(10):996-1014.

64. Verstraeten S, Aimo L, Oteiza P. Aluminium and lead: molecular mechanisms of brain toxicity. Arch Toxicol. 2008;82(11):789-802.

65. Bale AS, Barone S, Jr., Scott CS, Cooper GS. A review of potential neurotoxic mechanisms among three chlorinated organic solvents. Toxicol Appl Pharmacol. 2011;255(1):113-126.

66. Kim MH, Kim H, Paek D. The health impacts of semiconductor production: an epidemiologic review. Int J Occup Environ Health. 2014;20(2):95-114.

67. Thomas TL, Stolley PD, Stemhagen A, et al. Brain tumor mortality risk among men with electrical and electronics jobs: a case-control study. J Natl Cancer Inst. 1987;79(2):233238.

68. Carton M, Barul C, Menvielle G, et al. Occupational exposure to solvents and risk of head and neck cancer in women: a population-based case-control study in France. BMJ Open. 2017;7(1):e012833.

69. Heineman EF, Cocco P, Gomez MR, et al. Occupational exposure to chlorinated aliphatic hydrocarbons and risk of astrocytic brain cancer. Am J Ind Med. 1994;26(2):155-169.

70. Wesseling C, Pukkala E, Neuvonen K, Kauppinen T, Boffetta P, Partanen T. Cancer of the brain and nervous system and occupational exposures in Finnish women. $J$ Occup Environ Med. 2002;44(7):663-668.

71. Anttila A, Pukkala E, Sallmen M, Hernberg S, Hemminki K. Cancer incidence among Finnish workers exposed to halogenated hydrocarbons. J Occup Environ Med. 1995;37(7):797-806.

72. Benke G, Turner MC, Fleming S, et al. Occupational solvent exposure and risk of glioma in the INTEROCC study. Br J Cancer. 2017;117(8):1246-1254.

73. U.S. Centers for Disease Control and Prevention National Center for Health Statistics. Compressed Mortality File 1999-2016 on CDC WONDER Online Database, released December 2017. http://wonder.cdc.gov/cmf-icd10.html. 
74. U.S. Census Bureau. 2006-2016 American Community Survey 1-Year Estimates, Median household income (in 2016 inflation adjusted dollars), United States. 2018.

https://factfinder.census.gov/faces/tableservices/jsf/pages/productview.xhtml?src=bkmk.

75. Roth GA, Dwyer-Lindgren L, Bertozzi-Villa A, et al. Trends and Patterns of Geographic Variation in Cardiovascular Mortality Among US Counties, 1980-2014. JAMA. 2017;317(19):1976-1992.

76. Lu TH, Anderson RN, Kawachi I. Effect of coding rules on reporting of hypertension mortality. Epidemiology. 2013;24(1):168-169.

77. U.S. National Cancer Institute. Surveillance, Epidemiology, and End Results (SEER) Cancer Stat Facts: Non-Hodgkin Lymphoma. 2017. https://seer.cancer.gov/statfacts/html/nhl.html.

78. U.S. National Cancer Institute. Surveillance, Epidemiology, and End Results (SEER) Cancer Stat Facts: Kidney and Renal Pelvis Cancer. 2017.

https://seer.cancer.gov/statfacts/html/kidrp.html.

79. Wartenberg D, Reyner D, Scott CS. Trichloroethylene and cancer: epidemiologic evidence. Environ Health Perspect. 2000;108(Suppl 2):161-176.

80. Lynge E, Anttila A, Hemminki K. Organic solvents and cancer. Cancer Causes Control. 1997;8(3):406-419.

81. Gold LS, Stewart PA, Milliken K, et al. The relationship between multiple myeloma and occupational exposure to six chlorinated solvents. Occup Environ Med. 2011;68(6):391399.

82. Blair A, Hartge P, Stewart PA, McAdams M, Lubin J. Mortality and cancer incidence of aircraft maintenance workers exposed to trichloroethylene and other organic solvents and chemicals: extended follow up. Occup Environ Med. 1998;55(3):161-171.

83. [Under review] DeBono NL, Kelly-Reif, K., Richardson, D. B., Keil, A., Robinson, W. R., Troester, M., Marshall, S. Mortality among autoworkers manufacturing electronics in Huntsville, Alabama: External comparisons of cause-specific mortality. Am J Ind Med.

84. Lloyd-Jones DM, Martin DO, Larson MG, Levy D. Accuracy of death certificates for coding coronary heart disease as the cause of death. Ann Intern Med. 1998;129(12):10201029.

85. Arrighi HM, Hertz-Picciotto I. The evolving concept of the healthy worker survivor effect. Epidemiology. 1994;5(2):189-196. 
86. Rusyn I, Chiu WA, Lash LH, Kromhout H, Hansen J, Guyton KZ. Trichloroethylene: Mechanistic, epidemiologic and other supporting evidence of carcinogenic hazard.

Pharmacol Ther. 2014;141(1):55-68. 